Portland State University

PDXScholar

1990

\title{
Facing both ways : Yan Fu, Hu Shi, and Chen Duxiu : \\ Chinese intellectuals and the meaning of modern science, 1895-1923
}

Niobeh Crowfoot Tsaba

Portland State University

Follow this and additional works at: https://pdxscholar.library.pdx.edu/open_access_etds

Part of the Chinese Studies Commons, and the Intellectual History Commons

Let us know how access to this document benefits you.

\section{Recommended Citation}

Tsaba, Niobeh Crowfoot, "Facing both ways : Yan Fu, Hu Shi, and Chen Duxiu : Chinese intellectuals and the meaning of modern science, 1895-1923" (1990). Dissertations and Theses. Paper 4134.

https://doi.org/10.15760/etd.6017

This Thesis is brought to you for free and open access. It has been accepted for inclusion in Dissertations and Theses by an authorized administrator of PDXScholar. Please contact us if we can make this document more accessible: pdxscholar@pdx.edu. 
AN ABSTRACT OF THE THESIS OF Niobeh Crowfoot Tsaba for the Master of Arts in History presented June 11, 1990.

Title: Facing Both Ways: Yan Fu, Hu Shi, and Chen Duxiu-Chinese Intellectuals and the Meaning of Modern Science, 1895-1923

APPROVED BY THE MEMBERS OF THE THESIS COMMITTEE:
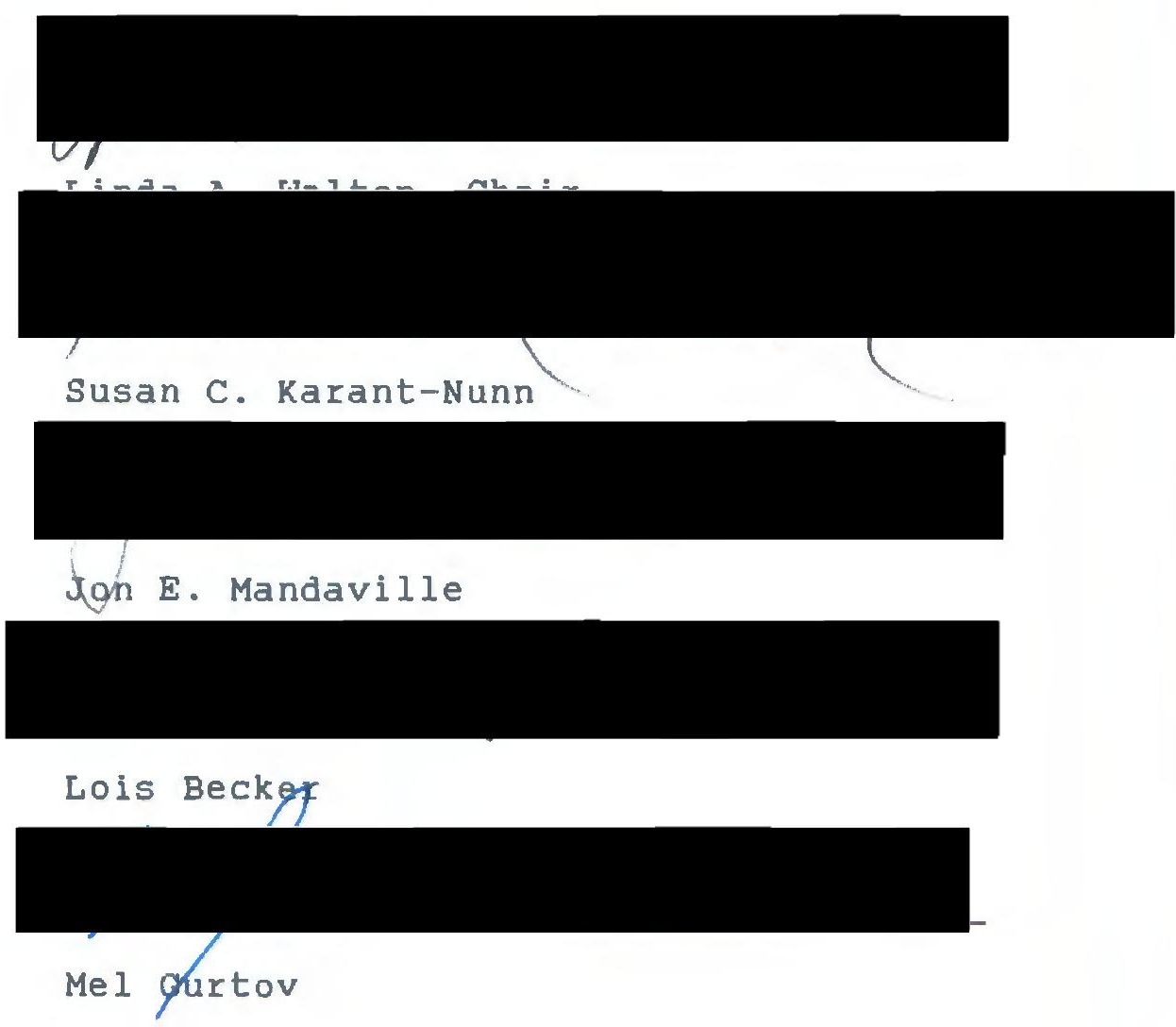

The concern of Chinese intellectuals with the "idea" of modern science from the West in the transition generation from 1895 to 1923 was fundamentally a concern about "national survival" and modernity. The value and 
meaning that accrued to science as "method" -- as a "thinking technique" -- and to the evolutionary ideas of Charles Darwin and Herbert spencer as the "science of choice" among Chinese intellectuals of this period, was due to belief or disbelief in the power of these ideas to describe, explain, or solve the problematic of "modernity" in a Chinese context.

Yan Fu's (1853-1921) translations of Thomas Huxley and spencer and articles about ideas from the West, with their adherence to Confucian categories of description and assumed acceptance of aspects of Confucian-Taoist cosmology set the stage for much of the discussion for and against modern science, and evolutionary thought in particular, among social thinkers that was to follow. In the influence of Yan's notions of the meaning and role of modern science in China on the Iiberal Hu Shi (1891-1962) and the republican-turned-communist Chen Duxiu (1880-1942), a clear trend emerges. An examination of the essays of Hu and Chen written between 1915 and the journalistic polemic on "Science versus Metaphysics" in 1923 reveals that their views represent further development of strains in Yan's thought whose consequences had been insufficiently explored or about which he had been ambivalent. The trend of thought represented by Yan Fu, Hu Shi, and Chen Duxiu, with its belief in the transvaluative power of "scientific thinking" and increasing subsuming of a Chinese or Western 
"essence" ( $\underline{\underline{i}}$ ) in the usefulness (yonq) of a borrowed idea or technique, was not a clean break with the native Chinese philosophical tradition. Though they would come to promote radically divergent views, by relying on ideas from the science and philosophies of the West to solve China's problems, while casting their presentations of these ideas in traditional Chinese philosophical terms, these three figures all managed to "face both ways." 
FACING BOTH WAYS:

YAN FU, HU SHI, AND CHEN DUXIU -- CHINESE INTELLECTUALS AND THE MEANING OF MODERN SCIENCE, 1895-1923

by

NIOBEH CROWFOOT TSABA

A thesis submitted in partial fulfillment of the requirements for the degree of

\author{
MASTER OF ARTS \\ in \\ HISTORY
}

Portland state University

1990 
TO THE OFEICE OF GRADUATE STUDIES:

The members of the Committee approve the thesis of Niobeh Crowfoot Tsaba presented June 11, 1990.

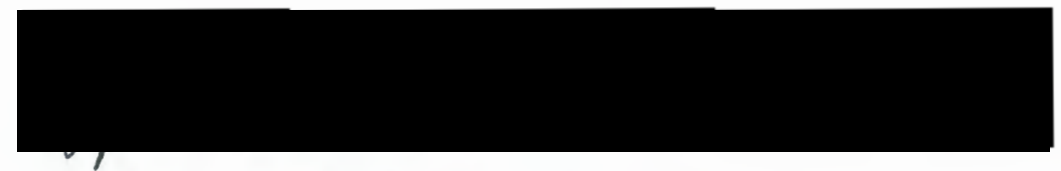

Linda A. Walton, Chair
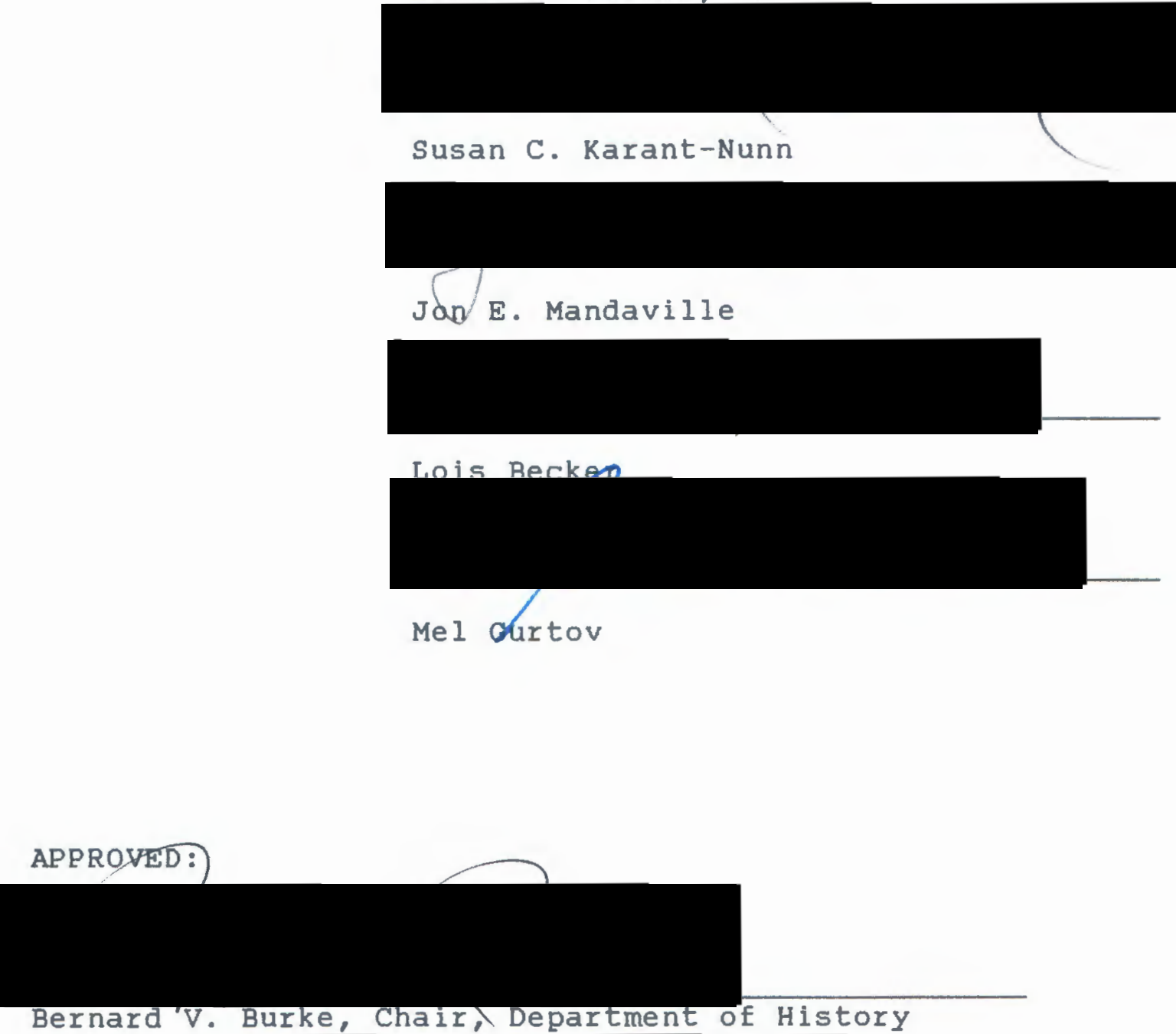

Bernard V. Burke, chair, Department of History

C. William Savery, Interim Vice Provost for Graduate studies and Research 


\section{ACKNOWLEDGEMENTS}

There are many people to thank for their contributions to my research and writing, and to my state of mind, while I prepared this thesis. First and foremost, thanks go to my thesis advisor, Linda A. Walton, of portland state University, for encouraging my development of many of the ideas in this thesis when they were only nagging questions for an ex-biology major about Chinese (and Japanese) Confucianism and the history of "the sciences" in her undergraduate and graduate seminars and survey classes. Her feeling for the "life" of Chinese and Japanese intellectual and social history is infectious. While I often found myself in nearly uncharted territory in seminar paper and thesis research, her gentle prodding and polnting, and faith in my perceptions, kept me focused on the project at hand. I would also like to thank the rest of my thesis defense committee, which included susan $C$. Karant-Nunn, Jon E. Mandaville, Lois Becker, and Mel Gurtov, for their insightful suggestions, rigor, and goodnaturedness during our various fruitful discussions.

Speclal thanks go to Mr. Charles Liu, Department of Forelgn Languages, Portland state university, for taking the time to check my translations from Chinese to English, 
guiding me through the twists and turns of academic Chinese, and for the long-term benefits to come from his excellent teaching.

A number of my fellow students and Teaching Assistants in the department of History at Portland state University aided and abetted the research and writing of this thesis through their support, critique, and comradery. They include Judith Armstrong, David Armontrout, Andrea Asbell, Lynn Botelho, Sylvia Kaplan, Caroline Litzenberger, Kathleen Merrow, John Morrison, Dorothy Rackley, John Rosenberg, Scott Satterlee, Becky Walker, and John Witherow. Because the majority of my fellows work in other fields of history, our discussions helped me to keep the real communication of ideas in the forefront. Last, but not at all the least, I want to give my humblest thanks to my partner in living a multi-cultural life, K.B., for enriching my intellectual life beyond my wildest dreams, letting me take the space to stretch the boundaries of my creativity, for putting up with my ruminations on bringing Chinese intellectual history alive for EVERYONE, and for just being there. 
To the memory of my mother

\section{Lois Leach Bond}

\section{$(1929-1985)$}

For instilling in me the value of straddiing both my African American and Native American heritages while preserving my integrity in the dominant European-American culture.

Thank you for showing me that a person can "face both ways." 
TABLE OF CONTENTS

P AGE

ACKNOWLEDGEMENTS $\ldots \ldots \ldots \ldots \ldots \ldots \ldots \ldots \ldots \ldots \ldots \ldots \ldots$ I1

A NOTE ABOUT ROMANIZATION OF CHINESE NAMES AND TERMS... vi A NOTE ABOUt TRANSLATIONS .................. vil

CHAPTER

I INTRODUCTION $\ldots \ldots \ldots \ldots \ldots \ldots \ldots \ldots \ldots \ldots \ldots$

I I YAN FU AND THE MODERN WEST $\ldots \ldots \ldots \ldots \ldots \ldots$

II PROGRESS, SCIENCE, AND THE LATE IMPERIAL

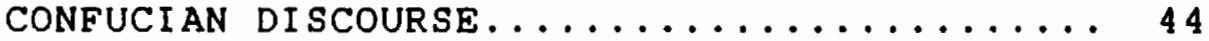

IV HU SHI BEFORE $1917 \ldots \ldots \ldots \ldots \ldots \ldots \ldots \ldots \ldots 61$

V CHEN DUXIU BEFORE $1917 \ldots \ldots \ldots \ldots \ldots \ldots \ldots 9 . \ldots 9$

VI THE IDEA OF SCIENCE IN THE MAY FOURTH ERA AND THE 1923 DEBATES ON SCIENCE VS METAPHYSICS .................. 137

VI I CONCLUSIONS: THE MEANING OF SCIENCE,

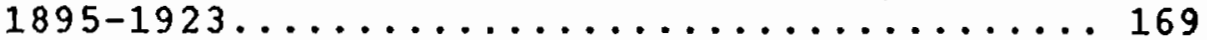

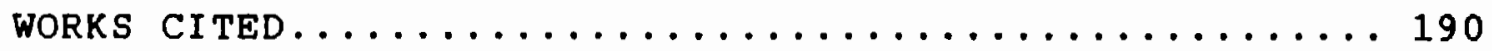


A NOTE ABOUT ROMANIZATION OF CHINESE NAMES AND TERMS

This essay employs the pinyin system of romanization of Chinese names and terms in the text. This system was developed in the People's Republic of China and officially adopted in 1979. Although pinyin is becoming more universally used, the Wade-Giles (and sometimes the Harvard or Yale) system is found in older works and frequently in newer ones. Quotations and citations using one of these older systems have been left intact. The first time a Chinese name or terms appears in a chapter, the pinyin romanization will be immediately followed by the wade-Giles rendition, in brackets [ ], to aid the non-specialist in moving from the text to the quotations and bibliographical references. 


\section{A NOTE ABOUT TRANSLATIONS}

Translations of Chinese sources are mine only where indicated. Quotations from English language secondary sources are treated in the following manner: if I have seen the primary source, but used the translation of the author of the secondary source, the primary source is cited as "translated in..."; if I only had access to the quotation translated in a secondary source, the primary source is cited as "quoted in...." 
CHAPTER I

INTRODUCTION

The period between the "100 Days of Reform" in 1898 and the May Fourth Movement in 1919 is widely acknowledged as a "watershed" era in the intellectual history of modern China.1 A fundamental psychic tension had been building

1 Charlotte Furth, "Intellectual Change: From the Reform Movement to the May Fourth Movement, 1895-1920," in The Cambridge History of China: Volume 12, Republican Ch1na, 1912-1949, Part I, ed. John K. Fairbank (Cambridge: Cambridge University Press, 1983), 322. The "100 Days of Reform" was a an attempt at a comprehensive remake of ineffective Chinese governmental and educational institutions during the summer of 1898. Based on proposals put forward by Kang Youwel [K'ang Yu-wel] and his follower Liang Qichao [Liang Ch'i-ch'ao], and supported by the Manchu emperor of China Guangxu [Kuang Hsu], it was intended to modernize the confucian approach, not to overthrow it. It was ended by a reactionary "coup" in September 1898 that forced Liang and Kang to flee the country for Japan. The May Fourth Movement began on May 4, 1919, in the intensely activist response of students at Beijing University to the acquiescence of the Nationalist government to the terms of the Versailles Peace Conference. In late Apr11, 1919, the Chinese were informed that the shandong [shantung] peninsula, that Japan had selzed from the Germans during World war I, would remain under Japanese control, instead of reverting to China, despite the fact that China considered Japan an enemy. The students began a demonstration and street fighting broke out. By forging ties with other, and older, intellectuals of the New Culture movement, their ideas spread throughout China's cities. The widespread critique of the old Confucian government and culture that ensued from this enlarged front helped to set new soclo-political developments in motion. 
since the 1840s, generated by the pressing need for "men of talent" to understand and utilize the "wealth and power" of the West. Many put their faith in a trickling-in of "Western studies" (xixue) [ㅆsi-hsüeh], belleving it would enable China to politically and militarily expel the "Western barbarians" who were "carving-up China like a melon." China's military loss to the British in the Opium Wars of 1840-1842 and to the French in the sino-French war of 1848, and the destabilizing political and economic consequences, convinced two generations of "selfstrengtheners" that China should take a lesson from the west and strengthen itself technologically and militarily - while maintaining a "true" chinese identity. China's defeat in the sino-Japanese war of 1894-95, by a country that the Chinese had considered a "puny little brother," was devastating to the morale of the those who were responsible for the day to day running of the government, as well as to the next generation of young leaders, then in their late teens and early twenties.

In searching the horizon of the west for the secret of lts strength and power in the world, the Chinese selfstrengtheners of the mid-nineteenth century had already pinpointed Western technology as a source of that strength. But they had based their assessment of the value of Western technology on a separation of its theoretical foundations 
from its utility in a given situation. This separation of "essence" (t $\underline{i})$ [t'i) from "function" (yonq) (yung] was to reappear, indeed to haunt, the thinking of intellectuals involved in the process of modernizing China throughout the early twentieth century. In the 1990 s it still occupies a not-so-hldden agenda in the continuing debate in china over the "correct" attitude of chinese students to Western ideas when they are sent to European and North American universities to learn "techniques" to modernize china's economy, agriculture, industry, and medical care.

The Chinese application of the ti yong paradigm to contact with the west implies the belief that the practical techniques of one society can be absorbed by another without recourse to their theoretical underpinnings, and without regard to the cultural, social, and economic circumstances in which the ideas originated. The integrity of the borrowing culture would, ostensibly, be preserved by maintaining its "essence" ( $\underline{\underline{i}}$ ) and borrowing what is merely "utilitarlan" (yong), an important consideration in the face of repeated military losses to Western nations. The most famous statement of this paradigm in the early modern period in China was that of zhang zhidong [Chang Chih-tungl (1837-1909). His slogan of "Chinese learning for the essentials, Western learning for its utllity" (zhonqxue wei t1, Xlxue we 1 yong) (Chung-hsüeh we 1 t'i, Hsi-hsüeh wei 
yungl was the real hope of many among the selfstrengtheners. It was important to strengthen the nation against the incursions of the West and Japan, but critical to preserve what was "essentially Chinese" while doing so. Self-strengtheners, who had been educated as members of a scholar-gentry class within the boundaries of a NeoConfucian intellectual tradition, still believed that what was "essentially Chinese" was a clear-cut entity.

Chinese intellectuals in the late nineteenth century admired the West's modern sciences along with its technology. China had experienced, first hand, the power of the practical application of modern science in Europe's successful military, maritime, and industrial technologies. But the arrival of European science in China, beginning with the astronomy and physical science of the Jesuits who worked in China in the sixteenth century, had been hampered by piecemeal presentations. Few European books on scientific subjects were translated into Chinese until the late nineteenth century; many were only excerpts or incompletely translated.2

The first attempts to present the modern sciences as whole systems of thought began only in the late nineteenth

2 See Chapter III below, pp. 45-46, for a discussion of the status of Western science in China prior to the late nineteenth century. 
century. This was made possible by improved translations, better facilities for the production of Chinese editions, and the support of the government authorities who controlled the import of European books and kept a close watch on the translating and printing of books within China. With increased instruction available in foreign languages, greater numbers of students were being sent every year to study industrial and military technology and medicine in Europe and the United states. Whlle abroad they were exposed to the sciences in their "pure" forms, as systems of thought. They returned to china excited about the prospects of applying what they had learned in modernizing China. But their effectiveness was hampered by their low numbers in the population as a whole.

In the late $1890 \mathrm{~s}$ all of these factors -- improved translation and publication facilities, greater instruction In forelgn languages, the exposure of students traveling to Europe and the United states for tralning in technological areas to "pure science" -- came together at the same time that China suffered her most humiliating loss, the sinoJapanese War of 1894-95. The first presentations of modern science as a whole system of thought, as an effective "way" of thinking, and as a key ingredient in the success of the modern west were made in the midst of these other factors, and when Chlnese morale had reached a very low ebb. 
One of the most systematic and satisfying presentations of sclence as a system in China in the $1890 \mathrm{~s}$ was that of blological evolution. As the idea of Charles Darwin's theory of the evolution of species was absorbed into Chinese intellectual culture, its power of social explanation became immediately clear. Partially a social reading of Darwin's theory as a Spencerlan/Malthusian "soclal Darwinism," it was being interpreted through the template of an already existing set of Chinese intellectual categories which helped to define and shape it. Elements of Darwin's theory of evolution had a "utility" (yonq) that filled a crying need among many of the younger generation of intellectuals who felt called to "save China." An "evolutionary cosmology" began to develop among social and political thinkers which represented a major stream of thought about "how science works" in China in the late nineteenth and early twentleth centuries. 3

Chinese intellectuals were first exposed to Darwin's theory of the evolution of species in the articles and

3 "Evolutionary cosmology," as used by Charlotte Furth (and others), is a "systematic conception of the universe, in which natural, spirltual, and soclal phenomena were percelved as manifestations of a single cosmic reality," which had its Chinese roots in Confucian-Taoist thought. The "external" sources for this new view were the Western notion of progress, a new knowledge of "world history," and the social implications of Charles Darwin's theory of the evolution of species. See Furth, 325. 
translations of Yan Fu [Yen Fu] (1853-1921). His writings exerted a powerful influence on reform thinking in the generation between the "100 Days" and the May Fourth period. The range of those indebted to him for fundamental elements of their ideology includes constitutional monarchists, Confucian revivalists, nationalists, liberals, and communists. Yan's work represents the first comprehensive attempt to present modern science from the West in more than its obviously technological aspects. It was science as a "way" of working with the world that was important to Yan. He still percelved the "way" of sclence as the way to save China, but in his thinking there is a shift toward the belief that the "nuts and bolts" of this "way" are in its method of operation rather than simply in its assemblage of "facts."

By comprehensively presenting sclence in general, or a particular science, as a system of thought, Yan Fu succeeded in giving those whom he influenced not only a complete "scientiflc system," but right or wrong, a lasting impression of "how" sclence works as well. His translations of the work of Thomas Huxley and Herbert Spencer gave many reform-minded intellectuals a biological model of change that seemed to perfectly fit the social circumstances in China at the time.

The understanding of the workings and uses of modern 
sclence that Yan Fu developed was far from "seamless." In fact, certain ambivalences and contradictions in his work are the origin for elements of the thought of other important figures in the early twentleth century. Though detalled textual comparisons of Yan Fu's translations and miscellaneous writings with those of other intellectuals concerned with the lssues of China's social survival have yet to be done, a critical part of his importance for the intellectual history of this period in China is due to his often subtle influence on other social thinkers. As a member of the class of bureaucrat-literati trained in the Neo-Confucian tradition, and therefore accustomed to its categories of description and explanation and 1 ts styles of presentation, he is an important bridge between the intellectual cultures of china and the West. In his unavoidably synthetic approach are the seeds of the thought of others who came after him. His use of Darwin, Huxley, and spencer's blological explanations as analytical tools for the examination of social, political, and economic issues and the view of science implicit and explicit in his work was the starting point for many Chinese intellectuals' relationship with modern science.

Two nearly opposing strains of thought in Chlna which were borrowed from the West and born in the intellectual heat of the May Fourth Movement owe much to Yan Fu's 
concept of science and his blologlcal mode of social and political explanation. Chinese communism and Chinese liberalism were the two major viable alternatlves to "national death" after the initial fervor of May Fourth died down. Though it was ultimately communism that won in the marketplace of Chinese ideas, they both express elements that are present in Yan's own work. Despite the marked difference in their conceptualizations of change and continuity, modernity and tradition, and "how science works," the Chinese variants of both Marxism-Leninism and liberalism are linked to the thought of Yan Fu through their "evolutionary cosmologies" and through their mutual bellef in the transformative power of "scientiflc thinking" to secure China's survival in the modern world.

The work of liberal Hu Shi [Hu Shih] (1891-19) and communist Chen Duxiu [Ch'en Tu-hsiu] (1880-1942) in the May Fourth era have frequently been linked to Yan Fu. Both of them were known to have read his works and openly admitted their debt to him for elements of their own thought. Part of their inheritance from Yan were certain conceptualizations of modern science, both in general and In the particularity of his application of modern biology to socio-political concerns. Though both 1 iberalism and Marxism as they developed in the West have their own connections to evolutionary thought and to "scientific" 
thinking, Hu and Chen were especially influenced by these ideas from the west as they had previously been interpreted by Yan Fu.

By examining the work of Yan Fu, and that of $\mathrm{Hu}$ Shi and Chen Duxiu as two divergent strains of thought equally influenced by Yan's work, a picture begins to emerge of scientific understanding among Chinese intellectuals of the late imperial and early republican periods.4 That

4 In this study the primary textual sources for the thought of Yan Fu were several influential essays published between 1895 and 1898 , and Yan's Chinese translation of Thomas Huxley's Evolution and Ethics, published in 1898 as Tianyan Lun [T'ien-yen Lun]. The essays were unavallable in Chinese, necessitating a greater reliance on extensive quotations in English language secondary sources. Primary textual sources for $\mathrm{Hu}$ Shi and Chen Duxiu were articles that they wrote between 1915 and 1919 for the journal New Youth (Xin Qingnian) [Hsin Ch'ing-nien], and their prefaces to the two volume collection of the polemic on "science versus Metaphysics", published in 1923. This focus on published essays and journal articles, because their audiences were similar, helps to give some basis for comparing their ideas.

Pertinent biographical information on all three figures was primarily obtained from English language biographies. Information on $\mathrm{Hu}$ Shi was particularly rich, as there were additionally an autobiography, Sishi zizhuan [Ss'u-shih tz'u-ch'uan] (Autobiography at Forty) in Chinese, and a synopsis of the development of his personal "Credo," written in English in 1931. Chen Duxiu's

"autobiographical fragments" of two chapters of an unfinished longer work were available in English translation. Certain aspects of their biographies are problematic and are discussed in the chapter devoted to each thinker.

Finally, a large number of secondary sources were consulted, far too many to mention in an introduction. Where it was felt to be helpful, the original work of a European or American thinker whose influence on Yan, Hu, or Chen is the subject of discussion was consulted as well. 
scientific understanding was carried into the following period of turmoil throughout the 1920's and 1930's and helped to form the revolutionary ldeologies of those who eventually came to power in the 1949 communist revolution.

This study will be confined to the single generation bounded by the publication of Yan Fu's earliest articles and translations, from 1895 to 1898 , and the "Debates on Science and Metaphysics" in 1923. The period of the May Fourth Movement extended beyond the initial incident in Beijing, May 4, 1919 to include a number of 1 mportant events that have their origins in the changing intellectual culture of urban china at that time. The "Debates," though occurring several years after the peak of activity surrounding the May Fourth Era, brought together all of the strains of thinking then current on the nature and role of modern science in China's immediate future. The earlier writings of $\mathrm{Hu}$ and Chen, from 1915 to 1919, were pivotal in generating the discourse among intellectuals concerning the meaning of science that eventually took the form of the "Debates," and their essays preface the published collection of the polemic. For these reasons the "Debates" provide a clear stopping place for periodizing this generation under consideration. The outcome of the "Debates" was a generalized acceptance of a "scientific view of life" as a necessity for achleving modernity among 
many Chinese intellectuals. This set a certain tone for much of the political and social thought in China from that point on.

Yan, Hu, and Chen share certain aspects of their background and educations that make them an ideal group for the study of a trend of thought over a single generation. They all came from famllies who were part of the class of Neo-Confuclan trained scholar-officials, literati educated to serve the state, though they were exposed to different strains of Neo-Confucianism. They span the last generation of Chinese trained for the government sponsored examination system, and after its abolition in 1905, the first for whom it could not be the road to a valued career.

But their responses to the transitional educational opportunities avallable were quite different. Though wellprepared for the examination route from an early age, Yan Fu's financlal circumstances (his father had died when Yan was guite young) probably kept him from pursuing the specialized tutoring in the confucian canon needed to pass the exams. Instead, he opted for an education in "Western studies," studying naval science, while maintaining a deep interest in the Chinese classics. He eventually took and falled the exams four times before he ceased trying. Hu Shi also received thorough early training in the Confucian canon, but as a youth, attended a serles of so-called "new- 
schools" that combined traditional Confucian studies and some "Western studies." Chen Duxiu is the only one of the three who took and passed the entry level prefectural examinations and recelved the xlucal [hsiu-ts'al] degree. He started but never finished taking the provinclal examinations for the juren [chü-jen] degree.5

All three men studied science or technology outside of China: Yan in England, Hu in the United States, and Chen in Japan. They shared the alienating experience of many "returned students" in China, frustrated in their attempts to use the technical skills they had learned. They all had command of at least one Western language, in addition to the scholar's acquaintance with terse and eloquent "academic" Chinese. Hu and Chen were also deeply involved in language and literary reform in the first quarter of the twentieth century. All three of them were deeply committed to education as the starting place to bulld a soclety, as Chinese scholars had been for centuries. The common elements in the backgrounds of these men help to point out more clearly the diverse directions that their thought eventually took.

5 There was a third level, the metropolitan examination, held in Beifing. Success lead to the highest degree, the jinshl [chin-shih], whlch granted access to the most prestiglous and powerful opportunities in the chinese bureaucracy. 
Though the thought of Yan Fu, Hu Sh1, and Chen Duxiu certainly constitutes a chinese strain of the world-wide phenomenon of "social Darwinism" -- defined by one hlstorian as "...lalssez-faire political economy rendered "scientific" by association with Darwin's theory of natural selection..."6 -. this essay is concerned, above all with what did occur in the thought of Chinese intellectuals coming into contact with the ldeas of Darwin, Huxley, and spencer. The Chinese context is not simply an important element in the story. This essay is a study of how sclentific ldeas from the west interacted with existing Chinese patterns of thought at the turn of the twentieth century. "social Darwlnism," while perhaps a useful analytical tool in the larger, world context, is a Western term, describing Western responses to Western ideas. The same may be sald of the label "scientism" -defined by D.W.Y. Kwok as "...that view which places all reality within a natural order and deems all aspects of this order, be they blological, social, physical, or psychological, to be knowable only by the methods of

6 John C. Greene, "Sclence, Ideology, and World View," in science, Ideology, and World Vlew: Essays in the History of Evolutionary Ideas (Berkeley, CA: University of Callfornia Press, 1981), 3 . 
science."7 It, too, may be a useful tool in placing the thought of Hu shi and Chen Duxiu into a larger, world context. Group studies of intellectuals in this period which included both $\mathrm{Hu}$ Shi and Chen Duxiu have been done which used "social Darwinism" or "sclentism" as organizing themes and analytical tools.8 But in an "Internal" study such as the present essay, "scientism," like "social Darwinlsm," as a rubric is loaded with the intellectual history of the west and may move attention from the Chinese context to that of the Western source.

In an effort to explore the interaction of the ideas of modern sclence with the changing Chinese intellectual context in the late nlneteenth and early twentieth centuries, this study will try to show what actually occurred rather than to apply prefabricated labels of Western origin to these circumstances. The situation was conslderably more complex than labels can express. Instead of simply imitating the ways of the West, Yan Fu, Hu Sh1,

7 D.W.Y. Kwok, Scientism in Chinese Thought, 19001950 (New Haven: Yale University Press, 1965; reprint, New York: Blblo and Tannen, 1971), 21 (page references are to reprint edition). The emphas is is mine.

8 For a treatment of Hu ShI and Chen Duxlu in terms of "sclentism" see Kwok. The most complete analysis of both men in terms of the "social Darwinism" of their thought is Lin Yü-sheng, The Crisis of ChInese Consciousness: Radical Ant 1-traditlonal1sm in the May Fourth Era, with a Forward by Benjamin I. Schwartz (Madison: University of Wisconsin Press, 1979). 
and Chen Duxiu unavoidably worked at their understandings of the meaning of modern science within a conceptual

framework that was essentially Chinese. In doing so, and in the intellectual resolutions each achieved, they "faced both ways." 
CHAPTER II

YAN FU AND THE MODERN WEST

When Yan Fu's (Yen Fu] (1853-1921) translation of Thomas Huxley's Evolution and Ethics (1893) was published in China in 1898 as Tlanyan Lun [T'ien-yen Lun] (on Evolution), it started a revolution in thought. It appeared at a time when modern sclence and technology were increasingly acknowledged by Chinese intellectuals and government officials as crucial to China's survival.1 It also appeared on the heels of the Empress Dowager Cixi's [Tz'u-hsi] quashing of the "100 Days of Reform" in 1898, the first comprehensive, government sponsored reform that included modern science in the program. The fallure to achieve the alms of the "100 Days of Reform" left many Chinese searching hard for the answer to why China seemed not to be able to save itself.

Yan Fu was not a born lconoclast. Much of his early background was not unusual for a man of the scholarofficial class. He was born in 1853 , in the village of Yanggl xlang [Yang-ch'1-hslang], Houguan [Hou Kuan]

1 see Chapter III, pp. 57-60 below, for a discussion of the attitude of nineteenth-century chinese "selfstrengtheners" to Western science and technology. 
prefecture, Fujlan [Fukien] province. His father, Yan Chenxian [Yen Chen-hsien], was a practitioner of traditional Chinese medicine of some local repute. Yan Fu was apparently a bright child (as are all famous scholars, In China as elsewhere!), and as the only surviving son in the family, was prepared from a very early age by his father for tutoring in the canon of Confuclanism and study for the civil service examinations. 2

Yan Fu's father secured a suitable tutor for him, when he was ten years old. It is clear that the young scholar had a high regard for his first teacher, Huang shaoyan [Huang Shao-yen], whose death when Yan Fu was fourteen was "grieved no end." 3 Huang presented Yan with a "multidisciplinary" approach to learning the Confucian classics that were still the core of Chinese learning for the examinations. Rather than approaching study through only one or the other of the major intellectual trends in contemporary scholarshlp, Huang exposed Yan to both "Han learning" (Hanxue [ Han-hsüeh] and the older and more orthodox Neo-Confucian "Song learnlng" ( Sonqxue) [Sunq-

2 Benjamin Schwartz, In Search of Wealth and Power: Yen Fu and the West (Cambridge, MA: Harvard University Press, 1964), 22-23, 252 note 3 . Yan Fu had two younger sisters and a brother, two years older than he was, who died as a child.

3 Ibld., 23. 
hsüeh].4 Despite Yan Fu's eventual rejection of the emplrical textual methodology (kaozheng) [k'ao-cheng] used by the practitioners of "Han learning," 5 this early synthetic approach to learning may have left its mark in his own work. Benjamin Schwartz has suggested that Yan's "...combination of enthusiasm for the metaphysical sweep of the spencerian cosmology and equal enthusiasm for lJohn stuart] Mill's inductionist logic and empirical method reflects to some extent the efforts of his teacher to combine the values of 'Han and sung'."6 A reverence for methodologies that purport to remove bias from an inguiry and ensure a balanced view was an important aspect of Yan's later admiration of Herbert spencer, and hls own synthetic approach to the problematic of "Chinese learning" versus "Western Learning." These aspects of Yan Fu's young adult thinking may be seen to have an affinity with his earliest formal schooling experience.

When Yan was thirteen years old his father died. With the death of his beloved teacher the following year, Yan's

4 There is a discussion of Han and Song "schools" of Neo-Confucianism in the Ming (1368-1644) and $Q$ ing [Ch'ing] (1644-1912) dynasties, and their relationship to each other, in Chapter III, pp. 51-57, below.

5 For a discussion of the empirical methods of Han studies and their relevance to acceptance of modern Western thought, see Chapter III, pp. 55-57, below.

6 Schwartz, 24. 
formal Confucian education came to an end. His father's death meant that strain on the family finances might have prevented him from getting adequate schooling to pass the examinations.7 His own dedication to further educating himself after a brief three years under the guidance of a teacher is evident in his terse, elegant style of writing, even when translating a European text. It is a style that is deeply rooted in the tradition of scholarly writing on the Confucian classics. Even when criticizing or overhauling Chinese tradition, he is thoroughly indebted to it, and somewhat dependant on 1 f for his metaphors, flavoring, and certainly the setting for his explorations of the West.

Yan Fu pursued what was, for him, clearly a viable alternative to the traditional routes to a career. He chose to attend a school of "Western affairs" (yangwu) [yanq-wu] at the Fuzhou [Foochow] Shipyard School. The superintendent of the school, Shen Baochen [Shen Pao-chen], was from the same county as Yan's family and insured his admission to the school. His admission essay won him first place among those entering that term. Yan chose the school of Navigation where instruction was in English. English Ideas would come to dominate his explorations of European

7 Ibid., 25. 
thought and his own intellectual development. 8

The Fuzhou shipyard school (Chuancheng qu xuetang) [Ch'uan-cheng chu hsüeh-t'ang] was founded in 1866 by ze Congtang [Tso Tsung-t'ang] as the educational wing of a "self-strengthening" (zi giang) [tz'u-ch'iang] institution. It was designed to train young men to staff, build, and repair the ships that were to become the backbone of China's modern navy. Though it maintained close ties with the more traditional academies in Fuzhou, at the time that Yan Fu attended it was the primary location in Fuzhou, and one of the more important in the country, to receive an education in "Western affairs" of any kind.9

While Yan Fu was a student in Fuzhou, he was exposed to modern Western sciences for the first time, studying arithmetic, geometry algebra, trigonometry, physics, chemistry, geology, astronomy, and navigation, in addition to English and "Chinese studies" (Zhongxue) [Chung-hsüeh]. His first hand experience with basic sciences must have contributed to his "volce of authority" when he later began to write about modern science. After graduating with honors in 1871, he spent a number of years sailing the

8 Ibld., 26-27.

9 Suzanne Wilson Barnett, "Foochow's Academies: Public ordering and Expanding Education in the Late $\mathrm{Nineteenth}$ Century," Journal of the Institute of Modern History (Academia Sinica) (1987): 513-514, 537. 
vessel Yang Wu (Western Affairs) and went on an "actual naval mission" to take soundings of various ports off the island of Formosa in preparation to defend China against attacks from Japan.10

In 1877 Yan was sent to England to continue his studies. Very little seems to be known about the two years that he spent in England.11 Benjamin Schwartz states that It was already clear to Yan by the time that he returned to China that the key to "wealth and power" in the west lay in Western thought and that he had "already become familiar with Darwinism in England and was also reading Spencer's other books at this time."12 But this is nearly all there is to go on. In the next decade after his return he was to become frustrated with his inability to use what he had learned about naval science to positive effect. After a serles of false starts and dead-end jobs in various aspects of self-strengthening, he declded to make an attempt to pass the examination for the lowest of the civil service

10 Schwartz, 27-28.

11 The only monographic study of Yan Fu in English, Benjamin Schwartz's In Search of Wealth and Power, glosses over his years in England entirely, while stressing the Importance of English ideas in his overall intellectual development. The only other work in English to treat Yan Fu in any depth, James Reeve Pusey's China and Charles Darwin (Cambridge, MA: Harvard University Press, 1983), doesn't dwell on these years in England elther.

12 schwartz, 33-34. 
degrees in 1885. He was to fall four times before he stopped trying.13

One aspect of English culture that Yan Fu certainly could not have missed observing while he was in England was "progress." At that time "Britannia" did rule the waves, and had proven 1 ts might as the major Industrlal and naval power in the world. It seemed that nothing could stand in Britain's way. England became the epitome of human progress for Yan, as the United states would for Hu ShI and France for Chen Duxiu.

Yan Fu's first widely read essays appeared in 1895 , the year of China's defeat in the sino-Japanese War. A number of them, as a group, may be seen as a preface to his translations of Western thought that would have such a profound effect on reform and revolutionary thought in the next two generations. One of these essays, "On the speed of World Change" ("Lun shiblan zhl qi") ("Lun shih-pien chlh chi"l, was focused on the Western ldea of progress, offering "the first definitive reform analysis of the idea of progress" in China.14 In the following passage about the relationship between the processes of change in the world, which he refers to as "destiny" (yunhul) (yun-hui],

13 Ibid., 32 .

14 Furth, 326 . 
and "the sages'" apprehension of these processes, Benjamin schwartz has suggested that "destiny" can already be replaced in Yan Fu's thought with the notion of the "process of evolution."15 If the processes of the world are "destiny", and "destiny" in Yan Fu's thinking is the "process of evolution", then the relationship between the sage and his understanding of these cosmic processes is that of the scientific adept to those processes:

Once the [process of ] destiny had been fulfilled, the sages could not force it from its course, for after all, the sages were themselves a factor ( 1 wu) within the course of destiny. It is unreasonable to assert that they could change the course of destiny. The sages were men who knew the direction of the process and were able to anticipate its ultimate course... They were then able to regulate $1 t$, complete it, to cooperate with it, and thus lead the world (t'ien hsia) to a state of peace. Later men, observing their success, came to belleve that the sages were actually able to change the course of destiny.16

Yan Fu's vision is certainly deterministic -- the plotting of the "ultimate course" of the universe. But the destiny of the universe in this vision is not simply an external force applied to humanity; sages are not simply those who have learned to "give in" to its power. Through application of the human will the sage "anticipates its ultimate course." This is a vision of the sage

15 Schwartz, 44.

16 Yen Fu, "Lun shih-pien chih chi" IOn the speed of World Changel, quoted in ibid. The emphasis is mine. 
participating in the universe, and being a part of it, to "complete it, to cooperate with 1t." This strain of voluntarism in Yan's thought, a belief in the power of human will to change not only physical reality but the character of humanity itself, would echo throughout modern Chinese intellectual history in such diverse individuals as Hu Shi, Chen Duxiu, Sun Yatsen (Sun Yat-sen), and of course, Mao Zedong [Mao Tse-tung].

Like Chen Duxiu's notion of sclence after 1921 as something that exists a priori, what Yan is intimating in the above passage is "natural law." These are the "laws" of the processes of the universe and tianxia [t'ien-hsia], that is "all under heaven", or the sphere of human society. For Yan Fu, to understand and participate in these processes through comprehension of their "laws" was "progress." Yan believed that it was the "Western sages'" grasp of a determined course of destiny/progress that was the key to the Western nations' success in the world:

The greatest difference between the principles of West and East, that which is the most irreconcliable, is the fact that, while the Chinese love the ancient and ignore the modern, Westerners stress the new in order to overcome the old. The Chinese think of the process of nature (t'ien hs/ng) and of human affalrs in terms of a cycle of order and disorder, prosperity and decay. The Westerners make their ultimate principle of learning and political action the idea that the possibilities of dally progress are inexhaustible, that prosperity once achieved will not decline, and that order will 
not fall back on disorder.17

For Yan Fu the Western way of thinking about the processes of the world was self-perpetuating, self-sustaining; once the idea of thinking this way was learned, it was set in motion, in a forward direction. And progress itself, which Western thinkers participate in through their understanding of its workings, is constantly renewing itself: "order will not fall back on disorder."

In "On strength" (Yuan Qlanq) [Yüan-ch'lang], also written in 1895, Yan Fu for the first time pointed to the Western sages who he belleved had comprehended these processes of development and progress and described why the nations of the West were so strong. It was the evolutionary thought of Charles Darwin and Herbert spencer that described for Yan how to understand the preeminence of Western nations in the world. The "rise of the West," of course, had begun centuries before. But it was Darwin's work in the evolutionary blology of specles, followed closely by Spencer's evolutionary social theorles that Yan Fu saw as the encapsulating explanation of all that the West had become:

since the publication of this book (The orlain of species l vast changes have occurred in Western learning, government, and philosophy. Those who assert that the teachings of Mr. Darwin have done 
more to renew the eyes and ears and to change men's thoughts than Newton's discovery of physical laws are perhaps not Indulging in empty words. 18

For Yan Fu, as for European and American "social Darwinists," the key in the evolutionary processes that Darwin had brought to light was "struggle", which tended to be seen in its most concrete form:

Living things struggle among themselves in order to survive. Nature (lit. 'heaven') selects [among them] and preserves the superlor species. In his [Darwin's] view that humans and living things are born within a given space and together feed on the environment (heaven and earth) and on the benefits of nature. They come into conflict with each other...At first species struggle with species; then as [men] gradually progress, there is struggle between one social group and another. The weak Invarlably become the prey of the strong (ch'lang-jou), the stupid invariably become subservient to the clever.19

As Benjamin Schwartz has pointed out, Yan Fu was not particularly wary of the consequences of an aggressive, competitive spirit - he was exhilarated by them. $20 \mathrm{He}$ belleved that the dynamic energy of the West was harnessed by its particular grasp of the "struggle for existence", and its exploitation of the energy released in this struggle. His deepest criticism of China, even in these

18 Yen Fu, "Yüan-ch'iang" [On strength], quoted in Schwartz, 45.

19 Ibld., 45-46.

20 Schwartz, 46. 
earliest writings, was that its intellectual tradition did not allow for proper struggle, and hence did not have access to the social energies necessary for growth and progress. In the writings of Hu shi, and in particular Chen Duxiu in the 1910s, this criticism would build to a refrain.

Yan Fu's linking of Darwin's ideas to human society through the work of Herbert spencer was already evident in the essays of 1895:

Spencer is also a native of England, and a contemporary of Darwin. His books actually appeared before orlgin of species. He based himself on the theory of evolution to explain the origins of human relations and of civilization. I call this science the science of human groups [sociology], for, as Hsun-tzu states, man's superiority over the beasts lies in his abllity to form social groups. 21

From its origins in the thought of Confucius himself, the focus of the Confucian tradition in China has always been on human relationships in society. Yan Fu's initial attraction to spencer lies, perhaps, in the latter's treatment of the social group. In spencer, it was the individual who was the key to the survival energy of the successful group.

21 Yen Fu, "Yüan-ch'iang" [On strength], quoted in ibid: Yan's term for Spencer's "sociology" is qunxue [ch'ü-hsueh] -- "the study of human groups". The gun [ch'ün], or group one belongs to, is the central element in Confucian social theory, not the individual, as in the "post-Enlightenment" West. 
In Chlna, the individual had traditionally been completely submerged in the needs and identity of the group. Yan Fu was acutely aware of this difference between Chinese and Western attitudes and identifled this as the source of China's problems:

Our Chinese sages were not unaware that the universe is an inexhaustible storehouse lof infinite possibilities] and that if the subtle powers of the human mind are given free vent, human ingenuity and intellectual capacity can attain unfathomable results. However, we simply turned aside [from the pursuit] and did not concern ourselves with 1t. In our philosophy (tao) of sustaining the people we aimed only at harmony and mutual sustenance...

The products of heaven and earth are limited but the lustful desires of men are limitless. The procreation of children increases constantly, the cultivation of the soil is ever more extended. In the end there is insufficiency of food. The insufficlency leads to struggle but struggle is [in their view] man's greatest calamity. Hence they preferred to preach contentment with one's lot (chih-tsu, lit. 'knowing what suffices'). They saw to it that everyone was content with a rustic simplicity and a dull confined exlstence, that they cultivated the soll in the service of their superiors... Alas, such was the consummate skill of the sages in constraining the world, in preventing struggles and putting an end to disorder, they were unable to foresee that people's knowledge would decline steadily and their energy would steadily deteriorate! 22

In, or just before, 1895, at the same time that these essays were beginning to be published, Yan Fu began to write his famous series of translation/commentaries of

22 Yen Fu, "Lun shih-pien chih chi" lon the speed of world Changel, quoted in schwartz, 54-55. 
Western liberal thinkers. The early essays of 1895 contain the framework of Yan Fu's understanding of the transforming and transvaluing power of ideas in shaping human soclety. Benjamin Schwartz has described the essays and letters (there were many more than mentioned above) of 1895-1989 as the "matrix in which the whole translation effort must be understood...the...translations provide an elaborate and imposing commentary on the basic notions elaborated in the essays."23 In this light, Yan's translation/commentaries of the works of Thomas Huxley and Herbert spencer have their prologues in the essays "On strength," "On the speed of World Change," and others written in 1895. Yan's notions of how science works, in general, and how evolutionary biology works in human society, in particular, at first presented only partially in these essays, are presented more systematically in his translation/commentaries.

Yan's immediate concern with the structuring power of an evolutionary cosmology shows clearly in his translation efforts. He began with Tianyan Lun [T'ien-yen Lun] (on Evolution), a paraphrase translation of and commentary on Thomas Huxley's Evolution and Ethics. In spite of Yan's own intentions that his books "...were not designed to 
nourlsh schoolboys" and were "...translated precisely for those Chinese who do read many anclent books," 24 Tianyan Lun had a profound effect on established scholars and schoolboys alike. Its self-consclous literary style was aimed at the scholar of the literati class, those who traditionally grappled with the affairs of thought and the state.25 Desplte its difficult style, it was read for the beauty of its language as well as for the message it promoted.26 Both Kang Youwel [K'ang Yu-wel] (1858-1927) and Liang Qichao (Liang Ch'1-ch'ao) (1873-1929) apparently read the text of the book before it was finally printed in

24 Yen Fu, Hsin-min ts'ung-pao (The New People's Miscellanyl No. 7 (Apr11 1, 1903), quoted In Schwartz, 94.

25 Yan once responded to the criticism that because his works employed a sinewy academic style of writing instead of a more journalistic, accessible style, they were too difficult to read to be of wide-spread interest, "Those who read my translations often find them impossible to understand readily and criticlze thelr abstruseness. Do they know that the original works surpass this in difflculty? Principles of original subtlety certainly cannot be mixed together with language lacking in eloquence." Yan Fu, Ch'ün-chl ch'uan-chieh lun lon Liberty]. Yen 1 ming-chu ts'unq-k'an, Volume 4. A translation of John stuart Mill's on Liberty, quoted in Jerome B. Grieder, Hu Shlh and the Chlnese Renaissance: Liberalism in the chinese Revolution, 1917-1937 (Cambridge, MA: Harvard University Press, 1970), 84.

26 Schwartz, 94. 
1898 and were admirers of Yan's work.27

Yan Fu was not interested in Darwin's biology, per se, but rather in how his ideas impacted the realm of human activity and the legitimating power of their standing as "science." Yan's reading of Darwin's ideas had been summed up in "Yuan Qiang" [On strength], in two terse, classical Chinese phrases of his own invention: wu ing (wu ching) (IIIving] things contend) and tianze [t'ien tse] (Heaven (or Nature] chooses): "'Things contend' means that things struggle to preserve themselves. 'Heaven chooses' means

27 Hao Chang, "Intellectual Change and the Reform Movement, 1890-8," in The Cambridge History of China: Volume 11, Late Ch'ing, 1800-1911, Part 2, eds. John $K$. Fairbank and Kwang-Ching Liu (Cambridge: Cambridge University Press, 1980), 297; Schwartz, 82-83. Liang Qichao is known to have read Yan's manuscript prior to publication and appears to have shown it to Kang Youwe 1. The extent of Yan's influence on Llang has not yet been worked out. Hao Chang accepts that Llang's early reading of Tlanyan Lun influenced his well known turn toward "social Darwinism." See Hao Chang, Liang Ch'i-ch'ao and Intellectual Transition in China, 1890-1907 (Cambridge, MA: Harvard University Press, 1971), 64. Philip Huang has presented strong evidence for the alternative view that Liang's initial exposure to "social Darwinism" (not Darwln's theory of evolution) came from Liang's reading of the works of Japanese "social Darwinist" Kato Hiroyuki. See Philip C. Huang, Llang Ch'i-ch'ao and Modern Chinese Liberalism (Seattle and London: University of Washington Press, 1972), 56-61 and 179-180, note 78. The issue as far as the present essay is concerned is Yan's influence on Liang, not whether Yan was the first evolutionary influence on Llang. They were in correspondence with each other, and their ideas were similar enough, that despite the fact that Yan was older than Liang, they could support each other's positions to a certain degree. 
that only the fit races are preserved."28 "Things contend", but in Yan's scheme, not for the benefit of the Individual. Spencer is brought in, on the wings of Xunzi [Hsü-tzu], to reclaim the gun, the group. The energies of "things contending" are released so that the group benefits. Heaven/Nature selects the group that is the most fit for survival, the group whose energies have been properly released for survival among other groups.

Remarkably, Yan Fu began writing Tianyan Lun within a year and a half of the initial publication of Huxley's Evolution and Ethics in England in 1893.29 He was clearly quite struck with Huxley's exposition in his hurry to get a translation of the new work out. He made it the first of his own major works. But like the essays, where Darwin's ideas are seen through spencer's eyes, here Huxley's apologia of Darwin's ideas are seen through spencer's eyes. Huxley's Evolution and Ethics is a parry to the "social Darwinism" of such social thinkers as Herbert Spencer. His aim was to remove the "stumbling block" of the

-..apparent paradox that ethical nature, while born of cosmic nature, is necessarily at enmity with its parent...this seeming paradox is a

28 Yen Fu, "Yüan-ch'lang" [On strength], quoted in Pusey, 61 .

29 Schwartz, 98. 
truth, as great as it is plain, the recognition of which is fundamental for the ethical

philosopher...We cannot do without our inheritance from the forefathers who were the puppets of the cosmic process; the society which renounces it must be destroyed from without. still less can we do with too much of it; the society in which it dominates must be destroyed from within. 30

Yan Fu stepped directly into the paradox, whlle at the same time accepting the gains to be had from the meliorating influences of the balance implied in Huxley's passage above. His historically determinant cosmos is, paradoxically, to be grasped by the person whose progressing understanding can act on the world. After reading Huxley's clear-cut attempt to cut Darwin's theories free of the social accretions built upon them, he rehitched the horse of Darwin's theory to spencer's wagon. It was Huxley's position that

...the science of ethics professes to furnish us with a reasoned rule of life; to tell us what is right and why it is so. Whatever differences of opinion may exist among experts there is a general consensus that the ape and tiger methods of the struggle for existence are not

reconcilable with sound ethical principles.31

Yan, on the other hand, belleved in an utterly unified cosmos, and that human behavior, including presumably

30 Thomas H. Huxley, Evolution and Ethics and other Essays, author's edition (New York and London: D. Appleton and Company, 1894), vili.

31 Thomas H. Huxley, "Evolution and Ethics," in ibid., 52-53. 
ethics, is a reflection of the "way" (ao) [t'ao] of the cosmos. There doesn't seem to be room for the central element of Confucian ethics, ren [Len], or "benevolence/humankindness," in Yan's cosmos. On the morality of the cosmos, he quotes the raoist philosopher Laozi [Lao-tzu): "Heaven and earth are not benevolent, they treat the ten thousand things as straw dogs." 32

It is in reference to Laozi and the cosmos where the mellorating influence of balance first appears in Yan's work; it will reappear in his comments about the "scientiflc method" of spencer. As Yan has resorted before to Legalism (the work of Xunzi) for descriptive categories for this new, Western thought with which to rebulld the way that chinese relate to the universe, he resorts here to Taolsm: "The non-benevolence (pu jen) of which Lao-tzu speaks is not really non-benevolence. It is something which transcends the dichotomy of benevolence and nonbenevolence."33 It is a greater process, the "Tao of Evolution", if you will, that is the ultimate single principle of the cosmos -- for heaven and man. It is the sage's job to understand it.

32 Yen Fu, T'ien-yen Lun [On Evolution], in Yen 1 ming-chu ts'ung-k'an, Volume 1, part 2 (Ya-tung Tushukuan), 14, quoted in schwartz, 107.

33 Ibld. 
This sense of the desirability of balance and order in society as a reflection of the cosmos and knowledge as the key to obtaining this balance has affinities with elements of Confucian thought as well. The following passage is from the Daxue [Ta-hsüeh] (The Great Learning), 34 one of the Four Books of the Confucian canon and important to zhu $X 1$ [Chu Hs1] (1130-1200), co-founder of the "rationalist" strain of song Neo-Confucianism, as well as to advocates of "practical studies" (shixue) [shlh-hsüeh] in the late Ming and Qing dynasties. In it the moral order is linked to the political and soclal order through "the investigation of things" (gewu) [ko-wu]:35

The men of old who wish to make bright virtue plain to the world first put their countries in order, for which they had first to regulate their families, and for that to improve themselves as Individuals, and for that to correct their hearts, and for that to give integrity to their intentions, and for that to extend their knowledge. The extension of knowledge lies in the investigation of things ( $\underline{\mathrm{ke}-w u}$ ). 36

34 The Daxue, or Great Learning, is a chapter from the Li Ji [Li Chi], or Record of Rites, a first century B.C. compilation of late zhou [Chou] (B.C. 770-265) and early Han (B.C.206-A.D. 25) texts on ritual.

35 The concept of gewu and its relationship to the acceptance of the Western notions of progress and modern sclence in China is discussed in Chapter III, below, pp. 48-50.

36 Willard J. Peterson, "Fang I-chih: Western Learning and the Investigation of Things", In The Unfolding of NeoConfuclanism, ed. Wllliam Theodore de Bary (New York: Columbia University Press, 1970), 376-377. The original 
There is a correspondence being drawn between the possession of moral qualities and the "investigation of things" (read: "science"). The need for the sage to achieve a moral uprightness and balance, and to link the pursuit of "true knowledge" to this "centeredness," is the dominant theme of the Doctrine of the Mean (another of the Four Books of the Confuclan canon), as well. Balance and the elimination of disorder and chaos are fundamental themes throughout Chinese Confucian philosophy. Yan Fu was still interested in achieving order, which would be based on China's survival as a nation. But he seriously challenged the effectiveness of the old Confucian methods in preparing its leaders for a modern world.

Yan Fu's interest in the work of spencer as a scientist lay in his perception of spencer's scientific methodology. Sociology, as spencer presented it in the study of Sociology, was the "Queen of sclences," "a science in which all other sciences are included." To Yan it must have seemed the very rectification of science itself. He stated that until he had read spencer, he had

Chinese may be read as paragraph four in The Great Learning, translation with exegetical notes by James Legge (Oxford: Clarendon Press, oxford University, 1893; reprinted in Confucius: Confucian Analects, The Great Learning, and The Doctrine of the Mean (New York: Dover Press, 1971), 357-358 (page references are to the reprint edition). 
believed that "...life tends to lop-sided extremes (or to biases)." 37 spencer's scientific method, which Yan saw as eliminating blases, became for him the uprightness and moral rectitude described as the mark of the ancient sage. The change of mind and heart that chlna needed to engage in was to the "way" of science, as a method for thinking.

In much the same way that the "laws" and theories of modern science are believed to be universally applicable to phenomena observed anywhere on the planet Earth, Yan had a strong belief in the universality of knowledge, which informed his attitude to "Western studies." Scientific method was a critical aspect of what Yan Fu believed "Western studies" had to offer china. In a letter to the editor of Waljiao Bao [Wai-chiao-pao] (Journal of Western studles) written in 1902, his plea for a general overhaul of thinking in China is clear:

What are China's principle troubles? Are they not ignorance, poverty, and weakness?... Any method which can overcome this lgnorance, cure this poverty, lift us out of this weakness, is desirable. The most urgent of all is the overcoming of lgnorance, for our fallure to cure poverty and weakness stems from our ignorance... We must exert our utmost efforts to seek out knowledge. We have no time to ask whether this knowledge is Chinese or Western, whether it is old or new. If one course leads to ignorance, and thus to poverty and weakness, even if it originates with our ancestors or is based on the authority of our rulers and teachers... we

37 Quoted in Schwartz, 34-36, passim. 
must cast it aside. If another course is effective in overcoming ignorance and thus leads to the cure of our poverty and weakness, we must imitate it, even if it proceeds from barbarians and wild beasts...38

Yan exhibits, here, a clearly utilitarian streak in his thinking. He was able (or willing) to use correspondences between Western thought and Confucian and Taolst thought to criticize the Chinese tradition. He was also prone to focus on the methodological elements of modern science, rather than on its data. It is his stress on Western "methods" that brings us back to a discussion of the ti/yong, or "principle" vs "utility" dualism in late Imperial and early modern chinese thought. There is another paradox lurking here. Yan Fu's abllity to see Western "thought", rather than Western "technique" as the foundation of the strength of European nations should have been a radical break with the tendencies of the "selfstrengtheners" of the mid-nineteenth century. But it resulted instead, in an odd twist, in subsuming ti (the essence or principle, in this instance "Western scientific thought") under yong (the usefulness of a thing). The value of the most theoretical aspects of Western scientific thought rests, then, in its usefulness. These scientific methodologies do not, however,

38 Yen Fu, "Yu Wal-chiao-pao chu-jen lun chiao-yu shu," quoted in schwartz, 49. The emphasis is mine. 
completely disappear inside their function. They are singled out, separated time and again, by Yan Fu. For example, volumes seven and eight in his series of translations are Mingxue gianshuo [Min-hsüeh ch'ien-shuo] (Logic), a translation of William stanley Jevons' Loglc, and Minqxue (Ming-hsüeh) (Logic), a translation of John stuart Mill's Logic. Science, as scientific method, and as theory, becomes a technology for changing society by reordering the way people think -- an "intellectual technology."

The idea of an intellectual technology is not new to China in this period. Robert Hartwell's description of "historical analogism" as the dominant methodology of governmental problem solving during the song (960-1279) and subsequent dynasties amounts to an intellectual technology used in running the vast machine of the state bureaucracy.39 The orthodox interpretations of the

39 Robert M. Hartwell, "Historical Analogism, Public Policy, and Soclal Sclence in the Eleventh and TwelfthCentury China," American Historical Review 76 (1971): 690727. "Historical analogism", as used by Hartwell, refers to the technique of using discussions about, and solutions to, problems posed in the confucian classics as a starting place for analysis of analogous current problems. Its centrality as an intellectual technology is reflected in the expectations of the chinese examination system: the Palace Examination, a critical determiner of ultimate rank within the bureaucracy, was based on the concept of using historical analogism in solving governmental policy problems (703-704). Hartwell has further suggested that "... In China the use of historical analogism was 
Confuclan canon that scholar-bureaucrats were trained in and the "elght-legged essay" format they used to write commentaries on this canon were intellectual technologies -- used to produce a predictable, obedient official for the government. Mathematics, in any culture, functions as an intellectual technology -- to keep track of number in time and space.

Because the Chinese tradition had made use of a number of sweeping intellectual technologies in ordering human behavior and in problem-solving over the centuries, closely tied to the educational system, it was a short leap for Yan Fu to come to believe that education in science as a "useful" way of thinking was a necessity for the "new" sage. But Yan wanted only to "use" science as a technique. It was the key to wealth and power, and not yet an end in itself.

On a practical level, Yan had more in common with the two generations of "self-strengtheners" who had come before him than he did with the more anti-traditional May Fourth generation that followed, building on many of the often incomplete understandings he had arrived at about the meaning of modern sclence for China's survival. He wasn't

responsible for many steps in [the] process of making the study of society a science. As a mode of investigation, however, it was inadequate to complete this transformation by itself." (718) 
interested in "overthrowing" anything. He believed that through the application of the "useful" (yong) "methods" that had made the West powerful, the Chinese would gradually evolve the modern institutions they needed to remain politically free and regain economic strength. But their fundamental Chinese identity ( $\underline{t i})$, based on a Confucian value system, would remain intact. The ways of the modern West would be lifted up out of the postRenaissance soclo-political circumstances that had created them, and added to Chinese ways.

At the same time, Yan had presented sclence, for the first time, as more than a set of techniques for understanding and controlling the world. The dominance of Europe seemed to prove the "scientific" truth of Darwin's evolutionary theory. The "evidence" was overwhelming. The power of Darwin (through Huxley) and spencer's ideas to explain China's weakness and point in the direction of the only way out, through struggle, to yan and a growing number of intellectuals also lent credibility to the "idea" of science, because they were presented as "scientific." Thinkers such as Hu Shi and Chen Duxiu Inherited more than simply general tendencies about the meaning of modern sclence from Yan Fu; they acquired many of his specifics as well. Among them, Yan's emphasis on science as "method," the voluntarism of the continuation of the moral 
obligation for the educated (or skilled) person to "cultivate the self," and a deep falth in the ability of ideas to change social and political structures became Important elements of Hu's and Chen's formulations of the meanlng of modern sclence to China's survival. These concepts themselves would evolve in the 1910 s and into the May Fourth period into new and powerful tools to chip away at the very foundation of Chinese culture itself. But $\mathrm{Hu}$ and Chen and others of the next generation would also inherit many of the Confucian (and Taoist and Legalist) categorles into which Yan had set his ldeas about science and Darwinian evolution. The following chapters will show that the strain of Chinese thought about the meaning of modern science that originates in Yan Fu and branches off into Hu Shi and Chen Duxiu is not just focused on the West, or on China, but "faces both ways." 
CHAPTER I I I

\section{PROGRESS, SCIENCE, AND THE LATE IMPERIAL CONFUCIAN DISCOURSE}

At the time that Yan Fu's essays and translations were being published in the late nineteenth century, the state of affairs in Chinese Confucian intellectual clrcles was a complex of competing stralns, increasingly confronted in various ways with ideas from the West. Since the twelfth century Chinese Confucian scholarship had been dominated by strains of Neo-Confucianism influenced by Buddhist and Taoist cosmological and metaphysical presumptions that had become less and less effective in running the state. The political and fiscal fallures of the government in the late Ming dynasty (1368-1644) generated an active internal crltique of the Neo-Confuclan orthodoxy that had legitimated the status quo. In addition, a number of powerful concepts from the West, including elements of Western science, were introduced to Chinese intellectuals, who were increasingly skeptical concerning inherited wisdom and demanded practical solutions to Chlna's political and military problems. This only intensified the existing Internal pressure on the "whole fabric" of Confucian thought. 
Chinese acceptance of the ideas of Charles Darwin and Herbert spencer, introduced largely through Yan Fu's translations, would be paved by the prior acceptance of two Ideas from the West: "modern sclence" and "progress." The scientific traditions and recent innovations of the West had begun to trickle into China with Jesult missionarles in the seventeenth century. The earliest ideas to arrive were those of astronomy and physical science, two flelds of science with an immediate usefulness. Certain aspects of mechanics were applicable to construction and hydraulics systems. More accurate astronomy was essential to agriculture as well as the chinese government, which depended on maintaining aspects of Imperial authority through judicious portents observed in the heavens. An entire system of Western astronomy was never presented to the Chinese by the Jesuits. Though Jesult astronomers were aware of the new Copernican astronomy, they were forbidden by a 1616 decree of the Congregation of the Index of the Cathollc church from discussing it with the Chinese. It wasn't until several years after Copernicus' De Revolutionibus was taken off the Index in 1757 that it was introduced, and even then, it was presented without the approprlate new mathematical scheme 
needed for its computations.1 Until Yan Fu's translations in the late nineteenth century, science as it developed in the West was never presented to the Chinese as a "way" of thinking, or as systems of seeing and ordering the world, with their own logical integrity, languages of description, and regimes of practice.

When Yan Fu was studying modern science in China and England in the 1870s, the attitude of the West toward modern science had already taken on much of its "modern" cast. The "descriptive" phase of natural philosophy had been left behind in nearly all fields in favor of a new materlalism and quantification of phenomena, and a parallel emphasis on measurement. In many ways it was the development of biology -- a science in which the place of humanity can hardly be argued away -- that brought the concerns of mechanlcs, chemistry, and mathematics into the human sphere. By bringing chemistry into medicine, mechanics and physles into anatomy, and mathematics into human population studies, the gap between science as a study of "nature" and science as a study of humanity began to close.

By the mid-nineteenth century Europeans and Americans

1 Nathan Sivin, "Wang Hsi-shan," in Dictionary of Scientific Biography, Vol. 14, ed. Charles Coulston Gillispie (New York: Charles Scribner's Sons, 1976), 160. 
were caught up in the idea of progress, which was closely allied to notions of the value of modern science. The idea of progress was not new in the West at this time; versions of it have been part of intellectual history in the West since late elghth century B.C. Greece.2 But by the eighteenth century, in a recognizably modern form, progress had become the central element of the intellectual doctrine of educated elites in the west. It had become modernity 1tself. Lewis Mumford's comment concerning the concept of progress in relation to technology and culture brings out some of the nature of its intellectual power, especially in regard to its primary handmaiden -- Science:

value, in the doctrine of progress, was reduced to a time-calculation: value was in fact movement in time. To be old fashioned or to be "out of date" was to lack value. Progress was the equivalent in history of mechanical motion through space...3

Progress was where the physical world and human capabilities met, and in a "science" sense, where human blology, society, and the laws of physical science met. Nowhere was this made more systematically clear than in the

2 A good introductory essay on the idea of progress in the ancient Greek world is E. R. Dodds, "The Anclent Concept of Progress", in The Anclent Concept of Progress and other Essays on Greek Literature and Belief (Oxford: Clarendon Press, oxford University Press, 1973), 1-25.

3 Lewls Mumford, Technlcs and Clvillzation (New York: Harcourt, Brace, and World, 1962 (1934)], 183-184. 
work of Charles Darwin and Herbert Spencer. Spencer provided the framework, and for many, Darwin's theory of organismal evolution provided the mechanism of the "progress of human societies." what is commonly referred to as "soclal Darwinism" is the nearly lmmedlate link Ing of spencer's interpretation of the development of human society with Darwin's theory of the evolution of the human as an organism. "Social Darwinism," focused as it was on a simplistic interpretation of the concept of the "survival of the fittest," was descriptive to many Europeans enfoying a relatively high standard of living of the reality of the domination of the technologically more advanced cultures over those which were less well developed. And the key to technological advance was sclentific advance. This was Progress.

The idea of progress was not originally part of the native intellectual tradition of China. Progress is essentially a perspective on history, and the historical sensiblities of China were quite different from the notion of progress as it developed in the West. The Confucian sense of history places "truth" in the past, and it is there one must go to find answers to the present state of affalrs. Progress is only nominally concerned with the present; it is always looking to the future.

There were developments within Neo-Confucianism in 
China in the seventeenth and eighteenth centuries that may have prepared the way for the epistemological shift that allowed for some acceptance of the idea of progress among scholars in nineteenth-century China. The two main issues have to do with shifting conceptualization of gewu [ko-wu], or "the investigation of things." The term is from the

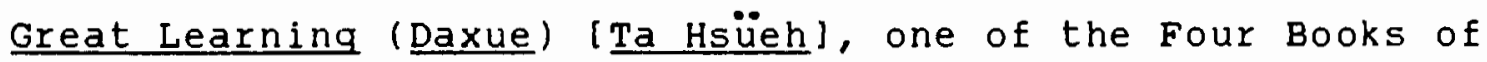
the confucian cannon. In this particular passage (discussed in chapter I above) public service and morality are closely linked and the achievement of both ultimately rests in "the investigation of things" (gewu) [ko-wu].4 The kind of "thing" to be investigated, however, was a critical consideration, and shifted over time.

By the sung dynasty (960-1279) the interpretations of the Cheng [Ch'eng] brothers and zhu $x i$ defined wu ("thing") not as "material", but as "activities". The proper focus of inquiry into wu was defined as $\underline{1 i}$, that is the "principle" underlying the "thing/activity" rather than its partner gi [ch'i], "matter or force." The tacit acceptance of the duality of $\underline{1 i}$ and $q \underline{i}$ is fundamental to the later acceptance of the duality of ti [til] and yong [yung]. Ti as "pattern" is akin to $\underline{1} \underline{i}$ and is often translated as "principle", while yong, "usefulness" is

4 see Chapter II, above, pp. 36-38. 
sometimes translated as "function" and as such implies the "matter and force" of q1. The focus on "princlple" moved Confuclanism away from study of materlal concerns. Wang Yangming (Wang Yang-ming] (1472-1529) in the sixteenth century, building on the Cheng-zhu [Ch'eng-Chu] interpretation, further moved the concept of gewu away from the external world of sense perception, internalizing the moral purpose of gewu in the mind.5

In the late Ming (1368-1644) and early Qing [Ch'ing] (1644-1912) dynasties there occurred what Benjamin Elman has called "a revolution in discourse". 6 It began at roughly the point when a number of late-Ming scholars became critical of what they saw as the increasingly metaphysical and "vacuous" focus of orthodox NeoConfuclanism, based closely on the interpretations of zhu $X i$ and the Cheng brothers (often referred to as the "ChengZhu" school of Neo-Confucianism). They became convinced that official Imperial sanction of and reliance on this "impractical empty speculation" for guidance in governing was responsible for the current breakdown in Ming authority and organization. Government inefficacy was confirmed for

5 Peterson, 376-378.

6 Benjamin A. Elman, From Philosophy to Philology: Intellectual and Social Aspects of Change in Late Imperial China (Cambridge, MA: Harvard University Press, 1984), 1. 
many of them by the fall of the Ming in 1644 to the "barbarian" Manchus. Many of these scholars became Ming loyalists, refusing service to the Manchu government.

The men who developed this "revolution in discourse" were concentrated In the Lower Yangtze River Basin, in a group of particularly rich and prosperous provinces known collectively as Klangnan [Ch'lang-nan) (Including parts of Jlangsu [Klangsu], Anhul [Anhwe1], and Zhejlang (Cheklang]). Since the late Tang (T'ang) dynasty (619907), this region, as both the southern end of the Grand Canal and the gateway from the Yangtze River (zhang Jiang) east to the Yellow sea (Huang Hai), had been a commerclal and communications hub. A merging of merchant and literati interests through merchant sponsorship of schools, academles, and the arts, and strong growth in the printing and book trades in the area created a powerful support system for strengthening the growing community of scholars. 7

In the late Ming a type of small scholars' group known generically as wenshe (wen-she) that met to discuss history, literature and philosophy in their varlous forms was at the helght of its popularlty. These types of groups had probably existed since the time of Confucius. But

7 Ibld., 8-9. 
population pressure on the civil service job market, congealing of the examinations around the highly technical (requiring specialized training) bagu [pa-ku], or "eightlegged" style of essay writing, and a more personal approach to enlightenment and attainment of the "Way of the sages" helped to generate growth in the numbers of and membership in the wenshe. 8

After the success of the Manchus in wresting away the rule of China in the mid-seventeenth century many members of wenshe began to stress practical statecraft. In addition there was a trend away from the rarefied, metaphysical 11-centered philosophy of song NeoConfucianism toward a philosophy of gi, or "material force." Many scholars began to place a new stress on shixue [shih-hsïeh], or "practical learning" as they tried to figure out how they had lost the governing of china to the Manchus. This new emphasis was largely the result of a belief among many scholars that the overly-metaphysical 1ibased Cheng-zhu orthodoxy, on which the Ming political philosophy was based, was the cause of the fallure to

8 william S. Atwell, "From Education to Politics: The Fu She", in The Unfolding of Neo-Confucianism, ed. William de Bary, 333-337, passim. 
retain rule.9

Shlxue was originally the term sung Neo-Confucianists applied to their "real" or "practical" (shi) [shih] critique of earlier Han and Tang style Confucianism based on textual exegesis and commentary and the "selfish negativism and quietism" of Buddhist and Taoist developments in the period just before the sung. Practicality and "realness" were stressed as an antidote to the "heresy and heterodoxy" of "Buddhist emptiness" and "Taoist nothingness." By the late Ming in China, and the early Tokugawa perlod (1605-1868) in Japan, shixue and jitsugaku had shifted from a preoccupation with "selfcultivation" as a "practical" aid to producing "good men" for the government, to a more materialistic concern with day to day statecraft. Mathematics, military technology, navigation, foreign languages, and eventually European technologies and sciences became increasingly the focus of both shixue and 1itsugaku. 10

9 Peterson, 400; Elman, 43-44. Shixue, as both a trend within Neo-Confuclanism and a critique of it, has been very little studied. There has been no monographic treatment of it. The most comprehensive look at shixue (though focused primarily on its Japanese variant, itsugaku) is the series of essays edited by william Theodore de Bary and Irene Bloom, Principle and Practicality: Essays in Neo-Confucianism and Practical Learning (New York: Columbia University Press, 1979).

10 William Theodore de Bary, "Introduction", in de Bary and Bloom, 1-33. 
Scholars such as Fang I-chih (1611-1671) began to reinterpret the concept of gewu in a more "material" or "practical" way. The sung reading of the word wu ("thing") as "activity" -- having primarily a social meaning, directing the investigation of such a "thing" to the human sphere, the traditional domain of Confucian thought -began to give way to an interpretation that was more experiential, more empirical, and hence more material. For Fang I-chih and an increasing number of anti-Manchu Confucian scholars in the late seventeenth and eighteenth centuries,

Things (wu) are that which fill the space between heaven and earth. Here is where human beings attain life. Life being contained in our bodies and our bodies being contained in the real world, all that we experience are events (shih). Events (or activities) are a class of things...

Particular physical objects (ch'i) certainly are things, and mind (hsin) is a thing as well. On a more profound level, the nature (hsing) and fate (ming) (associated with any particular being) together are a thing. viewed comprehensively, heaven and earth together are a thing.11

Fang and many other scholars renewing their interest in gi-based philosophy were members of the Fu she (The Renewal Soclety), a wenshe that was viewed as a serious political threat in the mid-seventeenth century. Many of their number did well in the examinations, often placing

11 Fang I-chih, Wu 11 hsiao chih, "Tzu hsu", 1a, quoted in Peterson, 378; also see 405, note 61 . 
first or second. Their interest in political power was linked directly to their interest in reforming decaying and ineffective institutions of education and government. Fang and others scholars of his generation are important as antecedents of the reform-minded scholars that would become the backbone of both the 1898 Reform movement and the May Fourth Movement in 1919.12

A new academic discipline of evidential scholarship, known as kaozheng (k'ao-cheng) began to develop in the Ming-Qing transition among members of the wenshe wishing to recover and evaluate techniques for ordering the world, gleaned from the classics. Phonology and philology, and in due course, history, were revived and revitalized with a new purpose in the practical desires of scholars loyal to the Ming. These men were desperately trying to recover what the sages of the classics really meant about proper government and society, before the metaphysical accretions

12 See Peterson, 376; Atwel1, 339, 344-346; and the article on Fang in Arthur $w$. Hummel, Eminent Chinese of the Ch'ing Perlod (1644-1912), Volume I (Washington, D.C.: United states Government Printing office, 1943), 232. Fang was also apparently familiar with most or all of the books on European natural phllosophy that the Jesuits had brought into China prior to the fall of the Ming. His interests included astronomy, geography, mathematics, medicine, and music, as well as phonetics, history, philology, calligraphy, and palnting. Willard Peterson has suggested that his contact with Western science through the Jesuits may have led $\mathrm{him}$ to $\mathrm{h}$ is new interpretation of the previously mentioned passage in the Daxue. 
of sung Neo-Confucian "misunderstandings" (some said they were inspired by influences from Ch'an Buddhism) destroyed the "pure wisdom" of Confuclus and his immediate followers. Evidential methodologies developed in their desire to retrleve original Han and earlier treatises, interpretations, word usages, and accounts of historical events in an attempt to get closer to the "truth."13 This trend of scholarship came to be called "Han studies" (Hanxue) [ Han-hsüeh] to distinguish it from the focus of its critique, "Song studies" (Sonqxue) [Sunq-hsüeh]. K'ao-zheng approaches to scholarshlp in statecraftcentered astronomy and in phonological research in the seventeenth and eighteenth centuries contributed to a shift In the conceptualization of the directionality of knowledge. Scholars such as Huang Zongxi [Huang Tsung-hsi] (1610-1695), a member of the Fu she 14, and Mei Wending (Mel Wen-t'ing] (1633-1721) contributed to this new understanding. The approach scholars took was often quite synthetic. For example, Mei Wending, who attempted to rectify Chinese natural philosophy and mathematics, understood mathematics as an inductive process whereby the patterns of 11 underlying things (wu) in the universe could

13 Elman, 51-53.

14 For more information about the Fu she wenshe, see Atwe 11 . 
be fathomed by collecting data. Both Mei and Huang Zongxi had worked extensively with European astronomy avallable in China at the time and believed that there had been an accumulation of knowledge in this area, with the most recent techniques for calculation being the most precise. They had a profound influence on men such as Yan Ruochen (Yen Jo-ch'en) (1636-1704) who applied astronomy and chronography to the study of Confucian documents, believing that their increasing precision would lead to the discovery of forgeries in the various "official" versions.15 In the early Qing dynasty the accumulative nature of the data of kaozheng scholarship combined with an increasingly secure sense of the concreteness of things (wu) led scholars to a nearly unanimous and new understanding of knowledge as cumulative and moving forward in time.16 This understanding provided the epistemological shift necessary for the apprehension of the Western idea of progress.

After the disastrous military defeats China suffered at the hands of Britain and France in the early and mid-

15 Elman, 133, 180-181, and 228-229.

16 Ibid., 228. Elman feels that the overall progressive quality to kaozheng research was due to the tendency of practitioners to work in areas that lent themselves to cumulative results. The tendency is clearly there, but the causal relationship hasn't been cleared up yet. For a detalled discussion of cumulativeness in phonology and other kaozheng scholarship, see ibid., 204-220. 
nineteenth century, there was another renewed interest in the "ways" of the West, in what was called "Western studies" (ㅍue) [ Hsi-hsüeh]. There was a new demand for "practical studies" (shixue), infused with ideas borrowed from the West, in order to strengthen China against the west. This time it was justified as "self-strengthening" (ziglang) [tz'u-ch'lang]. Self-strengtheners like Li Hongzhang [Li Hung-chang] (1823-1901), Ceng Guofan [Tseng Kuo-fan] (1811-1872) in mid-century, and zhang zhidong [Chang Chih-tung] (1837-1909) in the 1890s, understood that the West had somehow "progressed" beyond China. The West was "modern" and China was not. They came increasingly to value some change, though not the fundamental change in the very underpinnings of the culture that would mark the China's call to "progress" in the May Fourth period. The "self-strengtheners" wanted china to "catch up", a notion that was embedded in the modern notion of progress as "movement in time."

Progressive scholars who were concerned with China's survival were not, however, ready to accept Western values - in fact, they were not ready to accept the west as an equal. Even men such as Tan Sitong [T'an Ssu-t'ung] (18651898), who was often a strong advocate of "Western learning," were guarded in their appraisal of the possibilities it offered China: 
If China counts ten years, how will "Western affalrs" (yangwu) taste? A scholar-officlal can make progress with control! It is not possible to make progress with "Western affalrs" at the present time. There is a whole thing called "Western affairs", but what we see of it is steamships, that's all; electric wires...trains...firearms, mines...iron-smelting to make various machines, that's all...we should be well prepared, not always watching dreams... These "Western affalrs" are minor deta11s, not the fundamentals." 17

Desplte the move in the seventeenth and eighteenth centuries toward a more q1- or materlal-based Confucian phllosophy -- one that would have more "practical" application and had alded in the acceptance of the notion "progress" -- the duality of "principle" and "material" remained in the application of the ti/yong paradigm to the promotion of "Western studies" in the late nineteenth century. In zhang zhidong's formula of "Chinese learning for the essentials, Western learning for lts usefulness" (zhongxue wel $t 1, x 1$ xue we 1 yong) I Chung-hsüeh we 1 t' , Hs 1-hsüeh wel yungl, the West's material and technlques could be borrowed for their usefulness (yong) without effecting the "essence" (t 1 ) of Chinese culture. Chinese thinkers in this perlod did not assume that what was useful from the West would be carrying the $\underline{t}$, or essence of

17 Tan sitong, quoted in Li Kan, "Wushu we $1 x$ in yu zhongguo Jindal sixiang wenhua shi" (The Reform Movement of 1898 and the History of Modern China's Ideology and Culture) Lishl Yanjiu (Historlcal studies) No. 5 (1983): 59. The translation and emphasis are mine. 
Western cosmological assumptions or the philosophical underpinnings of the science and technology that were to be borrowed. As the concept of "self-strengthening" stretched after the fallure of the 1898 Reform Movement, and the power of Western thought to create Western science and technology was increasingly recognized by figures such as Hu Shi and Chen Duxiu in the first decade of the twentieth century, ti and yong began to come together. And some began to wonder if it wasn't the West's essence -- what lay at the foundation of the wealth and power of Western nations -- that would be the most useful to China in embracing the challenge of survival. 
CHAPTER IV

HU SHI BEFORE 1917

Hu Shi [Hu Shih] (1891-1962), China's leading advocate of Western liberalism in the early twentieth century, exemplifies the synthetic response of many Chinese intellectuals when exposed to the "idea" of modern science: they often relied on certain traditional Chinese patterns of thought while simultaneously accepting and advocating the power of modern scientific method.1 strongly influenced by the reformers of the 1890s, especially Yan Fu [Yen Fu] and Liang Qichao [Liang Ch'i-ch'ao], Hu's writings are notable for their clarity and modern-ness of expression. Unlike the previous generation of reformers and "self-strengtheners" who still directed their work to Confucian educated elites in a very academic style of Chinese, his early use of a vernacular style of Chinese made his writings more widely accessible. His ideas are,

1 This chapter will examine the development of $\mathrm{Hu}$ Shi's thought concerning his understanding of science and its role in social change up to 1917 only. In that year Hu returned to China from graduate school in the United states, with most of his ideas concerning science already formulated. It was after 1917 that he had his greatest impact on young scholars and intellectuals of the May Fourth generation. Also see Chapter VI below, p. 137, note 1 . 
nonetheless, complex and full of nuances. As a widely-read author and professor, dean, and ultimately president of Beijing University, one of this century's most productive and volatile centers of intellectual activity, his influence in twentieth-century China has been profound. The synthetic character of his thought provides a window into some of the thornier dilemmas of the Confucian-trained Chinese intellectual grappling with the epistemology of modern Western science at the opening of the twentieth century.

Hu Shi was born Hu Hongxing [Hu Hung-hsing], near Shanghai, December 17, 1891, in the village of Jiqi [Chich'ij.2 At the time that Hu was born, his father, Hu Quan [Hu Ch'uan], was a minor official, a collector of transit

2 Hu changed his name while he was a middle-school student in Shanghai. His version of the story is a famous instance of the popularity of the rhetoric of Darwinism in China durlng his youth: "In the course of a few years many of the evolutionary terms and phrases became proverbial expressions in the journalistic writings of the time. Numerous persons adopted them in naming themselves and their children, thereby reminding themselves of the perils of elimination in the struggle for existence, national as well as individual... Even my own name bears witness to the great vogue of evolutionism in China... I asked my brother to suggest a literary name for me. After only a moment's reflection, he said, "How about the word shih [fitness] in the phrase "Survival of the Fittest'?" I agreed and, first using it as a nom de plume, finally adopted it in 1910 as my name." Hu Shih, "Untitled essay", in Living Philosophies: A series of Intimate Credos (New York: Simon and Schuster, 1931), 248. Hereafter this work will be referred to as "Credo." 
taxes, who had only passed the lowest level of the exams due to civil war (the Talping Rebellion) and dislocation. The Hu ancestral home was in southeastern Anhui [Anhweil, an important center of Han studies ( kaozheng [k'ao-cheng] evidential philology in the seventeenth and eighteenth centuries. Despite the potential for coming under the influence of Han learning that existed, Hu Quan's formal education, such as it was, was in the tradition of sung learning. 3

In the 1890s Shanghai was in the thick of China's current social, economic, and political troubles. The Chinese city - the part of Shanghai left to the Chinese by the French concession and the International settlement, constant reminders of the city's "treaty port" status -was still a walled and gated maze of narrow alleys. Despite being squeezed between the politics of internal struggles for local gentry power and foreign treaty-portism (or perhaps, because of it), Shanghai was an important center for intellectual activity, and has remained so up to the present time. After the Opium Wars of the 1840s, Shanghai became an important center of world trade,

3 Ibid., 241: "My father was a classical scholar and a stern follower of the Neo-Confucianist Rational Philosophy of Chu Hsi (1130-1200 A.D.). He was strongly opposed to Buddhism and Taoism." For a discussion of Han and Song strains of Neo-Confucian scholarship in the late Imperial period, see Chapter III above, pp. 51-60. 
transportation, and printing and publishing. Intense intellectual activity, frequently involving ldeas from the West, was common in shanghai at that time because the economic life of the city brought scholars, merchants, and others together where they had opportunities for exchange. Hu Shi's father, though prevented by financial circumstances from studying for any of the higher civil service examinations, and consequently locked out of the more prestiglous government positions, was a talented and enthusiastic Confucian scholar-official, even during the most difficult of times, and was considered a exemplary model for his sons. He died of beriberi in 1895, after serving on the island of Taiwan during the Sino-Japanese War. Hu's mother had told him, repeatedly, that his father was "the only complete man whom I have ever known." 4 She became the head of a household of children from her husband's second marriage, a son from his first marriage and his family, and her young son, hu shi. Hu had a deep feeling for his mother and the suffering she endured to raise and educate him.5

Hu Shi's education began rather early lat the age of four), but typically, at his family's school in shangchuang

$4 \mathrm{Hu}$ Shih, "Hsien-mu hsing-shu" [Reflections on my late mother's iffel, quoted in Grieder, Hu Shih, 8.

5 Greider, 8-10. 
[Shang-ch'uang]. The teacher there was his youngest paternal uncle. Following the practice of her husband, Hu's mother paid extra money to have the teacher actually explain the meaning of memorized passages in the Confucian classics to him. Hls father's family were firmly within the tradition of sung Neo-Confucianism and the extra attention he paid to these studies gave him a solid grounding in the standard interpretations and texts.

Hu shi enrolled at the first of the three or four "new schools" he was to attend during his childhood in 1904, at the age of thirteen. When a brother went to shanghai to see a doctor about his tuberculosis, Hu went with him and stayed to get a "modern education." Like the schools that Yan Fu had attended In Anhui, the "new schools" of Shanghal were focused on China's chances for survival in the modern world. At the first, Meiji [Mei-chi] School (Meiji xuetang) (Mei-ch1 hsüeh-t'ang], Hu began to study mathematics and English. Even his Chinese studies were directed to the problem of China's survival, and Japan's impending threat, with assignments to write essays on such topics as "The Sources of Japan's strength." The thriving Shanghai publishing culture of newspapers and political tracts exposed $\mathrm{Hu}$ for the first time to political events with international rather than simply village importance. Hu and his classmates began to read ant1-Manchu 11 terature 
and to think about rebellion. 6

Despite Yan Fu's emphatic admonition agalnst it, Hu Shi, like many others attending the "new schools" which combined "Chinese learning" (hongxue) [Chung-hsüeh] and "Western learning" ( $\underline{\text { Xixue }}$ ) [ Tianyan Lun [T'ien-yen Lun] as a schoolboy. While Hu was a student at the second of the schools he attended while in Shangha1, the zhanqzhong xuetang [Cheng-chung hsïeh-t'ang], his apparently reform-minded Chinese language teacher gave his students writing assignments based on new ideas coming from the West. After having the class read Yan Fu's translation of Huxley's Evolution and Ethics (Tianyan Lun), essays were assigned asking the students to "try to explain "[Living] things contend, Nature [Heaven] chooses" (Wu Ilng, Tian ze) ([Wu-ching, T'len-tse] and "Survival of the fittest" (Shizhe sheng cun) [ Hu remembers the experience in his autobiography,

...this was my first reading of Tianyan Lun, and I was very happy... This kind of topic naturally wasn't something for teens to elucidate, but... [we] read Tianyan Lun, and undertook essays on "Things contend, nature chooses" -- this was representative of the fashion of the period.8

6 Ibid., 20-24.

$7 \mathrm{Hu}$ Shih, Sishi zishu [Ssu-shih t'zu-shu] [Autobiography at Forty] (Shanghal: Yatung Tushuguan, 1933), 55-56. The translation is mine. Hereafter this work will be referred to as Autoblography.

8 Ibid., 56. The translation is mine. 
In 1906 Hu changed schools again, attending the newly opened China National Institute, in Shanghai. Founded early in 1906 by radicalized students recently returned from Japan, its first director, Ma Qunwu [Ma Ch'un-wu] (1881-1940), had been active in a number of student groups that had supported the republican efforts of sun Yatsen against the Manchu Chinese government only a few years before. There was an atmosphere of stimulating intellectual contact, republican politics, and revolutionary fervor among many of the students and faculty, and a churning mixture of old and new China at the school,g of men in gueues writing of Darwin.10

In 1906, during his first year at the National Institute, Hu Shi was among a group of students who began

9 Grieder, 24-25.

10 In the period of the Reform Movement of 1898 (Wushu bianfa) many intellectuals, especially those who were studying overseas, cut-off their queues. Like the refusal to bind one's feet for women, cutting the queue was, for men, symbolically defiant toward the Manchu government and foreign domination. It became a sign of the "modern man" to wear one's hair in "the Western style". When Hu shi left Shanghai for the United states in 1910, he still wore a queue. See Grieder, 37. There is an apocryphal story from Hu Shi's autoblography about why the other, mostly revolutionary, students at the China National Institute left him alone and didn't pressure him into cutting his queue despite his different political views. They apparently felt that he had such revolutionary potential that he should not be "distracted." See Min-chih Chou, Hu Shih and Intellectual Choice in Modern China (Ann Arbor, MI: University of Michigan Press, 1984), 17-18. 
to publish a small, activist newspaper. In the dominant "social-Darwinist" rhetoric of student circles in China at the time it was called The struggle (Jinye xunbao) ( yeh hsün-paol and published until 1908. A participant in the baihua [pai-hua], or the vernacular language movement, the paper was, in Hu's words, "...primarily interested in instilling new ideas into the uneducated masses...." By 1907 Hu had become its editor.11

In the articles that Hu shi wrote for The struggle he was admittedly "iconoclastic and atheistic", vehemently attacking "the superstitions of the people."12 He was only fifteen when he began to write for the paper, and sixteen when he became its editor, but his overriding and 1 ife-long concern with what he saw as a necessary remaking of Chinese thinking patterns was already strongly evident. As a young child he had been impressed with the anti-Taoist and anti-Buddhist attitude of his father and uncles.13 After his father died in 1895, Hu grew up in a house of women who were observant Buddhists. Hu's early contact

$11 \mathrm{Hu}$ Shih, "Credo," 249.

\section{Ibid.}

13 Ibid., 241: "I remember seeing on the door of my uncle's house (which was my flrst school) a sun-bleached sign bearing the words, "No alms for Buddhist Monks or Taolst Priests," which I learned afterward, was part of the Rationalist tradition left by my father." 
with Buddhism was with the popular, non-intellectual strains popular among the women of his home village. He retained his father's disdain for Buddhism and other forms of thought he thought "superstitious", or non-rational. This was reinforced early in his academic training during an "intellectual crisis" over the relationship of the spirit to the material body while reading passages of $\mathrm{zhu}$ Xi's [Chu Hsi] The Elementary Lessons and Sima Guang's [Ssu-ma Kuang] General History when he was eleven. The result was an atheistic, rationalistic bent of mind which was to remain with him throughout his life.14

As Min-chin Chou has pointed out, it was part of being "modern" in China at the turn of the twentieth century to be anti-Buddhist, part of a "rising tide of iconoclasm in the nation." Before Hu went to shanghal himself to go to school in 1904, his brothers, who worked in the city, certainly may have brought him information about the new modes of thought.15 Regardless of how or when Hu Shi's decidedly rationalist and "anti-superstitious" attitude manifested itself during his childhood, it was to be a pivotal aspect of all of his mature thought, bringing together the disparate strains of Confucian, Darwinist,

14 Ibid., 243-245.

15 Chou, 12-13. 
liberal, and pragmatic philosophies into a cohesive whole.16

By the 1890 s the English language had become the preferred foreign language to study in China.17 Yen Fu's widely-read translations of Western thinkers were primarily of eighteenth and nineteenth century Englishmen. A large number of important reformers learned English and many went to England or the United states to study in the late nineteenth and early twentleth centuries. Even the great number of Chinese students opting for the less expensive, geographically closer, and culturally less dissimilar cholce of going to Japan to study Western science and technology in this period indicates the increasing importance of the English language. Many of these students, including many important reform figures of the

16 Ibid., 14. Min-chih Chou describes Hu's thought in his late teens as "...gradually moving away from the rationalist and skeptical attitude toward a more empirical, naturalist stance...." The rationalist strain in Hu's thought, though joined by an empiricist/naturalist aspect, is never entirely absent. His adoption of John Dewey's instrumental pragmatism was a commitment to humanity's intervention in its own affairs. Science, in Dewey's view, and in Hu Shi's, was not a method to escape humanity and its parameters, but rather to maximize human ability and potential, through wide-spread, dare we say universal, participation in the techniques of "good thinking." This voluntaristic faith in human thought is, above all, rationalistic, and forms the foundation for Hu's empiricism and naturalism.

17 Ibid., 22 . 
early twentieth century, went to Japan with the hope of eventually studying in the United states or England.18 $\mathrm{Hu}$ Shi's command of the English language was certainly a major factor in his eventual academic success in the United States.

Hu Shi's opportunity to study abroad came in 1910 after successfully taking the exams for the Boxer indemnity scholarships to study in the United States.19 The Boxer Indemnity Fund was established in 1908 by the United states Congress to reduce the U.S. share of the Boxer Indemnity imposed on China in 1901 as a result of the Boxer Rebellion. Its funds paid stipends to support Chinese

18 Ibid. Min-chin Chou's list of reformers of this period who had studied English includes Chen Duxiu [Ch'en Tu-hsiu], Ding Wenflang [Ting Wen-chiang, V.K. Ting], Wu Zhihui [Wu Chih-hui], Jiang Menglin [Chiang Meng-lin], Wang Guowei [Wang Kuo-wei], and of course, Yan Fu.

19 Ibid., 26-27. Hu's decision to take the Boxer exams came after an incident in shanghai after he left the China National Institute, when he was arrested during a night of drinking and gambling. He awoke the next morning, in jail, wet and muddy, and missing a shoe. At the time he was teaching English at small middle school, and resigned his position to go to Beijing to study for and take the exams. This act seems impulsive, especially when viewed with the overwhelmingly cautious tone most of his life took on. But perhaps it indicates that, like many other Chinese students, he had already been thinking of going abroad, of going to the United states, to study. The humiliation of landing in jall seems to have "awakened" him from his brief intellectual stupor. 
students studying in the United states. 20 The first group of forty-seven students arrived in 1909. Hu shi was among the second group sent, placing fifty-third out of seventy students who passed the examination.21 Theoretically, they were the best students with an all-around preparation in Western sciences, languages, history, and mathematics that China could recruit.

Hu chose a major at Cornell Universlty from the sciences for the same reasons that many other Chinese studying abroad had done so: the Qing government had insisted, from the beginning, that ninety percent of Indemnity scholarship students had to specialize in a scientific or technological field (although this was not strictly enforced);22 and training in the sciences or technology seemed to hold the promise of actually contributing to "saving China," unlike the "humanistic" tradition of China that appeared to have falled.23 Hu

20 Jerome B. Grieder, Chinese Intellectuals and the state in Modern China: A Narrative History (New York: The Free Press, 1981), 210-212.

21 Chou, 35-36.

22 Grieder, Chinese Intellectuals and the State, 212.

$23 \mathrm{Hu}$ Shi's comment on his choice of majors at cornell was, "My choice was based on the belief then current in Chlna that a Chinese student must learn some useful art, and 11 terature and philosophy were not considered of any practical use." See Hu Sh1, "Credo," 251-252. The writer Lu Xun [Lu Hsun] began hls studies in Japan as a 
entered Corneli University as a student of plant science in the New York state College of Agriculture, studying biology, botany, plant physiology, and pomology (the science and practice of fruit growing). While maintaining an idealized view of his responsibility to be trained in the sciences, Hu studied Latin on his own time, composed both Chinese and English poetry, and kept his interest in literature and thought alive by reading a very broad range of material -- from pre-Qin [Ch'in] classics and poetry, Plato, and history, to Darwin, Goethe, Dickens, and Francis Bacon. 24

Hu Shi did not act decisively on his true proclivity for humanities and literature rather than the natural sciences until 1912, mid-way through his second year at Cornell. A class in the history of philosophy piqued his interest, and after several more classes in various aspects

medical student and ultimately changed to literature; Jiang Menglin [Chiang Meng-lin] began his career at the University of California, Berkeley, as an Agriculture major and left with a degree in the social sciences. The linguist Zhao Yuanren [Chao Yuen-ren] (1892-1982) received a Ph.D. in physics at Cornell, switching fields after accompanying Bertrand Russell on his 1920 tour of China as a multi-dialect interpreter. Despite the widespread belief that the literature and social thought of China were not as important as science for China's modernization, many students who began their studies in Japan or the West intent on a career in the sciences ended up in the humanities, social sciences, and literature. See Chou, 3135 . 
of philosophy, humanities, and social sciences, he changed his major to philosophy.25 Having struggled with mathematics and botany, Hu was thoroughly "in his element" In philosophy and was a brilliant student while at cornell. He excelled in communicating his ideas to others and succeeded in "taking the campus by storm." Hu was elected to Phi Beta Kappa in 1913, and awarded a fellowship to the Sage school at cornell in 1914, after completing his B.A., to begin his graduate studies in philosophy. His facility with the English language, which can be traced back to his middle-school days in Shanghai, as well as his brilliance, were rewarded on numerous occasions with prestigious University writing awards. His English professor at Cornell, Martin sampson, summed up the effect of young Hu Shi on his teachers and fellow students alike when he said, "It is entirely possible that a thousand years from now Cornell may still be known as the place where Hu Shi went to college." 26

Hu shi's interest in the philosophies of China and the West began before his years at cornell. While he was a student in shanghai he began reading the works of many Western thinkers, at first in Chinese translations, and

25 Ibid., 33.

26 Ibld., 35-36. 
then In mostly English originals. But following exposure to Yan Fu's translation of Huxley, it was the work of Liang Qichao that began Hu's serious interest in Chinese philosophy and in the thought of the West. 27 Llang's political essays were published in 1903 in Xinmin conqbao [Hsin-min ts'ung-pao] (The New Peoples' Week (y) and concentrated on the ideas of elghteenth century European social-political thought, such as "liberty," "equality," and "popular sovereignty." His criticism of China's weakened and vulnerable state of affairs at the turn of the century was ruthless, believing that "...there is almost no characteristic of present-day chinese government which should not be utterly destroyed, the old

$27 \mathrm{Hu}$ Shi's'own belief was that Yan Fu's translations had less of an effect on Chinese youth at the turn of the twentleth century than the work of other intellectuals grappling with the socially transforming power of modern science and scientific thinking, in particular that of Liang Q1chao. In a discussion of "extracurricular" books that Hu read in 1906 while a student at zhengji Academy, he described Yan Fu's books as "...very much in the ancient, elegant style, so his influence on young people was not as great as that of Liang Qichao." See Hu Shi, Autobiography, 57. The translation is mine. See also Hu shi, "Credo," 247. Hu, himself, is an example of the depth of influence that existed on portions of the young and $r$ ising intelligentsia of the period. Min-chih Chou considers Yan Fu and Liang Qichao to have been the Chinese thinkers with the most lasting influence on $\mathrm{Hu}$ Shi. Yan Fu's influence on Liang only served to reinforce the separate influence of Yan on the thought of Hu Shi. 
eradicated and the new proclaimed." 28

Liang Qichao had also been strongly influenced by Yan Fu's Tlanyan Lun29 and was a secondary source of Yan's influence on Hu Shi. For Liang, Tianyan Lun had provided just that explanation of "survival" and "fitness" that he had been looking for in his effort to generate support, through his journalism, for China saving itself through changing it ways. Liang's essays were eloquently iconoclastic, forcing Hu to face the harsh reality of the cultural, as well as the social and political circumstances that appeared to contribute to China's current, and seemingly final, failures. Later in his life, Hu readily acknowledged his debt to liang for bringing the rest of the world outside china to him:

Mr. Liang was a great admirer of modern Western civilization and...frankly admitted that the Chinese as a race had suffered from the deplorable lack of many fine traits possessed by the European people... It was these essays which first violently shocked me out of the comfortable dream that our ancient civilization was self sufficient and had nothing to learn from the militant and materialistic West except in the weapons of war and vehicles of commerce. They opened to me, as to hundreds of others, an entirely new vision of the world.30

28 Liang Ch'i-ch'ao, "Hsin min i" [A discourse on the new peoplel, quoted in Grieder, Hu Shih, 28 .

29 see Chapter II above, pp. 31-32, note 27 .

$30 \mathrm{Hu}$ shih, "Credo", 247. 
Hu Shi was ready for more than just facts in his education. Ideas had been his primary interest since his days in Shanghai. Hu's main interest in philosophy, throughout his life, was in thinking, particularly in method. It is here that Hu re-enters the realm of the sciences. He was most interested in the philosophy of thinking -- he wrote his doctoral dissertation at columbia on "The History of Logical Method in China." But like Yan Fu, Hu was convinced that "scientific method" was the best way of thinking. Even though Hu chose to work in the humanities, and in literature, he placed the highest values on the mental patterns established by training in the sciences :

We hope that they [the youth] come to an early realization and concentrate on the knowledge and methods of the natural sciences. This is the road of hope, whereas the other road, that among old books and papers, leads nowhere. Even the best talents and intelligence of the last three hundred years, spent and wasted among books, did not produce and good results; we must, therefore, adopt another approach. Only after you l the youthl have achieved good results in the laboratory can you speak of and use your energies to tidy up our national heritage. 31

Hu Shi's decision in 1915 to pursue a doctorate in philosophy at Columbia University was probably the result of a number of important factors. He had, indeed,

31 Hu Shih, "Chih-hsueh ti fang-fa yu ts'ai-liao" [Method and Materials of study], Hsin-yüeh 1.9 (November 1928 ), quoted in Kwok, 95. 
discovered John Dewey's experimentalist pragmatic philosophy in the summer of 1915. He would become a disciple of Dewey's at Columbia, having found in his work just the sort of intellectual method that had the potential to bring about the cultural transformation he felt china required to create new, responsive, democratic social and political institutions. Philosophy at the sage school of Cornell University at the time was focused on "objective realism," which didn't suit him. He needed an academic environment more conducive to his interests in philosophy. In addition, while Hu was at Cornell he had become quite popular as a speaker on Chinese affairs and a participant in student forums. He apparently felt the need to "hide" in New York's cosmopolitanism. 32

There is another explanation for Hu's shift to Columbia, not touched upon by his primary American biographer, Jerome Grieder, but addressed in great detail by the later biography of Min-chin Chou. It is worth discussing for its important implications for Hu's overall approach to intellectual and cultural change over his career. While Hu Shi was a student at Cornell he developed a close friendship with Edith clifford williams, a fellow classmate and the daughter of a Cornell Geology professor.

32 Grieder, Hu Shih, 42 . 
He had come to the United states already betrothed to a "semi-literate" young woman with bound feet named Jiang Dongxiu [Chiang Tung-hsiul. The marriage had been arranged by his mother in 1904, just before he left for school in Shanghai and he was not to meet her until 1917, when he returned to China from America. 33

Hu's relationship with Edith while they were students at Cornell was one of shared intellects as well as love.

33 Chou, 58-63. Like many aspects of traditional Chinese culture, Hu's attitude toward the style of arranged marriage expected of him as a member of the scholar-gentry had already become problematic before he arrived in the United states and was confronted with an array of new alternatives in his social relations. In "On Marriage" ("Hunyin bian"), an essay written in Shanghai between 1906 and 1908, he was quite emphatic in criticizing the reliance of parents on "go-betweens" and marriage brokers and the lack of input from the children themselves concerning the selection of marriage partners. Yan Fu's translation of Montesquieu's De l'esprit des lois iThe spirit of the Law] even figures in the argument, as $\mathrm{Hu}$ agrees with Montesqieu's belief that the experience of guiding parents is necessary -- though Hu feels, not sufficient -- in arranging a marriage. He actually went so far as to say that because of the great unhappiness caused by the way that the Chinese had arranged their marriages for so many hundreds of years, "...you cannot blame the youths for advocating Eamily revolution." He was primarily concerned, as would become his habit with most issues, with the sociopolitical consequences of marriage. By this time he was already in the habit of expressing himself on social issues in the rhetoric of the "Darwinian" struggle to survive as a nation, or race: "If couples are not in love, if families are not in harmony, how can they have good children? For thousands of years, our race has been sinking day by day, our morality has been deteriorating day by day, our physique has been getting weaker day by day. All these have been because our parents have been too unautocratic...they should take their chlldren's marriages as an important national affalx." See Chou, 58-63. 
What Hu once called his "cold personality" 34 began to fade. They wrote poetry to each other and took long walks in the woods near the University campus. During Hu's last year at Cornell, Edith moved to New York to study painting. Minchih Chou has suggested that Hu may have transferred to Columbia, in part, to be near her. 35

Once a man prone to periods of despondency, Hu's mood had changed to one of aspirations and optimism.36 Though certainly absorbing this "optimistic view point" from the general tone of liberalism and progressivism that was present at Cornell in the 1910s, Hu owes a measure of his new-found feelings to his association with Edith williams. This "optimism" was to play a fundamental role in his development as a thinker. Jerome Grieder has observed that even Hu's eventual commitment to Dewey's gradualist social and political philosophy would have been impossible without the prior establishment of an "...optimism which gave him patience... and a strong faith in the ultimate triumph of logic and reason." 37 Hu wrote of it in a diary entry in 1914: "In letters to my friends at home I invariably urge

34 Ibid., 63.

35 Ibid.

36 Grieder, Hu Shih, 44.

37 Ibld., 44-45. 
upon them the 'optimistic viewpoint'...I believe of the various things that I have acquired since coming abroad, only this great concept is worthy to be counted."38

Hu's new attitude about the liberation of women from the traditional constraints imposed on their choices, absorbed from his close contact with the feminism and independence of Edith williams, helped to round out both his character and the scope of his belief in the necessity of intellectual change as the key to saving the nation. His sense of which Chinese would participate in the great social and intellectual changes he felt necessary to saving China as a nation became fuller and inclusive of women:

I have always had deep convictions about the importance of women's education, but I used to think that its purpose was to create for society sagacious wives and good mothers who would in turn provide a good education for their families. Now I realize that the highest goal of women's education is to create women able to live free and independent. When a nation possesses free and independent women, it can improve the morality and uplift the character of its citizens. This is because women have a special transforming power. When we take good advantage of it, we will be able to invigorate the weak and inspire the timid, to transform people to form better habits. It is important that patriotic people know how to...take advantage of [the resources of the free and independent women].39

As Min-chih Chou has inferred, Hu's new sense of

$38 \mathrm{Hu}$ Shih, Diary, quoted in ibid., 44.

$39 \mathrm{Hu}$ Shih, Diary, quoted in Chou, 65. 
women's role in bullding a new society has strong parallels with Yan Fu's belief that the release of the energy potential of the individual was the key to the progress of the societal group. 40 As discussed above, Yan Fu came into contact with this idea through his reading of Herbert spencer.41 By the time that $\mathrm{Hu}$ shi had written the above passage in his diary, he had certalnly read Yan Fu's Tianyan Lun, which Yan wrote with spencer in the "back of his mind."42 He would certainly have been familiar with the tenor of Yan's other works, as they were all popular among Chinese intellectuals at the time, even though there is no direct evidence that Hu specifically read spencer or Yan Fu's translation of A study of Sociology (qunxue yi lun) [Ch'ün-hsüeh i-lun]. Nevertheless, the tone of his attitude about the education of women at this time clearly indicates his belief in a spencerian type of "vitalist" energy-channelling that Yan Fu was well known for promoting.

Hu Shi arrived at Columbia University to pursue a doctorate in philosophy under the guidance of John Dewey in autumn, 1915. He had written in his diary the year before

40 Chou, 65.

41 See Chapter II, above, pp. 28-29 and note 21 .

42 see Chapter II, above, pp. 33-35. 
that he was looking for a "practical philosophy." Jerome Grieder has described Hu's initial interest in Dewey's pragmatism as a reaction to the objective idealism that dominated the Sage school at Cornell.43 It may also have been a "boomerang effect" from an attempt to explore Christianity during his undergraduate days at cornell, as well as a reaction to the "impractical" constraints of the Chinese tradition of family obligations he was feeling at the time due to his arranged betrothal.44

For Hu Shi, Dewey's instrumentalist pragmatism was a powerful antidote to the "illness of thought and culture" that he believed China suffered from. The universalism of Dewey's scientific method, which allowed its application in China or the West, combined with its particularistic approach, directed at specific social and political problems in a particular time and place, seemed made to order for Hu's intellectual agenda. It would allow him to

\section{Grieder, Hu Shih, 47.}

$44 \mathrm{Hu}$ made a brief exploration of Christianlty during 1911 and 1912. While embracing its ideals at first, contact with the rituals of both Catholic and Protestant groups convinced him that Christianity was just as "idolatrous" and "irrational" as Buddhism and Taoism. Ultimately Hu came to criticize Christianity for more than what he called "superstition." But it took him several years to develop a critical eye towards this, as well as other, aspects of Western civilization. For a full treatment of Hu's interaction with Christianity, see Chou, 39-57. 
borrow from the West while remaining firmly grounded in the special needs and requirements of the chinese situation. It would allow him to reconstitute a new chinese "essence" (ti) on the basis of "useful" (yong) Western techniques. In this sense, then, Hu shi's adoption of Dewey's very American, pragmatist philosophy, with its roots in Darwinian evolutionary theory, liberalism, and progressivism, retains the ti-yong dynamic of the "selfstrengtheners" of the late nineteenth century, including Yan Fu.

There were other, Important, aspects of Dewey's philosophy, however, with "revolutionary" value for Hu Shi. Many of these have strong parallels to elements of Yan Fu's interpretations of science as the source of power in the West. The strongest of these is "method." Hu had been looking for a "way" to solve China's problems since his middle-school days in Shanghai. Like Yan Fu, and perhaps partly due to Yan's early and clear admittance of the fact, Hu saw the key to China's survival in finding a "method" to instigate and drive intellectual, and thus, cultural and political change. In 1914, while still at Cornell, and before he had read any of Dewey's work, method was already the focus of Hu Shi's concerns:

What our country urgently needs today is not novel theories or abstruse phllosophical doctrines, but the methods [shu] by means of 
which knowledge may be sought, affairs discussed, things examined and the country governed. speaking from my own experience, there are three methods which are miraculous prescriptions to restore life [ch'i-ssu shen-tan]:

1. the principle of inductive reasoning

2. a sense of historical perspective

3. the concept of progress 45

Hu's reasons for adopting a method are much the same as those expressed in the passage quoted earlier from the Daxue [Ta-hsüeh]: "...to...put their countries in order...to improve themselves as individuals...to extend their knowledge... [which] lies in the investigation of things."46 But the kinds of methods he considered were a direct reflection of his exposure to ideas from the West. They are, in fact, all of those concepts that began to develop in China in the seventeenth and eighteenth century that ultimately paved the way for the ideas of Western science: inductive reasoning (empirical observation leading to generalized principles), an accumulative, or historical sense of time, and the forward directionality of progress .47

Later in his life, in his autobiography, Hu admitted to the primacy of method in his thought, and to his sources

$45 \mathrm{Hu}$ Shih, Diary, 167, quoted in Grieder, Hu Shih, 48-49. The emphasis is mine.

46 See Chapter II, above, p. 36 , for the whole quotation.

47 See Chapter III, above, pp. 48-57. 
for it: "When later I followed in the footsteps of Huxley and Dewey it was because since youth I had placed such great emphasis on intellectual method."48 Indeed Thomas Huxley, read by Hu Shi in Yan Fu's translation of Evolution and Ethics (Tianyan Lun), provided the foundation for Hu's sense of the importance of method upon which his appreciation of Dewey's approach to scientific method was constructed. In identifying the popularity of Tianyan Lun among the intelligentsia and youth of his generation, Hu also implied that there was more to Huxley's work than met the eye, something subtle, and missed by most:

Within a few years of its publication the popularity of on Evolution was widespread throughout the whole country, and even became reading material for middle-school students. Of those who have read the book, few can understand the significance of Huxley for the history of science and for intellectual history. All they understood was the application of phrases like "the strong win and the weak lose" (yu-sheng lieh-pai) in international politics.49

Hu felt most of Huxley's Chinese readers, in their rush to adopt his phraseology for the aphorisms of a new social rhetoric, had failed to notice that the power in Huxley's work rested in his methodology: "Huxley...teaches a method of intellectual honesty. [He] has...said, "The most sacred act of a man's life is to say and to feel 'I

48 Quoted in Grieder, Hu Shih, 48.

49 Hu Shih, Autobiography, 56. The translation is mine. 
believe such and such to be true.'" All the greatest rewards, and all the heaviest penalties of existence, cling upon that act."50 so the central issue here is truth, grounded in "a method of intellectual honesty." Yan Fu's interest in spencer was also partially focused on what he felt was his contribution to developing a methodology for knowledge and truth that was "free from biases" -- an adherence to the "Mean." 51

The key to understanding Hu Shi's eventual total commitment to Deweyan pragmatism as "the" correct scientific method in approaching problem solving of all kinds, and its background in Hu's attitude toward Huxley, lays in Hu's definition of science itself:

The basic spirit of science is the search for truth. Man in this world is oppressed by his environment, conditioned by customs and habits, and constricted by superstition. Only truth can free him, give him strength, and give him wisdom and intelligence; only truth can help him eradicate the strictures imposed by environment... Scientific civilization teaches us how to train our senses and intelligence to search gradually and progressively for truth...This is the only way to truth.52

For Hu Shi, science was method, the method for

50 Hu Shih, "Credo," 254-255.

51 See Chapter II above, pp. 37-38.

$52 \mathrm{Hu}$ Shih, "Wo-men tui-yu Hsi-yang chin-tai wen-ming ti t'ai-tu" [Our Attitude Toward the Modern Civilization of the West] (1916), quoted in Kwok, 96. 
ascertaining truth, the basis of knowledge. This emphasis on the "how-to" aspect of science is connected to Hu's desire to find a "practical philosophy," that is, a philosophy for solving social, political, intellectual, and technological problems. As Grieder has pointed out, many of Hu's motivations for seeking a "practical philosophy" have their roots in certain tendencies of late Imperial Chinese Confuclanism53, such as the movement for "practical studies" (shixue) [shih-hsüeh] and practical statecraft and explorations of Chu Hsi's admonition to "investigate things."54 As such, they were already present in Hu's intellectual makeup before he became acquainted with Dewey. By then he was, as well, already committed to the primacy of ideas in transforming social and political constructs. The ideas of science, particularly scientific method, were Immediately practical. Like Yan Fu, Hu Shi believed that the practice of thinking "scientifically" would lead the Chinese to a modern, democratic society, which he felt was the key to channeling the energies China needed to survive. Hu Shi's thought, by the time he entered Columbia to begin his doctorate in 1914, had already begun the adaptation of the ti-yong paradigm that would allow Dewey's

53 Grleder, Hu Shih, 50.

54 see P. 81 , note 46 , above. 
pragmatism a comfortable mooring. Instead of insisting on retaining a Chinese essence (ti $)$, while utilizing (yong) practical knowledge from the West, Hu Shi had begun to speak primarily in terms of yong, of practice. He was, while still an undergraduate at Cornell, fundamentally concerned with the lack of intellectual preparation among the chinese for the coming tide of republican revolution in China:
our country falls far, far short of attaining a republican character -- not one man in a hundred can read, you cannot speak with one in a thousand on topics of general knowledge, nor are you sure to meet one man in a million with whom to discuss foreign affairs.... When the masses are stupid to this degree, in truth I know not with whom to talk about republicanism! If, indeed, we have achieved a republic, it is the republic of a handful of people, not a democratic republic. 55

Yet at the same time, he was optimistic about the consequences of "practice", without mentioning principles at all. In an essay about attaining democracy, written for the American magazine The outlook in 1915, at about the same time as the above passage, Hu seems to subsume principle in practice, (something that Chen Duxiu, as we will see, carries to its extreme):

Young China believes in democracy; it believes that the only way to have democracy is to have democracy. Government is an art, and as such it needs practice. I would never been able to speak English had I never spoken it. The Anglo-saxon

$55 \mathrm{Hu}$ Shi, Diary, quoted in Grieder, Hu Shih, 66-67. 
people would never have had democracy had they never practiced democracy. 56

Yan Fu had believed that the Chinese people, as a whole, were not ready for republicanism or democracy. His reason for translating Western works in such a terse, Classical style was so that they would appeal to the highest levels of scholar-officials, who were in a position to make substantial changes in government policy, and who could, as they had traditionally done, serve as exemplars of the new thought to the masses. Yan still felt there was a need to ground the useful (yong) new thought in the old "Chinese-ness," in Chinese "essence" (t $\underline{\underline{i}})$. He would have accomplished this through the mediation of the scholarofficials, who were, after all, the exemplars of "Chineseness."

The above passage illustrates an important way in which Hu shi's thought, in its pre-Deweyan affinities with Dewey's thought, deviates from that of Yan Fu. Hu Shi's approach begins the move from the self-strengtheners' perception, shared to a great degree by Yan Fu, that $\underline{t i}$ and yong can be separated, with t1 dominant (because, of course, it is chinese $\underline{t i})$, to seeing $\underline{t i}$ in terms of yonq,

$56 \mathrm{Hu}$ Shih, "China and Democracy," The Outlook 3 (September 1, 1915): 27-28, quoted in Grieder, Hu Shih, 66, note 77 . 
that is, to seeing "essence" in terms of "function." $\underline{\mathbf{T}}$ becomes fully subsumed in yong in the thought of chen Duxiu after 1921. Hu Shi preserved the role of ti through the gradualism and "genetic sense" of Dewey's philosophy, rooted in Darwinian evolution: there would always be something chinese carrled into any problem to be solved in China simply because these problems were set into a Chinese situation and Chinese people were going to have to solve them. Hu was able to focus on practice (yong), because the nature of practice in social, political, or scientific arenas, using Dewey's method, grew out of the circumstances at hand, whatever they might be. Theoretically being Chinese was already worked into the equation for solving problems without allowing it to dominate.

What $\mathrm{Hu}$ Shi was most attracted to in Dewey's philosophy was its focus on method, and therefore on practice: "Dewey has given us a philosophy of thinking which treats thinking as an art, as a technique..." He believed that Dewey had succeeded in describing a universal technique,

...true not only of the discoveries in the experimental sciences, but also of the best researches in the historical sciences, such as textual criticism, philological reconstruction, and higher criticism. In all these fields the results have been achieved by the same technique, which in its essence consists of a boldness in suggesting hypotheses coupled with a most solicitous regard for control and verification. 
This laboratory technique of thinking deserves the name of Creative Intelligence because it is truly creative in the exercise of 1 magination and ingenuity in seeking evidence and devising experiment and in the satisfactory results that flow from the successful fruition of thinking.57

Because in Hu Shi's thought, $\underline{t i}$ is expressed in terms of yong, a certain amount of the "essence" ( $\underline{t i}$ ) of Western scientific method is always present -- because it is always expressed in terms of yong, that is in terms of method and practice. And the search for truth, objectively and without biases (which, as we have see, has strong roots in Confucianism), which is what science was for $\mathrm{Hu}$, determined method and practice.

Hu Shi clearly believed that Dewey's philosophy provided a "technique" for thinking, an "intellectual technology."58 Much of Hu's career would involve journalistic, literary, and pedagogical approaches for maximizing the intellectual potential, and therefore the social and political potential of the Chinese people. Hu's

57 Hu Shih, "Credo", 255.

58 The most outstanding example of an "intellectual technology" in pre-modern Chinese culture was the examination system. It can also be argued that systems of logic and mathematics are intellectual technologies, and have existed in many parts of the world. Hu's adoption of Western scientific method as a "thinking technique" or "intellectual technology," therefore, doesn't represent a complete break with the past, but shares continuities of role and purpose, though not of detalls with China's previous "intellectual technologies." See Chapter II, above, pp. 40-41 and note 39 . 
belief in the power of "intellectual technologles," even his involvement in the movement for the use of vernacular Chinese, become instances of the practice of Dewey's pragmatic instrumentalism.

D.W.Y. Kwok believes that the language reforms promoted by Hu Shi and Chen Duxiu, among others, were "...not primarlly technological -- to enable the Chinese language to absorb modern scientific terminology. It was based on social considerations --to achieve a unity of the spoken and the written languages for mass application."59 However "social considerations" in no way necessarily preclude a behavior from being considered "technological" or "technical." The operant words here are "achieve" and "application." Technologies are systematic methods for achieving practical purposes. Hu's own belief in the necessity of effective "thinking techniques," or "intellectual technologies," is linked to their use in achieving "social" ends -- the molding of the "old" Chinese people into a "new" Chinese people.60

59 Kwok, 8. The emphas is is mine.

60 The period of the late nineteenth and early twentieth centuries saw a world wide movement toward molding society by the use of wide-spread behavior modifying "mechanical" or "technological" processes. Taylorism is a well-known example of the application of these types of ideas in the West and in the soviet union. For a brief description of the American origins of Taylorism, see Howard. P. Segal, Technological Utopianism 
The idea behind Hu's and Chen's promotion of language reform was to bring written linguistic expression more into line with how people really communicated with each other. Language reform was a "systematic method" for preparing the way for new ideas and concepts to be introduced, and for the people to be able to express themselves and participate in a larger world more effectively. The "levelling effect" 61 of the reforms mentioned by Kwok parallels $\mathrm{Hu}$ Shi's belief in the universal character of scientific method. A vernacular language movement, together with the widespread application of scientific thinking, would, in Hu's point of view, maximize the number of individuals solving particular problems, in order to maximize the survival of the group in Yan Fu's sense of the collective Great self -- Chinese society. Hu was ultimately interested in achieving a new state of "collective mind" in order to achieve a new society and a new polity.

in American Culture (Chicago and London: University of Chicago Press, 1985), 106-108. For an excellent discussion of the debate in the Soviet Union (another developing nation at the turn of the twentieth centuryl over the adoption of Taylorism in industry in the early 1920s, see Kendall E. Bailes, "Alexei Gastev and the soviet Controversy over Taylorism, 1918-1924," soviet studies 29.3 (July 1977): 373-394. I want to thank Dr. Lois Becker, Department of History, Portland state University, for bringing Taylorism and its soviet variant to my attention.

61 Kwok, 8. 
John Dewey's phllosophy, adapted by Hu Shi, owed a great deal to his understanding of Darwin, partly absorbed through the influence of psychologist and fellow philosopher William James (1842-1910). Distressed at the apparent Incongruity of the ldea of "free will" with the deterministic science of the mid-nineteenth century, James had come to view the human freedom to choose among alternatives as an adaptive product of the pressure of natural selection on the species.62 Dewey took James' ideas about evolution and the workings of the human mind one step further, seeing in Darwin's impact on philosophy a great organicist revolution in thought, returning man to his place among the plants and animals. As far as Dewey was concerned, the methods of the natural sciences could now be applied to all that is human, including morality and values:

...prior to Darwin the impact of the new scientific method upon the life, mind, and politics had been arrested, because between these ideal or moral interests and the inorganic world intervened the kingdom of plants and animals. The gates of the garden of life were barred to the new ideas; and only through this garden was there access to mind and politics. The influence of Darwin upon philosophy resides in his having conquered the phenomena of $l$ ife for the principle of transition, and thereby freed the new logic

62 James T. Kloppenberg, Uncertain Victory: Social Democracy and Proqressivism in European and American Thought, $1870-1920$ (New York and oxford: Oxford University Press, 1986), 38-39. 
for application to mind and morals and life.63

John Dewey was part of an "invisible college" of scholars in the late 1910 s and 1920 s that James

Kloppenberg, borrowing Dewey's own term, calls a via media, or "middle road."64 Hu shi had much in common with Dewey in this regard. Hu generally takes a "gradualist" and synthetic approach. Human morality and the need to seek objective knowledge were not contradictory for Dewey or $\mathrm{Hu}$, but worked together to achleve a "mean," in the Confucian sense of the word. Hu had very early on shown a tendency to view human nature as "neutral," neither following Xunzi's [Hsun-tzu] $(300-235$ B.C.) idea that it is Inherently evil or Mencius'[Mengzi, Meng-tzu] (372-289 B.C.E.) idea that it is inherently evil. His "middle road" followed Wang Yangming's (Wang Yang-ming] (1472-1529)

63 John Dewey, "The Influence of Darwin on Philosophy," in The Influence of Darwin on Philosophy and other Essays in Contemporary Thought (Bloomington: Indiana University Press, 1965, (1910)), 8.

64 specifically, Dewey's notion, inspired by the work of William James, was of "...a via media between the natural sciences and the ldeal interests of morals and religion." See Kloppenberg, 26 . Dewey and his fellows in quest of a "middle way" -- such thinkers as Walter Lippmann, William James, and Max Weber -- nursed a notion of knowledge founded on experience instead of Cartesian a priori deductive logic, a profound historicism, a commitment to democracy in all spheres of human life, and a gradualist program of reform focused on the achievement of proximate change rather than on an ultimate and revolutionary end. See ibid., 3-6. 
belief that human nature is capable of both good and evi1.65 He was not a revolutionary, despite many of the sources of his philosophy being the same as those of many who were revolutionaries. He believed, in general, that revolutionary activities hindered the intellectual reforms that he had in mind for the nation. By opposing both "utopian" or "anarchistic individualism" and a revival of the Confucian tradition of "self-cultivation,"66 Hu was standing on his own "via media." It sets him quite apart from his fellow traveler until 1921, Chen Duxiu, whose revolutionary, and finally Marxist approach shares the early well-springs of Hu's thought.

There are clearly identifiable origins for this idea of a "middle way" in the Chinese Confucian tradition 1tself. The 1deal of the "sage" who adheres to the "mean" -- the upright, what is "proper" under the circumstances -is a main theme of The Doctrine of the Mean, one book of the Confucian canon that was important to Yan Fu. Its importance to Yan only serves to reinforce its importance in Confucianism itself. The importance to Hu Shi of a method of inquiry that is free from biases, and gives "truth" is a modern reverberation of the Confucian concept

65 Grieder, Hu Shih, 31.

66 Ibid., 33-34; 98 . 
of the "mean." What is fundamentally different, of course, is the source of the measurement in each case: the testing of laws generalized from experience versus the selectlve interpretation of the appropriate confucian text.

By the time that Hu shi received his doctorate from Columbia and returned to china in 1917 to a professorship in the Philosophy Department of Beljing University, all of his fundamental ideas about how sclence works and what to use it for were already in place. They would be refined to some degree, but were largely maintained for the rest of his life. When Hu became a central figure in the New Culture Movement that overlapped with the May Fourth Movement after the spring of 1919, and culminating, for our purposes, in the 1923 "Debates on sclence versus Metaphysics," he was speaking and writing from his mature position concerning the role of science in society.

The Debates on Science and Metaphysics grew out of the discourse of the May Fourth Era after May 4, 1919, and therefore, in this study, form a single history with them. The fate of Hu Shi's ldeas in the New Culture and May Fourth periods and his role in the Debates of 1923 will be treated, along with those of Chen Duxiu after 1917, in Chapter VI. 


\section{CHAPTER V}

CHEN DUXIU BEFORE 1917

Chen Duxiu [Ch'en Tu-hsiu] (1880-1942) has been primarily regarded as a political figure, journalist, and promoter of the baihua [pai-hua] or vernacular literary movement in China in the 1910s and 1920s. A leader of the pro-democracy New Culture and May Fourth movements in the first two decades of this century, he also co-founded the Chinese Communist Party in 1921 with Li Dazhao lLi Tachao] (1888-1927). As D.W.Y. Kwok has noted, Chen is often singled out for his change of political stance from republicanism to Marxism.1 Kwok further points to Chen's

1 This chapter will examine the development of chen Duxiu's thought concerning science and cultural change only up until 1917. The year 1917 marks a significant intersection of Chen's and Hu Shi's [Hu Shih] professional and intellectual lives. In that year, Hu returned to China from the united states, they both began to teach at Beijing University, and Hu foined chen in writing for and editing the journal New Youth. It is also the year that Cai Yuanpei [Ts'ai Yüan-p'ei] $(1868-1940)$ began his tenure as the president of Beijing University, ushering in, by his faculty appointments, an era of unprecedented intellectual fervor and vigor that established the school's reputation as the center of China's student and intellectual culture up to the present time. For a discussion of the significance of Cal Yuanpei's reforms at Belfing University see Chow Tse-tsung, The May Fourth Movement: Intellectual Revolution in Modern China (Cambridge, MA: Harvard University Press, 1960), 47-57. Chen's and Hu's intellectual stances begin to pull away from each other in 
"basic philosophical understanding of science and its implication," as an important link between his early democratic republicanism and his later Marxism. 2 what is left unsaid is that Chen's notions about Western science, particularly evolutionary theory and its connections to soclal theory and its ideological expression, like those of Hu Shi, have strong parallels, and identifiable ties, to the earlier work of Yan Fu [Yen Fu].

Chen Duxiu's importance for early twentieth century Chinese intellectual history is largely due to his pivotal role as a publicist. "A man of singular and original personality,"3 rather than an originator of ideas, Chen "was a dazzling stylist prepared to talk about a broad range of ideas in an extremely appealing and attractive

the period between 1919 and 1921, when Chen co-founded the Chinese Communist Party (CCP) with LI Dazhao. By the "Debates on Science and Metaphysics" in 1923, they are standing in somewhat different positions, despite the fact that they are in the same "pro-science" camp during the debates. In order to differentiate their positions clearly it is important to establish their lines of thought prior to the New Culture and May Fourth Movements (1915 - 1921) (the focus of Chapter VI), so that the divergence of their thought after May Fourth stands out in bold rellef.

2 kwok, 59.

3 Benjamin I. Schwartz, "Ch'en Tu-hsiu: Pre-Communist Phase," Papers on Chlna 2: 168. Mlmeographed for private distribution by the Committee on International and Reglonal studies, Harvard Unlversity, May 1948. 
manner." 4 Lin Yu-sheng has described Chen's charismatic writing as a combination of "intellectual

straightforwardness with moral passion and dogged persistence" that cut through the "cultural anomie" and confusion of the times.5 Chen's role in this regard may be likened to that of a transformer in an electrical system -boosting the current, "cranking it up," so to speak. Not simply, and not quite, a synthecist, his "intellectual guerilla warfare" often paid no attention to the logical consequences of the sometimes contradictory stances that he took. 6 But it was Chen Duxiu, "orchestrating the writings of his friends,"7 who perhaps more than any other single person, helped to spread the New Culture that was developing in China in the 1910s and 1920s, and its belief In the efficacy of "scientific" and "democratic" thinking. Chen Duxiu was born in 1880 in Huaining, Anhui Province.8 Like Yan Fu and Hu Shi, Chen's family were part

4 Lee Feigon, Chen Duxiu: Founder of the Chinese Communist Party (Princeton, NJ: Princeton University Press, $1983), 100$.

5 Lin Yü-sheng, Crisis of Chinese Consciousness, 63.

6 Ibid., especially note 14 .

7 Feigon, 98 .

8 The plain facts of Chen Duxiu's biography are not clearly and definitively established. There has only been one published book-length biography of him in English, Lee Feigon's Chen Duxiu: Founder of the Chinese Communist 
of the lower gentry. Although definitive information about Chen's family is difficult to obtain, it appears that before the time of his paternal grandfather the family had

Party. Richard C. Kagan mentions three unpublished biographies, none of which I had access to in writing this essay: Julie Lien-ying Howe, "The Development of Ch'en Tuhsiu's thought, 1915-1938," M.A. thesis, Department of History, Columbia University, 1949; Chih Yu-ju, "The political thought of Ch'en Tu-hsiu," doctoral dissertation, Department of Government, University of Indiana, 1965; and Thomas C.T. Kuo, "Ch'en Tu-hsiu (1879-1942) and the Chinese Communist Movement," Ph.D. thesis, Department of History, University of Pittsburgh, 1969. See Richard C. Kagan, "Ch'en Tu-hsiu's Unfinished Autoblography," China

Quarterly 50 (Apr11-June, 1972): 295. There are also long biographical sketches in Benjamin Schwartz, "Ch'en Tu-hsiu and the Acceptance of the Modern West," Journal of the History of Ideas 12.1 (January, 1951), and Chow, 42. All of them use a varlety of different sources and give a variety of conflicting information. The problem of "facts" is further complicated by the following factors that mandate careful use of primary sources and the secondary works based upon them: 1 . blographies of Chen written by the Nationalists or Communists at the time of his arrest by Yuan Shikai's Nationalist forces may be suspect because both parties have a political point to prove; 2 . Chen's fragment (two chapters) of an autobiography, "Shih-an Tz'uchuan," written while he was in prison in 1932, and published in Cosmic Wind [Youzhou feng, Yu-chou feng] (Shanghai), Nos.51-53 (September-October, 1937), should be used carefully because it contains some exaggerations, not unusual in autobiographies, intended to arouse interest and sympathy from his Chinese readers after his case went to trlal; 3. accounts written in post-1949 China may be suspect because Chen was purged from the CCP in 1929. He became a persona non qrata in China as the communist revolution progressed, and has not been fully "rehabilitated" yet; 4. the remaining source of biographical information, interviews with his surviving relatives, taken after the cultural Revolution, may be suspect because of their desire to protect their own positions in society or in the Chinese Communist Party (CCP), or because of their desire to "rehabilitate" Chen on their own. 
primarily been farmers. Both his grandfather and his father, though not originally from the class of scholarofficials, had become teachers and minor officials. His father, Chen Yanzhong [Ch'en Yen-chung], was a tutor to a wealthy Suzhou [Su-chou, Soochow] family.9 Like Yan Fu and Hu Shi, Chen was quite young (two years old) when his father died.10

The examination system was still in place when Chen was a child, and his formal education was focused on the Confucian classics. His first teacher was his grandfather, an excessively moralistic and harsh taskmaster, who died

9 Feigon, 24 ; Schwartz, "Ch'en Tu-hsiu and the Acceptance of the Modern West," 61. There are discrepancies in the literature about the real social status of Chen's scholar-gentry family. Schwartz, whose article was a pioneering work on Chen in English, claims that Chen's family were "well to do," based on biographical work that was done at the time of Chen's arrest by Yuan Shikai's Nationalist army in 1932 (see note 8 above for a discussion of the problems with sources). Feigon claims that Chen's father was a minor official, working for a wealthy family. That would not necessarily make Chen's family wealthy, though Chow Tse-tsung flatly states, "In his home town, Chen's family was regarded as rich." see Chow, 42, note a.

10 In his unfinished autobiography (Shih-an Tz'uchuan), Chen states his age at the time of his father's death as two months old. Feigon, utilizing other sources, places his age at two years old, and considers this an example of Chen's exaggeration in order to push the idea that he was a fatherless orphan and came from a less-thanpriveledged scholar-official background. Neither of these assertions on Chen part seem to hold up under examination of other sources. See Feigon, 24-26; and Kagan, 301-302. 
when Chen was ten years old.11 But early on Chen showed an interest in the unorthodox, foreshadowing his "iconoclastic" nature. As Lee Feigon has pointed out, Chen never indicated in any of his autobiographical writings whether his education had been in the song or Han school of Neo-Confucianism. But he showed close affinities to Han learning ( its practitioners and their development of evidential philological research methods (kaozheng) (kao-cheng) as a basis for criticism. 12

After Chen's grandfather died, he reported going through a number of unsuitable tutors, until his older brother, Chen Mengji [Ch'en Meng-chi], who had already received his xiucai [hsiu-ts'ail degree (the lowest, local level of the examinations) became his teacher. The older brother was charged with preparing young Chen Duxiu for his xiucal exams. But Chen preferred studying the obscure characters in the zhaoming wenxuan [Chao-ming wen-hsüan], a

11 Chen's autobiography describes his grandfather as having a "perverted" hatred of "dirt and noise." "old white beard" was addicted to opium and was prone to beat Chen and his siblings for undefined infractions of his private codes of conduct and scholarship. See Richard Kagan's translation, 302-303.

12 Feigon, 28-29. Chen Duxiu's native province of Anhui had been a center of kaozheng development in the seventeenth and eighteenth centuries. For a discussion of kaozheng and Anhui's importance, see above, Chapter III, pp. 50-57. 
collection of parallel verse from the sixth century, to reviewing the various accepted styles of the rigid "eightlegged" essay he was expected to perform on the exams. Chen became "intractable," and his "indulgent" brother stopped insisting on study of the "eight-legged" form.13

In 1896, at the rather young age of seventeen, Chen took his xiucal examinations. As he describes the experience,

With my level of eight-legged essay such as it was, I was certain to be lowest on the list of examinees... At the time of the third and last examination for hsiu-ts'al...the topic was the selection of incomplete phrases from Mencius...For me, this kind of crazy topic deserved an illogical essay. I filled up my essay with the obscure terms for the birds, animals, and bamboo drawn from the Wen-hsüan, and padded it further with the absurd characters of the K'ang-hsi dictionary. I didn't care about coherence; whether the cow's head did not fit on the horse's mouth, or whether there was no connection between the beginning and the end of the essay.14

Chen, with this act of youthful defiance, was already on his way to becoming an iconoclast. But then, after writing an exam that he didn't really take seriously, he not only passed, he placed first: "No one would ever have thought that my muddled essay would deceive the muddled provincial Director of Education, but he marked me first place in the

13 Chen Tu-hsiu, Shih-an Tz'u-chuan, translated in Kagan, 307-308.

14 Ibid., 308 . 
examination. With this, I despised the examination system even more."15 Chen's disdain for "China's examination hell"16 was the beginning of a life-long critique of an antiquated Chinese culture he would describe some years later as the root cause of "...the old and rotten air that fills society everywhere...,"17 threatening "national survival."

The following year Chen and his older brother and an entourage of teachers and their brothers, and fellow candidates, travelled to Nanjing for the provincial exams for the second level, the zhuren [chü-jen] degree, which was the entré for lower-level government posts. His heart was apparently not in it -- he intimates that his attempts to pass the exams were mostly to please his mother.18 in

15 Ibid., 309.

16 This expression is from the title of Ichisada Miyazaki's study of the civil service examinations, China's Examination Hell: The Civil Service Examinations of Imperial China, trans. Conrad Shirokauer (New Haven and London: Yale University Press, 1981 [1976]). Chen's description of his experiences is particularly vivid. See Chen Tu-hsiu, Shih-an Tz'u-chuan, translated in Kagan, 309314 .

17 Chen Duxiu, "Chinggao gingnian" IChing-kao ch'lngnien] [A Call to Youth], Xin Qing Nian [Hsin Ch'ing-nien] [New Youth] 1.1: 1. The translation is in ssu-yu Teng and John K. Falrbank, eds., Chlna's Response to the West: a documentary survey, 1839-1923 (Cambridge, MA: Harvard University Press, 1961), 241 .

18 Ch'en Tu-hsiu, shih-an Tz'u-chuan, translated in Kagan, 309-310. 
the midst of waiting to take the first part of the zhuren exam, a strange naked candidate began walking up and down the alley that ran past everyone's rooms, reading loudly and posturing wildly. This disturbance caused Chen's stressed and wandering mind

...to question the whole phenomenon of selecting men of talent by the examination system. It was just like an animal exhibition of monkeys and bears performing every few years; and then I pondered whether this system was not as defective as every other system in the nation.19

After a harrowing experience in Nanjing for nine days in dirty, narrow, smelly examination stalls, with poorly cooked food (he didn't know how to cook for himself), he failed to finish writing the exam and didn't try again.20 Chen's early experiences with the examination system helped to establish his well-known stance against the habits and values of the Chinese tradition. At this early stage in his thinking he had nothing with which to replace that tradition, and no effective alternative thesis to back up an argument to do so. By 1919 and the May Fourth movement he will have promoted $\mathrm{Mr}$. Science and $\mathrm{Mr}$. Democracy" as field-marshals in his progressive war against the "lethargy and superstition" of the cultural status quo in China. The textual evidence for Chen's vehement

19 Ibid., 314.

20 Ibid., 313-314. 
promotion of "scientific thinking" as the basis of his attack doesn't appear until 1915, in the first issue of his Journal New Youth (xin Qingnian). From that point on, Chen's entire political point of view, even as it shifts from Republicanism to Marxism, is rationalized through his understanding of science as a set of laws that unified man's knowledge of an organically whole material world. However, it is important to take a look at Chen's development as a young anti-Manchu revolutionary because his understanding of science and the rhetoric he will use to express it after 1915 will come out of the context of his political activism up to that year, when he returned to China from Japan for the second time.

About the time that chen took the zhuren exam in 1897, he began to read the reform journals and newspapers that had sprung up in coastal cities and treaty-ports such as Shanghai and Changsha in the years leading up to the 1898 Reform Movement. A wave of reformism was sweeping though Chen's cohort of young examination candidates, and he was thoroughly caught up in it. In particular the work of kang Youwe $i$ [K'ang Yu-wei], and the articles of Liang Qichao [Liang Ch'i-ch'ao] in the Journal shiwu bao [ Shih-wu pao] 
[Current Affairs, or Chinese Progress]21 "really made some sense" to him, especially after he failed the provincial exam in Nanjing. 22 These writings helped Chen to make the leap from the critical Chinese studies he had pursued outside his official tutoring to a new iconoclasm which had thrown its support to "Western learning" (xixue) in the interest of "national salvation." 23 This is also the point at which Yan Fu's influence on Chen's thought begins.

Although there appears, so far, to be no record of Chen specifically saying that he had read the work of $\mathrm{Yan} F u$, it has been intimated in a number of secondary works; Yan's influence on Liang Qichao, in particular, and Kang Youwei

21 Kang and Liang's program of reform was the basis of the "100 Days of Reform" in 1898 that was quashed by the Dowager Empress Cixi [Tz'u-hsi], causing them both to flee the country. Liang wrote the major articles for and edited Shiwu bao, which began publication in 1896, in Shanghai.

The overall tone of the journal was a call to change (bian) [pien] and to break down the old barriers between classes in order to strengthen the group (gun) [chün]. Rather than focusing on the technological innovations advocated by most of the "self-strengtheners" as the key to bringing China independently into the modern world, Liang placed his emphasis on political reform, achieved through the spread of literacy and the total revamping of China's educational institutions. See Hao Chang, "Intellectual Change and the Reform Movement, 1890-1898," 295-296.

22 Ch'en Tu-hsiu, Shih-an Tz'u-chuan, in Kagan, 314.

23 Feigon, 32 . 
as well, is well known. 24 Though Yan's influence on Chen may not have been as direct as it was on Hu shi, relying to a degree on Liang Qichao as the "carrier," as we will see, it is no less pronounced.

After spending several years in Manchuria with an uncle, apparently being tutored, Chen Duxiu returned to his home area in about 1899 , to attend his mother's funeral. From there, the following year he went to Hangzhou, near Shanghai, where he got his first exposure to "Western learning."25 He entered Qiu Shi shuyuan ("Search for the Truth" Academy) and studied naval architecture (as Yan Fu had) and French. The academy took its name from a popular slogan of the radical kaozheng academies the southern Yangtze valley had been known for during the eighteenth century.26 The Qiu Shi Academy's program was a combination of non-traditional interpretations of the classics and the

24 For examples of secondary works that suggest, without further exploration, the influence that Yan Fu's writings had on Chen, see Chow, May Fourth, 64, note t.; and schwartz, Wealth and Power, 217. For a discussion of Yan's influence on Liang and Kang see Chapter II, above, pp. 31-32 and note 27 .

25 This part of Chen's chronology is very unclear. A number of the sources have conflicting information. I am accepting Feigon's chronology of the years 1897-1900. See Feigon, 33 and 35 , especially notes 41 and 42 .

26 See Chapter III, above, pp. 50-57, for a discussion of these academies and their relationship to the kaozheng scholarship movement. 
introduction of Western ideas. The first school in the region to teach both traditional Chinese and western studies, it became a center of the new student culture movement that was beginning to develop. A growing sense of alienation from the "old" Chinese culture and a selfawareness of themselves as "new," and as "youth," gave them a sense of mission. 27

By 1901 anti-Manchu feeling at the school had escalated to the point where an anti-government phrase slipped into an essay that had been circulating at the school resulted in the dismissal of several students and faculty. Apparently Chen spoke up in defense of those expelled and was forced to flee the school. Going first to Nanjing, where he may have stayed in zhang Shizhao's "underground revolutionary dormitory," by the end of 1902 he had gone to Japan with other "escapees" from Qiu Shi Academy. Chen and a group of his fellow student expatriots established the first openly revolutionary student organization among Chinese students in Japan, the zhongque gingnian hui [Chung-kuo ch'ing-nien hui] (Chinese Youth Society).28 By 1901-1902, Chen had established himself as an anti-Manchu revolutionary.

27 Feigon, 35-36; Schwartz, "Ch'en Tu-hsiu and the Acceptance of the Modern West," 61 .

28 Feigon, 36-37; Chow, 42 . 
The Chinese Youth Society was the first of dozens of organizations, newspapers, and journals that Chen would found or support over the next eighteen years or so that would have the word "youth" (gingnian) in their names and titles. Chen pinned all his aspirations for China's future existence on "youth," defined, as Richard Kagan has suggested," "...[not] by age or class but by a state of mind which was fresh, active and not yet destroyed by Chinese tradition." 29 Yan Fu's progress, instead of residing in a re-educated older generation of scholarofficials, was, for Chen Duxiu, to be found in the "younger generation," with the energy and fresh outlook to save China. Like Yan Fu and Hu Shi, Chen feared that China wasn't ready to save itself and he bemoaned the "corrupted" state to which China's youth had been reduced by the demands of a "rotten culture":

I am horrified when I see the people who have undergone our traditional education... They are sallow of face, slender of waist with hands lacking the strength to wring a chicken's neck... They are as weak and soft as invalids. How can people so feeble in mind and body bear the welght of heavy burdens?30

But Chen retalned falth in youth, because of the dream that

29 Kagan, 300 .

30 Ch'en Tu-hslu, "Chin-jih chih chlao-yu fangchen" lour Present Educational Pollcy], Hsin Ch'Inq-nien [New Youth l 1.2 (1915): 6, quoted in schwartz, "Ch'en Tu-hsiu: Pre-Communist Phase," 192 . 
some of them might have been untainted by the culture of China. Youth, which China had a lot of, would become Chen's symbol for the creative dynamism of the West that all of the reformers felt china had to acquire in order to survive.

The newness and the dynamism of "youth" would become the focus of his most famous journal of the May Fourth era, New Youth (Xin qingnian) (Hsin Ch'ing-nien) and the focus of his later professional career as Dean of the College of Letters and professor at Beijing University, and Commissioner of Education in Guangdong. Richard Kagan has further suggested that the centrality of "youth" in Chen's thought extended to his acceptance of Marxism, and that "he never fully completed the substitution of the proletariat for youth as the vanguard of the revolution." 31

A student culture was developing in Japan in the early 1900s, and there was a strong reformist feeling in the air. Western science and technology and Western ideas such as democracy and liberalism were popular and taught in the universities. Japanese students were quickly adopting Western styles of dress and behavior, in opposition to their own traditional Japanese culture of shinto, Confucian, and Buddhist values. Japan's success in 
becoming a "modern" nation, graphically illustrated by winning the sino-Japanese war of 1894-95, encouraged the Chinese students to take their cue from the Japanese students, and they became bolder and more vocal against the Chinese government.

Chen Duxiu gravitated to the radical wing of this Chinese student vanguard incubating in Japan. In 1903 members of the chinese Youth Society, in a dramatic gesture of nationalism and condescension toward the Manchu government, organized themselves into an army to fight the Russians threatening the border at Manchuria and offered themselves to the government. Shortly thereafter, Chen committed the revolutionary act that succeeded in getting him thrown out of Japan. A group of Chinese students were intensely critical of the government official whose job was to oversee Chinese students from Hubei while they were in Japan. They had accused him of trying to control the activities of all the overseas Chinese students in Japan, as well as of sexual impropriety. A group of students, including Chen, broke into his office, held him down, and Chen cut off his queue, which was hung in the chinese student union as a trophy. In the diplomatic tangle that resulted, chen and his fellows were deported, and returned to China. 32 
In the next few years Chen's revolutionary fervor continued to grow. Returning to Anhui, he formed a revolutionary library (which later became the Anhui provincial library) and began to form groups dedicated to political and social reform. In 1903 he helped to form what has been called the first revolutionary youth group in Anhui, the Anhui Patriotic Society (Anhui aiquo hui), based in Chen's native Anjing. Stressing "moral uprightness" and physical education in order to prepare to fight the Russians on the northern border, the group defined itself primarily in nationalist terms, "...seeking to unite the masses into an organization that will develop patriotic thought and stir up a martial spirit, so the people will grab their weapons to protect their country and restore our basic national sovereignty." 33

After Chen had given a particularly nationalist speech demanding that the Manchu government of China not sign treaties with Russia, putting the northern borders in jeopardy, a group of students from Anhui Academy who had heard the speech began to make demands on their school administration to allow them to prepare to "go to the Russian front." After a week of disorder and arguments

33 "Anhwei al-kuo-hui nichang" (Proposed constitution of the Anhwei Patriotic Societyl, Subao, June 7, 1903, quoted in Feigon, 41 . 
between students and authorities, several students were expelled and an order for Chen's arrest was issued, for instigating the disturbances. 34

Chen fled to shanghai and went to work for the China National Gazette (Guomin riri bao) (Kuo-min jih-jih-pao), a paper directing reform sentiments in a moralistic tone toward students who "were sure that their education had provided them with an understanding of society their elders did not possess."35 Their emphasis was on "historical progress" and "nationalism." For a short time Chen belonged to an assassination squad that ultimately turned into Cai Yuanpei's "Restoration society" (Guangfu hui) (Kuang-fu hui), a major revolutionary group in the Lower Yangzi Valley. 36

Chen Duxiu spent from 1904-1907 participating in a variety of newspaper projects and revolutionary action groups. After the actions of one of these groups, the "Yue Warrior society," were implicated in the assassination of the governor of Anhui in 1907, Chen and

34 Feigon, 45-48.

35 Ibid., 48-49.

36 Ibid., 56 . 
many of his cohorts fled to Japan again. 37

After the failure of the Nationalist Revolution of 1911 to bring substantive political or social changes, resulting in the nationalization of the warlord government of Yuan Shikai, Chen began to attack the cultural structure that underpinned those who had risen to power in the failed revolution. Returning to China, Chen began to put together the various pieces of the puzzle of how to save China from itself. Believing, still, that culture and thought had to precede politics and social structure, he founded the journal that would catalyze the whole New Culture movement, New Youth in 1915. It is in New Youth where his notions of science and its relation to social change, wrapped in the Spencerian/Darwinian rhetoric of Yan Fu, found their fullest and clearest expression.

The first page of the first issue of New Youth, frequently excised Erom subsequent Chinese and Japanese reprint editions, contained Chen's editorial policy for the journal, written in classical Chinese. Chen's later totalistic rejection of Chinese "essences" ( $\underline{t i})$ is not yet

37 Ibid., 56-82. Chen was apparently not in France at this time, as many scholars have said. It appears that Chen has never been to France. For a thorough investigation of the issue of whether or not chen had ever been to France, see Feigon, 82-84, and n.73 and n.74. 
evident at this early date (1915)38:

The strength of our country is weakening, the morals (of our peoplel are degenerating, and the learning [of our scholars] is distressing. Our youth must take up the task lof rejuvenating Chinal. The purpose in publishing this magazine is to provide a forum for discussing the ways of hsiu-shen (self cultivation) and chih-kuo (the methods of governing the state). 39

This early "manifesto" indicates that Chen's aims at that time were not completely divorced from traditional Confucian concerns, even while criticizing that tradition. Self-cultivation and a concern with the correct running of the state as ideals of the Confucian scholar were themes in the writings ascribed to Confucius himself, and have been central and recurring aspects of the ongoing Confucian discourse. Their importance in the Daxue [Ta-hsüeh] (The Great Learning) has already been mentioned. The language in the passage above closely resemble the language used in

38 Chen had, in fact, gotten interested in the "national essence" movement among Chinese students while he was a student in Japan. He remained interested in it for a time when he first returned to China in 1915. Feigon suggests that part of the lure of this type of conservative movement for him was its "research" aspect, in which he could exercise his interest in kaozheng evidential philology. See Feigon, 83-86.

39 Ch'en Tu-hsiu, "She-kao", Hsin Ch'ing-nien lNew Youth) 1.1 (September 15, 1915), unnumbered opening page, quoted in Lin, Crisis of Chinese Consciousness, 65 and note 17 . 
the Daxue, as wel1.40 At times they have seemed antithetical to each other, or have been treated as such by Confucian scholars.41 In Chen Duxiu, as in many of the reform and revolutionary thinkers of this period, the two are seen as linked, "self-cultivation" now perceived as an education in "Western ideas," science, technology, economics, or politics, and the proper route to correctly governing the state.

This particular combination of "self cultivation" and "statecraft" had been the core of Japanese Neo-Confucian attempts at an adoption of aspects of Western economic, mathematical, and scientific ideas and practices during their contact in the Tokugawa period (1600-1867). In an extension of jitsugaku ( $\mathrm{Ch}$. shixue [shih-hsüeh], "practical p. 36 .

40 Compare with the quotation in Chapter II, above,

41 Chinese shixue and Japanese jitsugaku orientations toward "practical studies" within the confucian discourse were highly critical of what they percelved as the useless, overly metaphysical, quietist and escapist approach of the $k$ ind of sung Neo-Confucianism that was focused on "selfcultivation" usually identified as lixue (study of Principle). See Chapter III, above, pp. 52-53. The ideal of a "cultivated" Confucian sage, teaching The Way by example was often perceived to be at odds with the ideal of the "acting" scholar-official, at work in the society that he was in the process of molding. For an example from Tokugawa Japan where the two are seen to be working together, the urban "merchant academy" of Osaka, see Tetsuo Nafita, visions of Virtue in Tokugawa Japan: The Kaitokudo, Merchant Academy of Osaka (Chicago and London: University of Chicago Press, 1987). 
studies"), Japan, after opening to sustained contact with the West during the Meifi Period (1868-1912), continued to absorb Western technologies, science, educational systems, and economic and political strategies from the imperialists crouching by their door. By the early twentieth century Japan itself had become a formidable imperialist threat to China and the rest of East and Southeast Asia.

Fearing the milltary threat from Japan, but recognizing the opportunity to learn about Western technologies and strategies from a culture and in a written language less different from their own than those of Europe, students started going to Japan in increasing numbers at the turn of the century.42 Chen's experiences as a young student in Japan, would likely have exposed him to that particular combination of Confucian culture and Western ideas that Japan had been developing since the late Tokugawa period. It would have served to reinforce his exposure to Chinese strains of shixue (Including "selfstrengthening") and various trends of practical statecraft that were current in many schools during his early education.

As Chen conceived it, the aim of New Youth was, on the

42 There is a detalled, but conclse discussion of Chinese students in Japan in this period in Grieder, Intellectuals and the state in Modern China, 141-148. 
surface at least, not political. He wanted to promote a cultural change in morality, and to reinvigorate China, through a change in the basic pattern of thinking. The pivot of Yan Fu's concerns had been the belief that thought drove action. To change the Chinese into a modern people who could survive and thrive in the modern world necessitated adopting new ways of thinking and new ideas - that is, the ideas and ways of thinking of the West. solidly based on a faith in the rationality of humanity that had deep roots in Neo-Confucianism, Yan expected that these new ideas would, in turn, create the necessary new institutions and social structures to ensure China's survival. Hu Shi, taking a cue from Yan Fu, also believed that cultural and intellectual change had to precede a change in social and political structures.

Prior to 1919, Chen too, believed that new thought must precede new politics in saving the nation: "If our countrymen have not reached a fundamental awakening in their ideas, there are no grounds for blaming the political administrators [for not having achieved much]."43 It is true that by staying close to non-political issues chen could keep New Youth out of the scrutiny of government

43 Chen Duxiu's reply to Wang Yunggong, Xin Qingnian 1.1 (September 15, 1915), correspondence section, 2, quoted in Lin, crises of Chinese Consciousness, 64. 
officials suspicious of the increasingly anti-government stance of the press. But the fact that Yan Fu before him, $\mathrm{Hu}$ Shi in America, and many others were calling for a change in thinking in order to form a basis for new social and political structures lends weight to Lin Yu-sheng's contention that Chen's motivations for the direction of the journal were part of a definite strategy and not simply self-preservatory.44 After the fall of Yuan Shikal's regime in 1916, the immediate threat to those engaged in critical journalism lessened somewhat, but Chen continued, until his shift towards Marxism began after 1919, to believe in the primacy of intellectual and cultural change: "Even if, for the time belng, the old is discarded and the new is sought, without a change of fundamental ideas the old pattern of behavior will naturally and definitely re-emerge." 45

Chen's "Call to Youth", the first article of the first issue of New Youth, serves as a manifesto of the New Culture Movement, lead by "New Youth". New Youth was an idea and a reality that materlalized in the hatching of

44 Lin, Crisis of Chinese Consciousness, 64.

45 Ch'en Tu-hslu, "Hslen-fa yu K'ung-chiao" [Constitution and Confuclanism], Hsin Ch'ing-nien [New Youth ] 2.3 (November 1, 1916), in Tu-hslu wen-ts'un [Collected Essays of Ch'en Tu-hslu] (Shanghal: Ya-tung t'ushu-kuan, 1922), 1:103, quoted in Lin, Crisis of Chinese Consciousness, 64. The emphasis is mine. 
dozens of fournals, newspapers, and organizations with the word "youth" in their title, and the aims of the "New Youth" mentality. The main themes of "Call to Youth" place Chen at the nexus of all of the major strains of thought current among reformers and progressives in China at the time, from liberalism to Marxism. The "six principles" he urges his readers to adopt are ones that Hu Shi, who was still at Columbia University in 1915 when the piece was published, would certainly be able to support:

1. Be independent, not servile (zizhude er fei nulide).

2. Be progressive, not conservative (Jinbude er fei baoshoude)

3. Be forward-moving, not retiring ( Jingongde er fei tuiyinde)

4. Be cosmopolitan, not isolationist (Shijelde er fel suoquode)

5. Be utilitarian, not vacuous (Shiljde er fei xuwende)

6. Be scientific, not imaginative (Kexuede er fei xlangxiangde) .46

The earliest example there is of Chen Duxiu's conceptualization of "sclence" and how it worked comes in "A Call to Youth" The sixth of Chen's "New Principles" for youth was to "Be scientific, not imaginative." (Kexuede er

46 Chen Duxiu, "Chinggao gingnian" [A Call to Youth], Xin Qingnian (New Youth) 1.1 (September 15, 1915): 2-5. The translation is mine. 


\section{fei xiangxiangde):}

What is science? It is our general conception of matter which, being the sum of objective phenomena as analyzed by subjective reason, contains no contradiction within itself. What is imagination? It first oversteps the realm of objective phenomena, and then discards reason itself; there is something constructed out of thin air, consisting of hypotheses without proof, and all the existing wisdom of mankind cannot be made to find reason in it or explain its laws and principles. 47

For Chen,"...the contribution of the growth of science to the supremacy of modern Europe over other races is not less than that of the theory of the rights of man."48 Here we have the first inkling of the slogan for which Chen would become famous during the May Fourth movement, "Welcome Mr. science and Mr. Democracy."

Chen's sense of progress and historical change was conceptualized in biological terms, but those of a vitalist blology. It is short leap from "self-cultivation" to "voluntarism" if the goal is movement in a particular direction. Chen's volce of progress, like Hu shi's, is that of Yan Fu reading Huxley reading Darwin -- with Spencer looking over Yan's shoulder:

It is Impossible to avoid the struggle for survival...The progress of the world is like a fleet horse, galloping and galloping onward.

47 Chen, "Chinggao qingnian" [A Call to Youth], 5-6, translated in Teng and Fairbank, 244.

48 Ibid., 6, translated in Teng and Fairbank, 245. 
Whatever cannot skillfully change itself and progress along with the world will find itself eliminated by natural selection because of failure to adapt to the environment. Then what can be said to defend conservatism! 49

It would seem that Chen perceived natural selection as a universal, governing "law" of the universe, applicable to the universe, the biological world, and the social world as well. This is the basic tenet of various forms of "social Darwinism," but what is more important for our study is not the label, but the source of Chen's thought. The elements of spencer's vitalistic social theory that appear in Chen's thought preclude the simple label of "social Darwinist." The mechanism for the "survival of the fittest" in Chen's way of thinking, is a spencerian release of the energles of the individual for the good of the larger society. The survival of the group -- the gun -- is still the primary goal. This clearly links his thought, like that of Hu Shi, with Yan Fu's work.

At the same time that Chen Duxiu was reassuring his readership (and the government authorities) that the intentions of New Youth were not political, the journal's "manifesto" reverberated with an "iconoclastic nationalism," couched in the language of antitraditionalist sentiments. In "A Call to Youth"

49 Ibid., 2, translated in Teng and Fairbank, 243-242. The emphasis is mine. 
["Chinggao gingnian"] Chen drew a clear line between

survival of the Chinese culture and survival of the Chinese

"nation/race":

All our ethics, law, scholarship, rites and customs are survivals of feudalism. When compared with the achievement of the white race, there is a difference of a thousand years in thought, although we live in the same period. Revering only the history of the twenty-four dynasties and making no plans for progress and improvement, our people will be turned out of this twentieth-century world, and be lodged in the dark ditches fit only for slaves, cattle, and horses. What more need be said? I really do not know what sort of institutions and culture are adequate for our survival in the present world if in such circumstances conservatism is still advocated. I would much rather see the past culture of our nation disappear than see our race die out now because of its unfitness for living in the modern world. 50

Chen's stance, though in opposition to traditional Chinese culture, was still focused on the survival of the Chinese race/nation. 51 In this sense he is nationalistic,

50 Ibid., 2, translated in Teng and Fairbank, 242. The emphasis is mine. This quote is also translated in Lin, Crisis in Chinese Consciousness, 66 .

51 The characters that have been translated as "race" are min zu . It must be remembered that the Chinese character zu is a generic word that means both "nation" and "race." Even when the character is used in min zu, there may be a connotation of either "race" or "nation." The Chinese nation was (and perhaps still is) largely identified with the Han "race," the dominant ethnic group in China for the past several millennia. The passage translated here suggests that Chen believes that a nation is two-fold: that it contains a biological element: the population (the race), and its culture, or civilization (wenming). The implication is that if the culture were to disappear, there would still be something left -- the 
as were nearly all intellectuals to one degree or another during this period. The real and continued military threat from Japan, as well as the humiliation of European and American treaty ports cast the desire for survival into a mode that was inevitably nationalistic. On the other hand, in the same essay, Chen advocated a strong cosmopolitanism. Point four of the six-polnt program for changing Chinese patterns of thought Chen proposed in "A Call to Youth" is the admonition to "Be cosmopolitan, not isolationist" (Shijiede er fei suoguode) .52

Chen's use of the word shijiede [shih-chieh-ti) for "cosmopolitan" should be noted here, for it provides an early clue to the shift in ti-yong dynamics that mark Chen's departure from Hu shi during the 1923 debates on "Sclence and a Vlew of Life." Shljlede literally means "of the world," and is markedly different from the "cosmopolitan" stance of Hu Shi. Hu was well known for his cosmopolitanism. He had belonged to the Cosmopolitan club while an undergraduate at Cornell, where he was active as a writer and speaker on behalf of world peace.53 Hu's word

biological population. And it would be left, as always, to struggle.

52 Chen, "A call to Youth," 2.

53 For an account in English of Hu Shi's cosmopolitanism see Grieder, Hu Shih, 52-61. 
for "cosmopolitanism" was datonqzhuyi (ta-tung chu-i), 54 which literally translates as "Great Unityism." Because Hu Shi's term has clear links to the idea of Datong, or the Great Unity, important to Confucianism, it suggests movement out from a Chinese center. This is the traditional way that China had looked at the world -- with itself as the center, looking out from civilization at a barbarian periphery. The implication here is that $\mathrm{Hu}$ Shi's cosmopolitanism is still rooted in the idea of a Chinese basis, or essence (t $\underline{t}$ ) of some kind.

Chen's term, shijiede, suggests a very different kind of cosmopolitanism. To be "of the world" is to join the world, to be embedded in it. The directionality of this term is not the same as datonqzhuyi; here one must move toward a "larger something." There is no implication of Chinese-centeredness in shijiede, as there clearly is in datongzhuyi. In Lee Feigon's recent book on Chen Duxiu as the founder of the Chinese Communist Party, he takes the position that chen was more nationalist than cosmopolitan. The point is a difficult one to answer definitively. Prior to 1917, when he began to be in close contact with Hu shi through their positions on the faculty of Beijing

54 In a passage of his Dlary, Hu shi uses the phrase datongzhul for "cosmopolitan." This passage is translated in Grieder, Chinese Intellectuals and the State, 68 . 
University (Beida) and their work for New Youth, at the time that "A Call to Youth" was written, nationalism and cosmopolitanism were undifferentiated in Chen's thought. Though it may seem to be a contradiction in terms, in Chen's early thought cosmopolitanism is put in the service of nationalism. In order to save the nation/race, it must adopt a cosmopolitan (shijiede) approach to its problems.

Like Hu Shi, Chen Duxiu was often pessimistic in these years before the May Fourth movement began. In Chen's case, it was a price paid for seeing "the big picture." In a letter to his friend Bi Yunzheng [Pi Yun-ch'eng], published in the November 1, 1916 issue of New Youth, he expressed his utter dismay that China was not ready for the struggle at hand, and that she would not survive:

My pessimism is not caused by having no quick success in our undertaking. It has developed from an awareness of the hopelessness of our catching up with European and American civilizations. They are progressing a thousand li a day, while we are left far behind. The majority of our people are lethargic and do not know that not only our morality, politics, and technology but even common commodities for daily use are unfit for struggle and are going to be eliminated in the process of natural selection. Although there are a few awakened people in the country, who can save us from the fate of perishing? 55

His despair dissipated, ironically, by taking a similar

55 Chen Duxiu, Xin Qingnian [New Youth] 2.3 (November 1, 1916): 3 (correspondence section), quoted in Lin, Crises of Chinese Consciousness, 59. The emphasis is mine. 
tact to $\mathrm{Hu}$ Shi's particularistic pragmatism -- by focusing on a smaller piece of the problem. That piece formed an Integral part of Chen's understanding of the republicanism of his favorite Western nation -- France. It was the individual.

The foremost writer in the 1890 s reform era on the role of the individual had certainly been Yan Fu. In his hands, spencer's belief in the fundamental integrity of the Individual as the building-block of soclety was wedded to Huxley's Darwinian portrayal of the survival of the fittest in a "general exaltation of the Faustian-Promethean dynamism of the west..."56 This dynamism was the result of the interaction of individuals, and, if harnessed, would ostensibly save Chlna. But by 1900 , several generations of reformers had believed that the Chinese Confucian way of the Three Bonds and the Five Relationships 57 had established social norms that had stifled the individual and left China weak and unable to face the technological

56 Lin, Crisis in Chinese Consciousness, 65.

57 San gang, wu lun [San-kang, Wu-lun]: The "three bonds" are the ties of minister to king, son to father, and wife to husband. The extension of these are the "Five Ethical Relationships," which are minister to king, son to father, wife to husband, older brother to younger brother, and equal to equal. It was virtually impossible to relate to anyone else outslde of these categorles, which had clearly deflned behavioral expectations. Soclety was, then, a constantly shifting hierarchy of relations, where someone is always "above" or "below" you. 
and political challenges of the modern world.

When Chen Duxiu began to write of the individual after 1915, it was, at first based on a concern with the "nation." Lin Yu-sheng has suggested that his attack on Chinese tradition took form in the interaction of his notion of individualism and his nationalism: "The nation consists of many persons. When the stature of these persons is elevated, then the stature of the nation is elevated. When the rights of these persons are consolidated, then the rights of the nation are consolidated."58 He believed national survival was possible through cultivation of the individual, much as he had stated in the opening editorial of the first issue of New Youth, the year before. 59

Chen began to build a cosmology for his antitraditionalism. He used a spencerian rhetoric that began

58 Chen Duxiu, "I-chiu 1-liu nien" [The Year 1916], Tu-hsiu wen-ts'un (The Collected Writings of Chen Duxiu), 1:44-45, quoted in Lin, Crisis of Chinese Consciousness, 67. Benjamin Schwartz has taken the view that Chen's "ardent individualism" cancels out his apparent nationalism. See Schwartz, "Ch'en Tu-hsiu and the Acceptance of the Modern West," 66. It seems to this author, however, that there is a high incidence of "individualism" and the concerns of a "nation" appearing together in Chen's writings in the period 1915 and 1916. Rather than indicating an ambivalence on Chen's part, their shared context points to a facultative relationship, the existence of either one serving the needs of the other.

59 See pp. 111-112, above. 
first in a Huxley-like admittance of a struggle (Chen says "resistance") against nature, and cast the story of the Individual and the nation in terms of a biological struggle to build strength for survival. He blamed the "feebleness" of China in standing up to its aggressors on an unwillingness to fight, on too great an emphasis on harmony, on the non-adaptive character of Confucian formalism:

The most regrettable fact is the feebleness of the moral leaders of our society... Whenever they confronted obstacles, they let themselves become frustrated. Some would commit suicide, others would flee to a life of contemplation, stjli others would drown themselves in wine. Such men -- so passive, feeble, and decrepjt -- are our great moral heroes...Taoism favors l the attitude of] withdrawal, Confucianism venerates rites and [trains people) to yield (jang), and Buddhism advocates [a theory] of vacuity...The spirit of our people is not filled with a single aggressive and energetic thought; hence the power of resistance cannot take root in our people.60

Chen's belief that the "culture of China" could be replaced with the "culture of the West" in China was made possible by Chen's conceptualization of both cultures as monolithic. In November of 1916 he wrote:

If we want to build a new state and organize a new soclety according to the Western model in order to survive in this world, the basic task is to import the foundation of the Western society,

60 Ch'en Tu-hsiu, "Ti-k'ang Ii" [The Power of Resistance), Tu-hsiu wen-ts'un (The collected Writings of Chen Duxiul, 1: 31-33, quoted in Lin, Crisis of Chinese Consciousness, 68 . 
that is the new bellef in equality and human rights. We must be thoroughly aware of the incompatibility between Confucianism and the new belief, the new society, the new state. We must courageously decide to throw away that which is incompatible with the new belief, the new society, the state!61

By the following spring (March, 1917) he had soundly rejected all possibility of a synthetic approach to the problematic of China's adoption of "the culture of the West" :

If someone thinks the old Confucianism is right, he must regard the newly imported culture of Europe wrong. There is absolutely no place where the new [European culture] and the old [Confucian culturel can coexist and be blended together. We can only choose one of these two.62

By 1917 Chen Duxiu's transfer of transvaluative power from "evolution" to "revolution" was well on its way. His totalistic conceptualizations of both the culture of China (particularly Confucianism) and that of the West was essential to this change of perspectives, so that one could be replaced with the other, in the way that atoms (atom means "unsplittable") replace one another in a materialist

61 Ch'en Tu-hsiu, "Hsien-fa yu Kung-chiao" [Constitution and Confucianism], Tu-hsiu wen-ts'un [The Collected Writings of Chen Duxiul, 1: 111-12, quoted in Lin, Crisis of Chinese Consciousness, 76.

62 Ch'en Tu-hsiu, "Ta p'ei chien ch'ing-nien" [Reply to the young man bearing a swordl, originally published in Xin Qingnian [New Youth] (March 1, 1917), reprinted in Tuhsiu wen-ts'un [The collected Writings of Chen Duxiu], 3: 48, quoted in Lin, Crisis in Chinese Consciousness, 76. 
world. Yan Fu himself had been vehemently against revolutionary change -- hoping that a developmental process of gradual change according to "the evolutionary laws of historlcal progress" would prevail in China.

However, in many ways, Yan Fu's evolutionary laws were the beginning of revolution for chen, and many others. It appears to have been Yan $F u$ who began to point to Confucianism as the source of China's weakness, 63 and to talk of the mechanism of this cultural debacle in "socialDarwinist" terms. By placing the blame for China's weakness on the dominant Confucianism's "disabling" focus on harmony and stability, which had protected china from the natural struggles which would have prepared her for a European-style modernity, Yan had committed a revolutionary act. 64 He had not only thought about Confucianism's culpability, but as Liang Qichao has said, he had "dared to speak" of the idea that confucianism "[could] not be protected and need not be protected."65 It would be replaced with Western scientific and democratic thought. Yan had set the stage for Chen's argument that in order to

63 Schwartz, Yen Fu and the West, 179.

64 James Reeve Pusey, China and Charles Darwin (Cambridge, MA: Harvard University Press, 1983), 225.

65 Llang Qichao, Yin-pinq-shih wen chi lCollected writings from the lce-drinker's studiol (Taipei, 1960) I, 1: 109, quoted in Pusey, 225. 
survive China had to completely rid herself of the old order and learn to struggle successfully, which was the opening for Chen's eventual revolutionism.

The role of science in this rebuilding of Chinese culture for Chen Duxlu in the formative period of his thought, between 1915 and 1917 was, as Benjamin Schwartz has put it, "...as a weapon -- a corrosive to be used in dissolving tradition." 66 It is clear that he saw it as the tool with which to conquer nature, necessary because, like Yan $F u$, the successful struggle against the environment is what Chen believed had made the West strong and powerful. So Chen's conceptualization of the role of science is completely tied to his view that science is what human potential at its greatest -- exemplified by the West - - has achleved. Science, and the democracy it ostensibly brings, is what humans do when they are successfully struggling against their environment, and by extension into chen's later Marxism, in the human political world as well.

In the next chapter, the relations between Chen Duxiu's and Hu Shi's conceptualizations of science and its role in the transformation of society are examined during their period of direct contact, from 1917 -- during the May Fourth perlod, and the subsequent "Debates on sclence and

66 Schwartz, "Ch'en Tu-hsiu and the Acceptance of the Modern West," 67 . 
Metaphysics" in 1923. All of the points of view about Western science that had been stewing in China since the turn of the twentieth century, including opposition to it, came to a head in these debates. When the line was drawn between those who saw science as a "sufficlent way" to relate to the day to day world, and those who did not, chen and Hu were clearly on the side of science. But their views diverged as they explored the logical consequences of the subtle differences in their beliefs about science and culture, many of them a legacy from Yan Fu, in the heat of the debates. 


\section{CHAPTER VI}

THE IDEA OF SCIENCE IN THE MAY FOURTH ERA AND THE 1923 DEBATES ON SCIENCE VS METAPHYSICS

The May Fourth era (wusi shidai) [wu-ssu shih-tai], as a period in Chinese intellectual history, extends from the nationalism, new journalism, and "new thought tide" of "science," "democracy," and "individualism" that began in Beijing, Shanghai, and other chinese cities in 1915, to the intellectual aftermath of these trends in the twin polemics of Eastern versus Western civilization, in 1922, and science versus metaphysics, in 1923. In the center of this chronology is the May Fourth Incident itself, in Beijing, May 4, 1919.1 The whole period constitutes an important stage in the larger Chinese Revolution of the twentieth century -- the stage of cultural and intellectual transformation that Yan Fu in the nineteenth, and ultimately Hu shi and Chen Duxiu and others in the twentieth century had said was the necessary first step

1 Although the May Fourth Incident is important to the overall history of the period, it has very little to do with the concerns of this essay. Most of the important trends among intellectuals of the period concerning the role of science in China's survival orlginate in the years before 1919 and have a life of their own, beyond the events of 1919, although they are certainly helped along by them. 
before a substantial change in political and social circumstances could be effected. Though Yan Fu was intensely opposed to the intellectual revolution of the May Fourth period (by then he had become a pro-Confucian monarchist), much of May Fourth thought owes its origins to the trends in thought that he began and the great influence his work had on other intellectuals in the period.

This chapter will be concerned with the further development of Hu Shi and Chen Duxiu's notions of the meaning of science in the May Fourth period, from about 1917 through the "Debates on Science versus Metaphysics" in 1923. The Importance of the year 1917 to the May Fourth era for one noted historian of the period is due to a "gathering momentum" in that year of the tide of new thought and new literature that began in 1915, "due to the rallying of the new intellectual leaders around New Youth (Hsin Ch'ing-nien) magazine and National University of Peking."2 Beginning in 1917, at Beijing University (National University of Beijing), Hu Shi and Chen Duxiu were part of a uniquely diverse collection of scholars, put together by then president of the University, Cai Yuanpei [Ts'ai Yuan-p'ei] (1868-1940). And they were also an important part of the editorial core of the reform journal

2 Chow, 6 . 
New Youth.

New Youth, founded in 1915 and originally edited in Shanghai by Chen Duxiu alone, was moved to Beijing in 1917 and edited from early 1918 to mid-1920 by a coalition editorial board of reform-oriented Beifing University faculty, which included Hu Shi.3 It served as an important link between the self-conscious, though loosely allied, group of the more progressive liberal and socialist/anarchist elements among the faculty and their students. Because it was widely read among non-academic intellectuals, it also helped to tie the Beljing academic community to progressives in other social, political, and labor movements.

of the important focal points for the May Fourth movement and the "new culture" it espoused, the one with the most sweeping ramifications for intellectuals of the day was, perhaps, the "new" Beijing University. The institution had gone through a number of changes since its inception in 1898, but none with such cataclysmic or long lasting repercussions as those that were begun in 1917 by Cai Yuanpei. 4

3 The six editors were Chen, Hu, Qian Xuantung, Li Dazhao, Liu Fu, and Shen Yinmo. See ibid., 44-45, noted.

4 The origins of Beijing University are in the 1898 Reform Movement (Wushu bianfa) [Wu-shu pien-fa] and the "100 Days of Reform." Most of the Imperial reform edicts, 
In its earliest years, Beijing University was popularly known as "the Brothel Brigade," "the Gambling Den," or "the Fountainhead of Ribaldry and Bawdiness" for the reputation its students and faculty had for gambling and sexual excess.5 The first serious attempt to reform it came four months after the 1911 Nationalist Revolution. In February 1912 Yan Fu, then well known as a translator of Western books and advocate of Western learning, was appointed the president of the University by Yuan shikai (Yuan Shih-k'ai) (1859-1916), who had recently wrested the presidency of the Republic from Sun Yatsen (1866-1916).

based on the proposals of its major proponents, Kang Youwe i and Liang Qichao, were annulled by the Dowager Empress, Cixi. The funding for what was then called Imperial University (Jingshi Daxue) [Ching-shi Ta-hsiieh], however, was not cut off. She appointed a well-known conservative scholar, sun Jia'nai [Sun Chia-nail, to be its first superintendent. W.A.P. Martin, appointed by sun to oversee the Western faculty, developed programs in French, English, Russian, Japanese, and other foreign languages, and a few courses in applied mathematics and astronomy, while basically not upsetting the basic curriculum of traditional Confucian studies. The students, who had all passed at least the second level (zhuren) [chü-jen] of the civil service examination, were less than enthusiastic about nonConfucian studies that would not contribute to their ability to pass the imperial examinations for the highest degree. The students were in the habit of being "...officials-in-waiting: gambling, whoring, and in general, expecting society to reward them for the mere fact of being students of the Imperial University." see Vera Schwarcz, The Chinese Enlightenment: Intellectuals and the Legacy of the May Fourth Movement of 1919 (Berkeley, CA: University of California Press, 1986), 39-41.

5 Chow, 49-50. 
Though Yan would grow politically more conservative as time went on, becoming one of Yuan's chief supporters in his attempts at an Imperial restoration (1915 and 1917), his ideas on educational reform, in terms of both curriculum and institutional structure, were the beginning of the complete transformation of Beijing University that would be accomplished in 1917 and 1918 by Cal Yuanpei.6

When Cai Yuanpei was appointed president of Beijing

6 Yan Fu revamped the foreign languages program, insisting that students go to classes (!), and practice speaking the languages they learned, particularly English. He asked the Ministry of Education to change the name of the school to Beijing Daxue [Peiking Ta-hsueh], that is Beijing University, reflecting a new identity as a Westernstyled institution of higher learning, rather than an elite bastion for "officials-in-waiting." He also argued forcefully for a raise in faculty salaries, insisting, in language that is still echoed today, that in order to maintain and raise the quality of the teaching staff, that salaries had to reflect the high value that should be placed on a good education. Conservative elements in the Ministries of Education and Finance began to work for Yan's dismissal (spreading "rumors" of the opium addiction he had apparently never denied), while he was in the midst of hiring a new group of faculty, a process that would continue after his resignation in November 1912. Many of the new faculty, beginning with those who were hired under Yan's tenure, had some education in foreign schools, and had been exposed to Western ideas and acquired Western skills in European, American, and especially Japanese schools. Many of the ideological differences between Beijing University faculty that were involved in the May Fourth movement can be partially ascribed to the very different intellectual histories and contemporary currents each was exposed to in the country in which they studied. see schwarcz, 43-45. 
University7 by Yuan Shikai's successor Li Yuanhong ILi Yuan-hung] on December 26, 1916, he had a clear vision of the $k$ ind of institution it needed to be to serve as the premier training ground for the "new citizen" of a new China. An active anarchist and nationalist prior to his appointment, he was able to collect a faculty of radically divergent opinions which encouraged an environment of discussion and inquiry. By the time he had served as Minister of Education under sun Yat-sen in 1912, he had already talked of an ideal system of education for china that was "above politics." Above all he advocated freedom of thought, but grounded on a strong morality and belief in the promise of human rationality.8

Cai gathered together a faculty of conservatives, liberals, socialists, monarchists, republicans, nationalists, and anarchists that was unparalleled in the world at the time for its diversity. Both Hu Shi and Chen Duxiu, with whom we are primarily concerned in this essay, owe their professional "base of operations" during the May Fourth period to their faculty appointments at Beijing University in this perlod. Cai Yuanpe 1 had known of chen

7 Beifing University (Beijing Daxue) is frequently abbreviated "Beida." Sometimes this abbreviation may be used in this essay.

8 Chow, 51-52. 
Duxiu since 1906, when they were both anti-Manchu revolutionaries in Shanghai. He brought Chen with him as the Dean of the school of Letters when he took office as president in late 1916.9 Chen was, at that time, deeply involved in editing and writing for the journal New Youth and was a public figure with quite a following among intelligentsia outside the universities. Because Chen was also known as an advocate (and practitioner) of revolutionary violence, his appointment was a bold move on Cai's part. 10

Hu Shi accepted a position teaching chinese and Western philosophy at Beida in the autumn of $1917.11 \mathrm{He}$ was already well known to intellectuals in China through articles that had been published in New Youth while he was st1ll in the Unlted States. By the time he began his tenure at Beida, he and Chen had begun their promotion of a "literary revolution" in the pages of New Youth. Beginning in 1917, the writers for New Youth stepped up their attack

9 Ibid., 52.

10 For more background on Chen's early political life see Chapter V, pp. 110-117, above.

11 Chow, 53. Hu would later serve as the chairman of the department of English Literature, dean of the School of Letters (1930-37), and Chancellor of Beijing University (1945-49). Additionally, he served as the Chinese ambassador to the United States from 1938-1942, during the second Sino-Japanese War. See Chow, 26-27, note c. 
on traditional Chinese culture, particularly

Confucianism. 12

The Beida faculty who were on the editorial board of New Youth all fundamentally believed in the need to achieve substantial intellectual and cultural change before real social and political change. But political concerns often made this nearly impossible to adhere to for those, like Chen Duxiu and Li Dazhao, whose political lives were activist to begin with. As Hu shi remembered the situation in a speech delivered at Beijing University in 1932:

When in 1917 we worked together for New Youth, we had a common ideal that we should for twenty years not talk politics. We promised to keep away from politics for twenty years and to be devoted only to educational, intellectual, and cultural activities, to bulld a political foundation by way of nonpolitical factors. But this promise was not easy to keep, because even though we resolved to refrain from talking politics, the practical political situation compelled us to become involved in it.13

By 1918, a student-lead wing of the New Culture movement was beginning to have a public identity. A group of students interested in history and literature and active

12 Ibid., 53, 57-58.

$13 \mathrm{Hu}$ Shi, "Ch'en Tu-hsiu yu wen-hsueh ko-ming" [Chen Duxiu and the Literary Revolutionl, in Ch'en Tu-hsiup'inglun [Discussions on Chen Duxiu], ed. Chen Tung-hsiao, 5157, quoted in Chow, 57. This essay was originally a speech delivered at Beijlng University, October 30,1932 , while chen was in prison and being trled by the Nationalist government in Nanjing. 
in the movement founded the monthly fournal New Tide (The Renaissance) ( $\underline{\text { Xinchao) }}$ [Hsin-ch'ao]. There was a strong 1 ink between the New Youth writers and their younger compatriots at New Tide. Chen Duxiu and Li Dazhao were able to secure funding for them from Beijing University and Hu Shi served as their advisor. Most of those associated with the journal would eventually become student leaders of the May Fourth Incident.14

As the "intellectual and cultural revolution" of the "new thought tide" began to grow and spread throughout 1917 and 1918, opposition to their aims began to grow as well, though it was never particularly effective. No doubt because it was staffed by faculty from Beida, New Youth was under attack by conservatives for attempting to destroy "Confucianism, the code of rituals, the "national quintessence," chastity of women, traditional ethics...traditional religion, and ancient literature, as well as old-fashioned politics." Fully accepting the responsibility for the attacks, on behalf of the journal, Chen Duxiu sloganized the two fundamental principles that "new thought" intellectuals would use in their "war of words" (wenzhan) [wen-chan] to bring China into the modern world, "Mr. Democracy" (Demokelaxi xiansheng) and "Mr. 
Science" (Saiyinsi xianshenq) $: 15$

All of these charges are conceded. But we plead not guilty. We have committed the alleged crimes only because we supported the two gentlemen, Mr. Democracy and Mr. Science. In order to advocate Mr. Democracy, we are obliged to oppose Confucianism, the codes of rituals, chastity of women, traditional ethics, and old-fashioned politics; in order to advocate Mr. Science, we have to oppose traditional arts and traditional religion... we are compelled to oppose the cult of "national quintessence" and ancient literature...has this magazine committed any crimes other than advocating $M r$. Democracy and Mr. Science? If not, please do not solely reprove this magazine; the only way for you to be heroic and to solve the problem fundamentally is to oppose the two gentlemen, Mr. Democracy and Mr. Science.16

There is a strong assumption, on Chen's part, that everyone who wanted to "save china" would want to support "(Mr.) Science" and "(Mr.) Democracy," ipso facto. "Science" and "democracy" were understood to be the basis of "modernity." Hu Shi, in his preface to the collected works of the "Debates on Science versus Metaphysics" a few years later, in 1923, would reiterate this assumption that the reform-minded were those who, for better or worse,

15 These words are not the words for "science" and "democracy," but rather chinese words used to transliterate English words. It is an indication of Chen's (and others') turn towards the English speaking world at this time that the Western language that was used for this rhetoric was English, and not French or German.

16 Chen Duxiu, "Benzhi suian zhi da bienshu" (A reply to the charges against our Journal], Xin Qingnian [New Youth ] 6.1 (January 1919): 1-2, translated in Chow, 59. 
nearly worshipped sclence:

During the last thirty years there is a name which has acquired an incomparable position of respect in China; no one, whether informed or ignorant, conservative or progressive, dares openly slight or jeer at it. The name is science. The worth of this almost nationwide worship is another question. But we can at least say that ever since the beginning of reformist tendencies [1890s] in China, there is not a single person who calls himself a modern man and yet dares openly to belittle science."17

Here we have an intimation of one of the fundamental differences between Hu Shi's and Chen Duxiu's notions of the character and social role of modern science. Chen's science comes as a unit, materialized and personified as "Mr. Science." science, then, is a total "thing," to be either accepted or not. Hu Shi's concern, however, is with the suppression of critique as a result of acceptance of a "total" science. As a philosophical pragmatist, Hu was precluded from a purely totalistic notion of science. Unlike Chen, Hu Shi's concept of knowledge was historical - "genetic" in pragmatist terms -- accumulative. Because it was a process, adapting to changing circumstances, critique was a built-in necessity.

Chen's notion of science after 1917 was increasingly focused on its "determinative" aspects. In this

$17 \mathrm{Hu}$ Shi, "Kexue yu renshengguan xu" (Preface to Sclence and Philosophy of Life), in Kexue yu Rengshengquan (Science and Philosophy of Life), I (Shanghai: Yatung Publishing Co., 1923), 2-3, translated in Kwok, 11-12. 
description of science as "law," the sense of constant change that is evident in Hu's thought is absent in Chen's beliefs:

I believe that in the future the true belief and course of action for humanity will be guided by the proper course of science. At such time all religions will be among the expendable ltems. The reasons for this...can be stated in outline. In the universe there are two kinds of law -natural law and man-made law. Natural law, to which sclence belongs, is all-pervasive, eternal, and inevitable. Man-made law, to which belong religion, ethics, and rules, is partial, temporary, and rational... The future evolution and progress of mankind must be based on the budding science of today; we must seek gradually to improve man-made laws so that they conform with the results of natural laws. Only when this is done can life and the universe be in perfect union. This is our greatest and most final purpose! 18

Chen conceived of a holistic-deterministic universe, much like that of the Chinese tradition, where "what is above" (in the heavens) is reflected in "what is below" (on earth, in human society). But in Chen's monism, there can only be a single unit for everything in the universe -matter. For Chen, sclence is a prlori, humans apparently just "discover" 1t. The mechanism whereby humans apprehend these relationships in the universe that he is calling "science" are not made clear in Chen Duxiu's writings. In

18 Chen Duxiu, "zal lun Kungjlao wenti" [Again on the problem of Confuclanism], xin Qingnian [New Youth) 2.5 (1917): 1 (Eirst article), quoted in Kwok, 76-77. The emphasis is mine. 
the above passage, Chen has set science (Natural law) against "the rational" (Man-made law), as though there were only room in all of "good thinking" for one of them. Their relationship to each other, if any, isn't spelled out. In fact, science seems to be substituted for rationalism in the fight against "superstition": "...I am in favor of replacing religion with science and of cultivating slowly our realistic faith, which is definitely attainable by science...."19

It is clear that materialism was part of what attracted Chen to Marxism. And, as "science" was the key to reality and materialism was the foundation of science for Chen, and he wished, fundamentally to rework society, his "science of society" would be completely materialist as wel1. By 1921, Chen was setting "science" against "metaphysics" in a way that presaged the Debates, still two years away:

From now on our duty towards learning and thought must be the analysis of human affairs and matter in order to establish unequivocal facts labout the two areas, social science and sciencel. This then is my idea of science; it can also be called a philosophy. If, however, we were to detach ourselves from the analysis of human affairs and matter and indulge in the empty speculations of metaphysics, wishing to $f$ ind a quick but illusory method to solve problems of the universe and life, we would be entertaining fanciful dreams that characterized the past. We must wake up!

19 Ibid., quoted in Kwok, 77. The emphasis is mine. 
Let me ask you: outside of human affairs and matter, is there still any universe or life?20

1921 was the year that Chen and Li Dazhao committed themselves fully to Marxism and founded the Chinese Communist Party (CCP). In this move to Marxism, Chen's total and social definitions of science came together -and in the process he ceased to call for democracy. Chen carried this new "social science," without the old aim of democracy, into the "Debates on science versus Metaphysics" two years later.

The "Debates on science versus Metaphysics" were able to occur in 1923 because effective opposition to the wave of pro-sclence sentiment had developed by that time. Opposition to the attack on Confucianism and the rest of the foundations of Chinese civilization that was being mounted by the new intelligentsia of the "new thought tide" was weak in the early years, and had posed little threat. Many of this opposition were old gentry who had no experience with modern, Western ideas, and couldn't maintain credibility with the new young scholars, increasingly educated in the West or Japan. But after 1919, the intellectual programs of the New Culture movement were criticized by scholars who had studied and

20 Chen Duxiu, "Da Jlebing" (Answering Jiebing), June 1, 1921, Tu-hsiu wen-ts'un (Collected Essays of Ch'en Tuhsiu), 3: 373, quoted in Kwok, 81. The emphasis is mine. 
compared the civilizations of China and "the West," and found the West wanting. The material, economic, and social devastation of World War I in Europe started many intellectuals, European and Chinese alike, thinking critically about the values of Western civilization.

After World war I, the Occidentalism that many Chinese had espoused since the turn of the twentieth century in their pursuit of the key to modernization and national survival was challenged by a new wave of orientalism from Europe.21 Philosophers such as Henri Bergson (1859-1941) and Bertrand Russell (1872-1970), disturbed by the events of the war, began to see "Oriental pacifism," especially in China, where Karl Wittfogel had once seen "Oriental despotism." And, they began to question the presumed value

21 Orientalism is a concept brought out in the open by Edward Said, in orientalism (New York: Random House, 1978; reprint, New York: Vintage Books, 1979). Basing a working definition on Said's, "Orientalism is a style of thought based on an ontological and epistemological distinction made between "the orient" and (most of the Time) "the occident"." (See p. 2) It should be added that these are simple differences, but ones that are assumed to cut to the "essence" of what each set of traditions is supposed to stand for. Strains of Orientalism have cropped up in twentieth century America is various movements to exhault pre-modern Chinese, Japanese, or Indian culture as superior, without examining any of the superficial presumptions on which such ideas are based. By extension, "Occidentalism" is "Orientalism" in reverse. Many of the "New Culture" movement supporters of the May Fourth era in China were "Occidentalists," promoting Western ideas without any real understanding of the historical circumstances that produced them. 
of the West's materialistic and scientific civilization. 22

Liang Qichao [Llang Ch'l-ch'ao], who had been one of the strongest "Occidentalists" in China before World War I, late in 1918 lead a group of "semi-official" Chinese observers from the Paris Peace Conference on a trip through Europe, during which they visited Bergson and other philosophers, intellectuals, and politicians. The group included two men who would be important players on opposite sldes of the 1923 "Debates on Science versus Metaphysics," Carsun Chang [zhang Junmai, Chang Chün-mai] and V.K. Ting [Ding Wenjiang, Ting Wen-chiang]. For the Europeans they met on this trip, the war had been the result of "the bankruptcy of Western civilization," and they looked to the relative stability of Chinese civilization for a corrective. 23

Liang's contact with the disenchanted Europeans had undercut his "dream of the omnipotence of science":

Those who praised the omnipotence of science had hoped previously that, as soon as science succeeded, the golden age would appear forthwith. Now science is successful indeed; material progress in the west in the last one hundred years has greatly surpassed the achievements of the three thousand years prior to this period. Yet we human beings have not secured happiness;

22 Chow, 327 .

23 Ibid., 328 . 
on the contrary, science gives us catastrophes.24 He took direct aim at New Youth (and Chen Duxiu in particular) by accusing "Mr. Science" of being a shadowy seducer, luring the unwary into "the slough of despond." Liang called the fact that Europeans had come to this conclusion about their own civilization "a major turning point in current world thought." 25 He even went so far as to lay the blame for the war at the feet of Darwin, who, because of the widespread regard in China of Yan Fu's translation of Huxley's treatment of Darwinian evolution, had become nearly synonymous with "science" in Liang's and many others' minds. 26

24 Liang Qichao, "Ou yu xinying lu jielu" (Impression of a European Journeyl, Shishi xinbao [The China Times] (Shanghai, March 1919), quoted in Chow, 328 .

\section{Ibid.}

26 Joseph R. Levenson, Liang $C h^{\prime} i-C h ' a o$ and the Mind of Modern China (Berkeley, CA: University of California Press, 1967), 203. In "Laozi zhexue" (The philosophy of Laozi) (1919?), while trying to explain Europe's interest in the Taoist philosophy of Laozi [Lao-tzu] in its current wave of orlentalism, Liang had his say about Darwin and World War I leven while confusing Yan Fu's translations of spencer with spencer's principles of Sociology and Huxley's Evolution and Ethics): "Since Darwin's discovery of the principle of the evolution of species, a great revolution has occurred in intellectual circles of the whole world. His service to learning must be acknowledged. But afterwards his theory of struggle for existence and survival of the fittest was applied to the study of human society and became the core of thought, with many evil consequences. This great European war nearly wiped out human civilization; although its causes were many, it must be said that the Darwinian theory had a very great 
Liang Qichao had "thrown down the gauntlet" In what was to be a sprawling debate over the next four years (1919-1923) on the relative merits of the "new" Chinese culture versus the "old." By extending the two fundamental points liang had to make in his influential 1919 articles, 27 the impetus for the two stages of polemics that follow emerges. The first point was a belief in the "failure of Western civilization." It took several years before anyone could mount effective support for Liang's contention. But in 1920 and 1921, Liang shuming li,iang Ssu-mingl, lecturer at Beijing University, gave a series of lectures on "Eastern and Western Civilizations and Their Philosophies." In these talks the Chinese "way of life," Confucianism and Chinese metaphysics in particular, was systematically defended in the process of explaining Western, Chinese, and Indian civilizations as stages in the development of society as a problem solving mechanism. His

influence. Even in China in recent years, where throughout the whole country men struggle for power...although they understand nothing of scholarship, yet the things they say to screen themselves from condemnation are regularly drawn from Yen Fu's translation of "The Principles of Evolution"... No wonder that Mencius said, "These evils, growing in the mind, do injury to government, and, displayed in the government, are hurtful to the conduct of affairs." Perhaps the European's current fondness for the study of Lao-tzu is in reaction to this theory." See Levenson, 203.

27 Chow, 328-329. 
systematic critiques of previous views on the issue of Chinese versus Western "ways of life" set the tone and intensified the issues for the polemics to come.28

It is the second of Liang Qichao's points, his criticism of the "dream of the omnipotence of science," that is of importance to this present study; it catalyzed enough controversy that the 1923 "war of words" (1unzhan) on science versus metaphysics owes its origins to Liang's discussions. As Chow Tse-tsung has noted, many who read Liang's articles converted his wary attempt to forge a balanced interpretation of the achievements of scientific culture into a belief in the "bankruptcy of science" itself. 29

The "Debates on Science versus Metaphysics" deepened and focused the issues of the "Eastern versus western Civilization" arguments, on both sides. The polemic of the debates began with a lecture given to a group of science students at Tsing Hua University, February 14, 1923, by

28 Ibid., 329-332.

29 Ibid., 328-329. At the end of ou yu xinying lu jielu [Impressions of a European Journey], Liang mollifies his ringing pronouncements against the "rightful" dominance of Western civilization with this more balanced comment: "The reader must not be mistaken [by this article] so as to belittle science; I absolutely do not recognize the bankruptcy of science, but then also I do not recognize the omnipotence of science." Quoted in Kwok, 138. 
Carsun Chang (1886-1969), a professor at the university.30 He was a graduate of Waseda university in Tokyo, in political science, and his post-graduate work in Germany and England added to the credibility of his opinions about Western civilization. He had travelled with Liang Qichao on the 1918 tour of Europe where he was developing his anti-Western ideas, and he was clearly sympathetic to the cause. 31

Chang's lecture, titled "The Philosophy of Life" was a severe criticism of the view that science was a unitary approach to all facets of $l$ ife, including morality and ethics - the area that was part of "a philosophy of life" (rensheng quan) [ jen-sheng kuan]. His post-graduate work in Germany had evidently exposed him to debates on the supposed split between "natural sciences"

30 There is only one article in English on the Debates, Lin Yu-sheng, "The Origins and Implications of Modern Chinese scientism in Early Republican China: A Case study - - The Debate on Science vs. Metaphyslcs in 1923," Proceedings of the Conference on the Early History of the Republic of China, 1912-1927 (1983) 2: 1181-1200. A fulllength study in English of the polemic on "Science versus Metaphysics" has never been done. Secondary discussions with a fair number of details may be found in Kwok, 135160; Chow, 333-337; Grieder, Hu Shih, 145-160, passim; and Benjamin I. Schwartz, "Themes in Intellectual History: May Fourth and After," in The Cambridge History of China: Volume 12, Republican China 1912-1949, Eart I, eds., Denis Twitchett and John $K$. Fairbank (Cambridge: Cambridge University Press, 1983), 439-444.

31 Grleder, Hu Shih, 145. 
(Naturwlssenschaft) and "spiritual sciences"

(Geisteswissenschaft), 32 as his own view placed "an unbridgeable gap between them." 33 For Chang a philosophy of 1 ife was "subjective, intuitive, synthetic, freely willed, and unique to the individual."34 And all the issues could be reduced to one:

No matter how developed science is, it can never solve the problems of the philosophy of life, which depends entirely on man himself and nothing more...From Mencius and Confucius down to the $\mathrm{Li}$ school of Sung, Yuan, and Ming, the thinkers all gave priority to the cultivation of the inner life and hence brought about a spiritual civilization. Europe... for three hundred years concentrated on the control of nature by human power with the result that it produced a materialistic civilization." 35

The geologist V.K. Ting (1887-1936) led the attack against Chang. Chang had set up "science" and "metaphysics" as dichotomous, with completely separate spheres of application, and Ting's attack was first directed to this issue. For Ting, the universe was

32 Schwartz, "May Fourth and After," 419-420.

33 Lin, "Science versus Metaphysics," 1181.

34 Chang Chun-mai, "Rensheng guan" [A view of life], in Kexue yu rensheng quan [Science and a view of life], with prefaces by Hu Shi and Chen Duxiu (Shanghai: Yadong tushuguan, 1923; reprint, Taipei, R.O.C.: Wenxue Zhubanshe, 1977), 9 (page references are to the reprint). Kexue yu rengsheng quan wlll hereafter be abbreviated as KYRG.

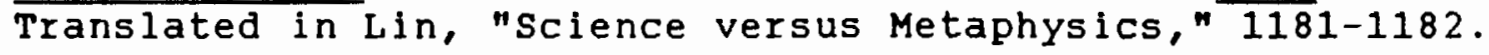

35 Ibid., 9-10, translated in kwok, 141-142. 
unified, and therefore science was also unified. To say that one part of phenonmena are not ultimately apprehendable using the methods of science is then absurd. His theory of knowledge was brought in to support his argument:

[The] contents of psychological phenomena are all material for scientific study. The nature of matter that we know is but [that derived from] psychological sensory stimulation; perception leads to conception, and conception leads to inference. What science undertakes to study is nothing but these conceptions and inferences; whence comes the difference between the so-called splritual sciences and material sciences? How can one also say the purely psychological phenomena cannot be governed by the scientific method? 36

For Ting, as for others such as Hu Shi and Chen Duxiu who would rally to support and augment his point of view as the exchange continued, there was one "law of causation" in the universe, applicable to all phenomena. For Ting, "science" was the "philosophy of life," a universally applicable approach: "The aim of science is to eliminate from the philosophy of life preconceived and subjective ideas, the greatest enemy of the philosophy of life, [and] to search for the kind of truth that can be recognized by all."37 And, as it had proven to be for Hu Shi, the

36 V.K. Ting, "Xuanxue yu kexue" (Metaphysics and science), KYRG, I:1 (second article), translated in Kwok, 144 .

37 Ibid., 20, quoted in Kwok, 144-145. 
universalizing aspect of science was linked to its strength and its "utility" as method, another echo of Yan Fu's faith in Huxley's and Spencer's "avoidance of bias":

The method of science is to distinguish the falsity and truth of things, to classify all available data, and then to bring order to these data, and to use the simplest and clearest language to express them... Science is allsufficient not so much in its subject matter as in its method and procedure." 38

Ting's notion of scientific method is more inclined to assign primacy to induction, over deduction or hypothesis. The science of Ting's training, geology, was, at that time, observational-classifying in character, and perhaps conditioned his predilection for the inductive approach to phenomena through empirical sense-perception.39 As Lin Yusheng has noted, hypothesis and deduction were not absent, but hlghly de-emphasized in Ting's point of view:40 "It is

38 Ibid., quoted in Kwok, 145. V.K. Ting was guite Involved intellectually with $\mathrm{Hu}$ shi at the time that this piece was written, and might had been influenced by him in terms of the importance of method. The article from which these passages are taken first appeared in a small weekly llberal fournal that $\mathrm{Hu}$ and $\mathrm{Ting}$ had founded in Beijing in 1922 called Nuli zhoubao [Nu-li zhou-pao] (Endeavor), after several years of discontent at the "political" direction New Youth had taken under the influence of Chen Duxiu. Ironically, Endeavor, turned out to be Hu's debut vehicle for political commentary. See Grieder, Hu Shih, 184-188, 150 .

39 Lin, "Science vs. Metaphysics," 1185; Schwartz, "May Fourth and After," 440.

40 Lin, "Science vs. Metaphysics," 1185. 
not that science attaches no importance to individuality and intuition. But individuality and intuition recognized by science are those which are derived from hints of experience -- those that emerge from living experience las Hu Shi has said)." 41

The parenthetical aside in Ting's comment above, tipping his hat to Hu Shi, brings up an important aspect of the way in which $\mathrm{Hu}$, and Chen Duxiu as well, enter the 1923 debate. Hu and Chen were not a part of the week to week "war of words" in the journals that lasted for nine months or more of that year. 42 However, their articles in New Youth and their influence among other intellectuals in the May Fourth period were fundamentally responsible for establishing the notions of "Chinese thought" versus "Western thought" and "science" versus "metaphysics" as a dichotomies, as well as defining those aspects of science valued by progressive intellectuals in the debates.

Hu had, since his days at Cornell, perceived "scientific thinking" as the remedy for religion and other

41 Ting Wenjiang, "Xuanxue yu kexue" (Metaphysics and Science), KYRG, 30, quoted in Lin, "Science vs. Metaphysics," 1185.

42 Grieder, Hu Shih, 151. Hu Shi was recovering from a physical breakdown during much of 1923, and was not in Beifing during the controversies. But, as many of the articles in the polemic appeared in journals that he edited, it is obvious that he kept close tabs on the affair. 
"superstitions." Chen had berated the "Impracticality" and "vacuousness" of the Confucian tradition unrelentingly and promoted a view of science as a pre-existing "law" for humans to align themselves with in the press since 1915 .

The 1923 Debates revolved around this very point: "science" versus "metaphysics." Hu and Chen wrote prefaces to the entire polemic when the various articles were published in the collection Kexue yu Rensheng Guan (Science and the Philosophy of Life) in 1923. It only indicates the importance others attached to their points of view on the issue of science and meaning in this period that they were asked to write the prefaces when they had not been active participants in the polemic of that year.

In Hu's preface to the debates, clarifying his own position regarding the primacy of "science" over "metaphysics," his faith in the human apprehension of the phenomenal world -- a supreme faith in the "rule of evidence" -- was his bottom line:

In the China of today where religious worship has been comparatively free, if we deeply believe in the scientific evidence available now, we can only deny the existence of God and the immortality of the soul. If this is the case, then we might as well proclaim ourselves atheists. This type of faith cannot be called dogmatic because it is based on evidence. 43

$43 \mathrm{Hu}$ Shi, "Kexue yu rensheng guan xu" (Preface to science and the Philosophy of Lifel, 14-15 of second preface, translated in Kwok, 105. 
In this important sense Hu was a rationalist and a materialist and approached his assessment of the issues in the debate on these bases. But his pragmatism led him to pluralism, as well. In an infinite unlverse, with a plurality of contexts, there is no single and final answer to the questions humans seek to answer, even when applying the scientific method to their solution: "The constant search for truth does not imply a complete success because truth 1 s infinite and the universe is infinite. That we must keep searching is merely to fulfill our obligation, hoping that we can add an iota to the total whole."44 It is in this respect that his conception of science differs from the "totalism" of Chen Duxiu.

By the beginning of the "Debates on science versus Metaphysics" Chen Duxiu had new rhetoric and a new focus in his response to the issues, indicative of his conversion to Marxism. Whereas previously he had treated the "scientific way of thinking" as a "corrosive" to eat away the infection of traditional Chinese society, in the period of the debates he switched to regarding science as the set of the "economic laws" of Marxism. He, had two years earlier, already joined the "laws" of human affairs to the "laws" of

$44 \mathrm{Hu}$ Sh1, "Kexuede rensheng guan" [The scientiflc Philosophy of Life], Hu Shl wenxuan ISelected Essays of $\mathrm{Hu}$ Shi) (Hong Kong, 1958), 77, quoted in Kwok, 106. 
matter in a single, unitary "science."45 In Marxism he finally had his "science of human affairs." Marx himself had believed his economic philosophy to be a "science of society." Chen's notion of science as a description of the "laws of nature" became even more deterministic in his application of these "laws" to human society.

In his section of the preface to the 1923 collection of the articles of the debates, Chen attacked the positions of nearly all the participants, on the basis of his reinforced materialism. The "metaphysicians" were guilty of "dream talks," the pro-science faction was guilty of not advocating a unitary schema of linear causation. In the rhetoric of Marxism, Chen attacked Liang Qichao's belief that "feeling and sentiment" don't lend themselves to scientific examination by reducing human emotions and values to the consequences of socioeconomic "laws and forces." 46 Chen believed "...that only objective, material causes can account for social evolution, can explain history, and can determine the philosophy of 1 ife."47

Hu Shi's notion of a "view of life," implied in many

45 See above, pp. 139-141.

46 Kwok, 152-154, especially note 36 .

47 Chen Duxiu, "Kexue yu Rensheng Guan Xu" lPreface to Science and the Philosophy of Lifel, KYRG, quoted in Kwok, 154. 
of his earlier writings, came together during the period of the debates. Later in his life, he formulated a "Credo" that he felt he had been stated in a "more general way" in his preface to the debates. Hu called his "Credo" the "Religion of social Immortality":

...the religion of social Immortality... is essentially based on the idea that the individual self, which is the product of the accumulated effect of the social self, leaves an indelible mark of everything it is and everything it does upon that larger self which may be termed Society, or Humanity, or the Great Being...This Great self lives forever as the everlasting monumental testimony of the triumphs and failures of the numberless individual selves." 48

It was a reverberation of Yan Fu's spencer, whose notion of the energies of the individual being developed in the interest of the progress of the larger group had shaped much of the May Fourth era discussion of individualism. And it was intellectual progress in Darwinian terms -- an accumulation of "numberless individual selves."

Hu proposed "a framework for a new philosophy of the universe and life." Some Christian missionaries "mischlevously" called the ten points of Hu's credo "Hu Shi's New Decalogue."49 But they represent what Hu considered essential to a "view of life" at the time of the 1923 debates. Hu's credo spelled out the scientific basis

48 Hu Shl, "Credo," 259.

49 Ibld., 260. 
for a proper "view of life" (rensheng quan). It was "...a hypothesis founded on the generally accepted scientific knowledge of the last two or three hundred years... I propose to call it, not 'a scientific credo', but merely 'the Naturalistic Conception of Life and the Universe." 50 Hu's credo was built upon his understanding of the "laws of causality" and the unity of phenomena in the adherence of all of their behavior to these same laws of causality. with echoes of Herbert Spencer, as presented by Yan Fu's translation of A study of Sociology, physical "law," biological "law," and the hypothetical "laws" that govern the evolution and maintenance of societies are all of a piece -- and can be "scientifically studied" by humans.

The capstone of Hu's credo is the tenth item, the raison d'etre for study and science, in fact for bothering with any of this at all:

On the basls of biological, sociological, and historical knowledge, we should recognize that the individual self is subject to death and decay, but the sum total of individual achievement, for better or for worse, lives on in the immortality of the Larger self; that to live for the sake of the species and posterity is religion of the highest kind; and that those religions which seek a future life either in Heaven or in the Pure Land, are selfish religions. 51

50 Ibid., 261-262.

$51 \mathrm{Hu}$ Shi summarized this aspect of his view of life in English in "Credo," 261. 
For Hu, change was the very basis of life. This change was not the first step to chaos, as Confucianism tended toward, but the first step on the way to survival, as Darwin and Huxley believed. Human capacities are the result of adaption to change, and intelligence is a sign of the "natural" freedom of humans within the perimeters of the "laws of causality":

Even the absolute universality of the law of causality does not necessarily limit [Man's] freedom, because the law of causality not only enables him to explain the past and predict the future, but also encourages him to use his intelligence to create new causes and attain new results. Even the apparent cruelty in the struggle for existence does not necessarily make him a hardened brute; on the contrary, it may intensify his sympathy for his fellow men, make him believe more firmly in the necessity of cooperation, and convince him of the importance of consclous human endeavor as the only means of reducing the brutality and wastefulness of the natural struggles. In short, this naturalistic conception of the universe and life is not necessarlly devoid of beauty, of poetry, of moral responsibility, and of the fullest opportunity for the exercise of the creative intelligence of $\operatorname{man} .52$

By the "Debates on Science versus Metaphysics" in 1923 the legacy of Yan Fu's initial presentations of "how" modern science works and its role in China's modernization and survival as a nation had split into two distinct streams, represented by the thought of Hu Shi and Chen

52 Ibid., 263. The emphasis is mine. 
Duxiu. They still shared certain important presumptions about the fundamental importance of the group in human affairs and a focus on scientific methodology as the way to rebuild the Chinese people into a competitive, progressive, independent, modern nation. But Chen, partly perhaps because of his intensely activist personality, in a revolutionary fervor had taken the energetics of Yan Fu's Spencerian vision and left the gradualism implied by Darwin behind. He was more focused on causality, and therefore had more of a single directionality to his thinking than $\mathrm{Hu}$ Shi by this time. Progress for Chen seemed to leave behind the past, unlike Hu's more historical, cumulative vision. Hu's vision allowed a more active role for man in determining his own circumstances than Chen's did. Hu's reality is interactive with humanity -- we can create "new causes and attain new results." The voluntaristic strain of Yan Fu's thought receives a stronger application in Hu's thought than in Chen's deterministic approach. Chen's sense of "law" precludes there being very many alternative routes to solving a problem, and only one possible route for history.

The "debates" themselves did not end on a definitive note, solving once and for all the issue of the "correct view of 11 fe" for Chinese to adopt. It could be sald that the success of the communists in the 1949 revolution is an 
indication that the pro-science faction won the debate. Communism is an approach that believes that it is applying the "economic science of society" to all human affairs, but it is inaccurate to say that "Western science" won the debate. However, the tendency of the pro-science faction to adhere to the yong side of the ti/yong paradigm had its cultural precedents in Chinese intellectual traditions as much as the "metaphysicians" tendency toward $\underline{\underline{t}}$ and "Chinese essences" did. By relying on ideas from Western thinkers for their arguments in the debate -- and in the polemic on Eastern versus Western Civilizations that preceded it -- while casting their arguments in traditional Chinese philosophical terms, both sides in the debate managed to "face both ways." 


\section{CHAPTER VII}

CONCLUSIONS: THE MEANING OF SCIENCE, 1898-1923

The concern of Chinese intellectuals with the "idea" of modern science in the first quarter of the twentieth century was, fundamentally, concern about "national survival" and "modernity." Given the military, economic, and political dominance of the west in East Asia and the need for Chinese national survival, thinkers such as Yan Fu, Hu Shi, and Chen Duxiu saw salvation in the very modern-ness of the modern west and the modern Japan it had successfully inspired. In fact, the value and meaning that accrued to science in general, and Darwinian evolutionary theory as the "science of choice" among Chinese intellectuals of this period, was due to their belief (or disbelief) in the power of these ideas to describe, explain, or solve the problematic of "modernity" in the Chinese context.

It is important for western trained historians, still emerging from the "monolithic, static, Confucian/superstitious China" meets "versatile, dynamic, democratic/scientific West" trend of historiography on nineteenth and early twentieth century China, to 
"deprogram" our ethnocentrism in overemphasizing the importance of the west in shaping chinese events in this period.1 on the other hand, we must not shy away from a critical examination of the impact of challenging ideas from the west on Chinese intellectuals of this period. One of the most problematic aspects of the "old" historiography has been the attempt to apply a "tradition versus modernity" paradigm to early twentieth century China. 2 Benjamin schwartz rejects such a category as inadequate to explain the behavior of Chinese intellectuals of the "transitional generation" (ca. 1890-1920), primarily because it doesn't focus on "what happened in China." 3

This present study of the meaning of modern science in the thought of three key figures in this generation, by focusing on "what happened," that is, on what Yan Fu, Hu

1 The "Introduction" and first essay, "China's Response to the West" in Paul A. Cohen, Discovering History in China: American Historical Writing on the Recent Chinese Past (New York: Columbia University Press, 1984), 1-55, offers an excellent summary of the main strains of "Western impact" historiography on nineteenth and twentieth century china, and some of the more recent correctives.

2 For a general discussion of the problems with tradition modernity models in recent Chinese history see Cohen, 57-96 (Chapter two, "Beyond 'Tradition and Modernity").

3 Benjamin I. Schwartz, "The Limits of "Tradition versus Modernity" as Categories of Explanation: The Case of the Chinese Intellectuals," Daedalus 101.2 (Spring 1972): $79-81$. 
Shi, and Chen Duxiu wrote, and not on applying the label of "traditional" or "modern" to their work, shows a complex development of thought within a chinese context, but informed by the western sources each man had turned to. Having said this, there are three inter-related overall conclusions that can be drawn from the writings of these three important figures:

1. Contrary to the "old" historiography on the period, sustained contact with the ideas of the west in the period leading up to the May Fourth era did not instigate a generalized "break with the past" among intellectuals. Rather, the thinkers in this study faced "both ways" at once -- outward, toward the West, and inward, toward the Chinese tradition.

2. The "idea" of modern science is positively regarded as a tool for solving the problematic of modernity in China -- it is the method for achieving the "transvaluation of culture" many felt to be the necessary first step in changing China's political, economic and social structures. Examination of the dynamic between the concepts of ti and yong in Yan, Hu, and Chen's writings about science shows this trend.

3. Yan Fu's influence on thinkers in the May Fourth period succeeded in establishing a trend of thought about the meaning of modern science in general, and Darwinian evolutionary theory in particular. This trend can be clearly seen in the thought of Hu Shi and Chen Duxiu; even the radical divergence in their views after 1921 are reverberations of elements in the thought of Yan Fu about which he was ambivalent or whose logical consequences he had insufficiently explored.

Establishing that there was no cataclysmic "break" with the chinese tradition is a necessary first step in understanding the meaning of modern science for the figures in this study. Despite the clearly "anti-traditional" and 
often frankly iconoclastic character of the thought of all three men, their language, categorizations, approach, inner logic, and choice of avenue of expression were often reflections of a submerged and unacknowledged intellectual context whose parameters were still largely Confucian. In fact, the great extent to which each man was aware of and participated in the "Confucian discourse" of late Imperial China and its extension into the Republican period, through conscious scholarship and critique, and through unconscious habits of thought, made the transmission of the meaning of modern science possible in this transitional stage between "old" and "new" China.

Yan Fu's approach with its adherence to Confucian categories of description and assumed acceptance of Confucian cosmology, even while promoting "progress," "democracy," "individuality," and "science," set the stage for much of the discussion, for and against modern science, that was to follow. Many of these Confucian, or "native" aspects of Yan's thought are deeply intertwined with the second and third conclusions arrived at in this essay as well, and will be discussed further in the contexts of science as a tool of cultural transvaluation, ti/yong dynamics, and Yan's influence on the thought of Hu shi and Chen Duxiu. But a few elements may be selected out for special mention. 
Yan initiated the practice of transferring the role of Sage as the adept of knowledge and the methods to obtain it to the scientist or "scientific" thinker as the adept of both the processes of change or evolution in the universe and of scientific knowledge in general. starting from the assumption that "knowledge is power," Yan Fu's belief that the power of the West lay in its scientific thinking led logically to the idea that the new sage would be the man who thought "scientifically." 4 In selecting the first Western book for his translation project, it was no accident that it turned out to be Thomas Huxley's Evolution and Ethics. Charles Darwin was one of the "new" Sages and Yan felt that his theory of evolution described the mechanism of the West's strength. Huxley's systematic and "unbiased" approach in presenting Darwin's theory in a social context suited Yan's Confucian need for intellectual balance and social order.5 Elements of the Doctrine of the Mean and the Great Learning, important texts of the Confucian canon, echo throughout Yan's thought, linking the Sage's (read: scientist's) elimination of disorder in the

4 See Chapter II, above, pp. 23-25.

5 Never mind that Huxley's motivation in writing his book was to thwart just exactly that social-engineering use Europeans like Herbert spencer had already made of Darwin's theory. It was this aspect that held such power for Yan Fu and those he influenced. 
running of the state to the centeredness to be achieved through the "integrity of intentions" and "the investigation of things." Morality, as it had been for Confucians for two thousand years, was still fundamental to the enlightened person.

Yan's ultimate emphasis on the "group" (qun) is another reverberation of Confucian considerations. Despite Yan's focus on individuality as the prime mover of society in the West, and $h$ is indebtedness to Herbert spencer's concept of the importance of releasing the "energies" of the individual in order to maximize their contribution to society, his greater concern is society. This ambivalence between emphasis on the individual and the group is one of the aspects of Yan's thought that finds expression in the divergence of Hu Shi and Chen Duxiu, and will be discussed later.

The second and third conclusions are so interlocked and dependent on an understanding of the general dimensions of the first conclusion that they cannot be fully pulled apart and must be presented together. A major part of Yan Fu's legacy to the thought of the May Fourth period was the idea of science as a tool and method for changing culture. The trend, through the "Debates on science versus Metaphysics" in 1923, was an increased separation of a notion of science's "usefulness" from any sense of its 
relationship to underlying principles, an increased ahistoricity. This is clearly seen in the way in which tiyong dynamics, conceptually part of the confucian past, change over one generation of intellectuals influenced by Yan Fu, represented by Hu Shi and Chen Duxiu, when examined in terms of their relation to notions of the meaning of science. That these new, "modern" issues are expressed in terms of "national essences" ( $\underline{t i}$ ) and their "usefulness" (yong) tie them to an ages old Confucian discourse.

Yurij Lotman and B.A. Uspensky have pointed out that during great changes in a given culture, what seem Iike contradictions in the blending of new and old forms and behaviors in a changed aspect of culture are simply part of the semiotic mechanism of cultural change:

It is significant that a change of culture (in particular, during epochs of social cataclysms) is usually accompanied by a sharp increase in the degree of semiotic behavior (which may be expressed by changing of names and designations), and even the fight against old rituals may itself be ritualized. On the other hand, the introduction of new forms of behavior and the semiotic intensification of old forms can testify to a specific change in the type of culture. 6

Language and categories of thought, as part of the system

6 Yurij Lotman and B.A. Uspensky, "On the Semiotic Mechanism of Culture", in Critical Theory since 1965, eds. Hazard Adams and Leroy Searle (Tallahassee, FL: Florida state University Press, 1986), 410. The emphasis is mine. "Semiotics" in this context has the meaning of "semantics," that is the study of "signs and what they signify" - systems of communication. 
of signs? of a culture, are a critical part of this semiotic mechanism.

The ti-yong dynamic in early twentieth century China is an example of such an "old form" (Confucian) being intensified with the introduction of new forms of behavior (Western).8 In moving from the thought of Yan Fu, to Hu Shi and Chen Duxiu, their notions of the meaning of modern science are expressed, implicitly and explicitly, in terms of this ti-yong category, and are thus an indicator of "specific change." In turn, by examining how this change in the ti-yong dynamic occurred, the way in which "modern science," a foreign idea, was taken into the intellectual culture of China in the early part of this century becomes clearer.

When cautious "self-strengtheners" of the midnineteenth century such as Tan sitong (T'an ssu-t'ung] and Zhang zhidong [Chang Chih-tung] first began to talk of Western science and technologies, they were thinking of "techniques" for modernizing China's military and

\section{Ibid.}

8 According to wing-tsit Chan, the concept of ti-yong originated with Wang Bi [Wang Pi] (226-249) in a commentary on the term wu (non-being) in Laozi. Wu, a "positive" state in Taoist thought, was equated in this commentary with $\underline{t}$, or "essence." It became a prominent metaphysical concept in both Neo-Confucianlsm and Buddhism. See Wingtsit Chan, ed., A Sourcebook in Chinese Philosophy (Princeton, $\mathrm{NJ}$ : Princeton University Press, 1963), 791. 
industrial technologies. The more conservative faction's intention to leave the whole cloth of chinese civilization intact while grafting on the "techniques" they believed were at the heart of the strength of the modern west was amply illustrated in 1898 by zhang $2 \mathrm{hidong's} \mathrm{famous}$ formula: "Chinese learning for the fundamental principles, Western learning for its practical use" (zhongxue wei tic Xixue wei yong). By resorting to the dichotomy, long in Chinese philosophy, of ti (principle, essentials) and yong (practical, useful), with ti given priority, zhang clearly lent his support to the state status quo, buttressed by an entrenched Confucian orthodoxy. At the same time, he succeeded in establishing the notion that $\underline{t i}$ and yong were mutually separable from each other. In his formula, they are not interactive, like the yin-yang duality of ancient Chinese philosophy, but characterize truly separate spheres.

Yan Fu's motivation for writing journal articles and undertaking his mammoth translation/commentary project in the late 1890 s was his over-riding concern with China's survival. If China was going to survive, autonomously, in the modern world, it was going to have to become modern. Four elements are discernable in Yan's writings that he felt were essential to the West's "wealth and power" as a modern nation: progress, individuality, democracy, ana 
Western science. All of these ideas had to be imported from outside the Chinese tradition. As Yan worked out the details, particularly in his translations of Thomas Huxley's Evolution and Ethics and Herbert Spencer's A Study of sociology, science, both in general as a way of thinking, and the specific case of Darwinian evolution, became a "wild-card" of a sort. All of the other elements were dependent on science, and science was the result, as we11.

Spencer had taught Yan that the power of the progressive West lay in harnessing the energy of individuals, trained increasingly in science. The result was democracy, where the individual could be of the greatest value to the group, the qun [ch'un]. The group has been recognized as the core of Chinese societal order for millennia.9 From reading Huxley and spencer Yan developed the belief that Darwinian struggle, where "[Living] things contend" (wu jing) and "Nature [Heaven] chooses" ( $\underline{\text { Tian ze}}$ ) was the arena where Europe (and England in particular) had fought and won. Europe was rich and

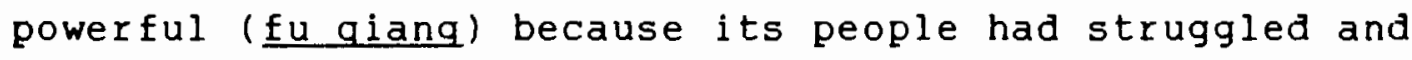
had proven the fittest. What did they have that China did not have? They had progress, individuality, democracy, and

9 The Confucian/Legalist philosopher Xunzi [Hsun-tzu], (fl. B.C.E.220) described man as the "grouping animal." 
science. Above all, they had science.

Yan Fu also contributed an emphasis on methodology, which, in essence, is an emphasis on yong. Yan believed that Huxley and spencer, in their presentations, freed investigation from bias, or "lop-sided extremes." Yan was, essentially, looking for balance and order. He was still, as Confucians for generations before him had done, seeking to adhere to the "Doctrine of the Mean." The "mean' was the resonance with the balance of Heaven/Nature that the "superior man", or sage, sought in his dealings with human society.10 "Science" would be the new source of balance and order, illuminating the path to truth and power. Because Yan Fu never mentions the fate of "Chinese-ness," that is, a Chinese essence (ti) (in fact it did not become an issue in the Chinese press until the 1910s), it is probably safe to assume that he believed that it was a

10 An example of the mean defined in this way is the following from Chapter I.4 of The Doctrine of the Mean: "While there are no stirrings of pleasure, anger, sorrow, or joy, the mind may be said to be in a state of EQUILIBRIUM. When those feelings have been stirred and they act in their due degree, there ensues what may be called the state of HARMONY. This EQUILIBRIUM is the great root from which grow all the human actings in the world, and this HARMONY is the universal path which they all should pursue." see The Doctrine of the Mean [Zhong Yung], in Confucius: Confucian Analects, The Great Learning, and The Doctrine of the Mean, translation and exegetical notes by James Legge, (New York: Dover, 1971, an unabridged republication of the second revised edition of Volume I in the "Chinese classics Series," (Oxford: Clarendon Press, $1893)), 384$. 
given, and not in jeopardy.

Between progressive intellectuals and in the new independent press at the turn of the twentieth century, a discourse on modernity and tradition began to emerge with "science" at the core. The rationale for the new interest in "science," a concept from the West, was its usefulness. "science" emerged, as it had in the West, as the "handmaiden" of modernity, as the method for transforming culture. As the generation of intellectuals who came of age between the $1890 \mathrm{~s}$ and $1910 \mathrm{~s}$ had been the last to be educated in the orthodox interpretations of the Confucian canon necessary to take the civil service examinations, this discourse was, to some extent, carried out in Confucian terms.

Yan Fu's influence on intellectuals of the May Fourth era (1917-1923) has been widely acknowledged, though never traced. By examining the influence of Yan's notions of the role and meaning of science on two very different figures from this period whose influence was wide-spread and who had close contact with each other, the liberal Hu Shi and republican-turned-communist Chen Duxiu, a clear trend of thought emerges. Even when the views of $\mathrm{Hu}$ and Chen concerning the meaning of science become radically divergent after Chen's turn to Marxism-Leninlsm in 1921, their branching-off can be viewed as further development of 
strains of Yan's thought whose consequences had been insufficiently explored or about which he had been ambivalent. In particular, there is an overall trend, in discussions of science as a transformer of culture, as the bearer of modernity, to subsume Chinese essence, or any cultural essence (ti) in useful techniques (yong). In moving through the thought of Yan Fu to Hu Shi and chen Duxiu, ti seems to evaporate, its importance dissipates. Hu's approach to modernity and science's place in it was still a kind of synthesis -- to forge a new national identity ( $\underline{t}$ ) out of the dialectic between the Chinese people, with their Confucian past, and modern "scientific" problem solving in their particular environment -geographical and cultural. While rejecting a disabling Confucian culture he felt had put china in the vulnerable position it occupied with regard to foreign "treatyports," Japanese imperialism, and internal warlordism, he was unwiling to be ahistorical. Progress for Hu was a process, an accumulation of smaller steps, not "leaps and bounds." The pragmatism of John Dewey that he adopted (and adapted) was a "genetic" method, knowledge formed by building on a series of experiences. The problem of "national essence" was solved, for $\mathrm{Hu}$, by "lettlng nature take its course" among a Chinese people educated to think using scientific method. 
Donald Munro offers another interpretation of the changing character of ti, especially as it relates to the thought of Hu shi. The concept of $\underline{t} \mathbf{i}$, or essence, in a consciously social setting can be described in terms of a group's "consensus on values"ll -- this is the group's ti. In the earlier discussion in chapter IV of ti and yong as they relate to Hu shi's effort to theorize the rebuilding of Chinese culture on a basis of "scientific thinking," it was already suggested that the evidence shows that $\mathrm{Hu}$, while focusing primarily on yong, on the usefulness of something, preserved the role of ti through the gradualism and "genetic sense" of Dewey's philosophical pragmatism.12 Some essence of being Chinese would always be present in solving problems in China because the problems were being solved in Chinese conditions, by Chinese. In Hu Shi's thought ti is partially submerged in the notion of yong. Philosophical pragmatism's conceptualization of theory and practice growing out of the circumstances at hand allowed Hu to neatly sidestep the issue of the fate of Chinese $\underline{t}$ - it would always be evolving, along with changing circumstances, and would, therefore, always be there.

11 Donald J. Munro, Images of Human Nature -- A Sung Portrait (Princeton, NJ: Princeton University Press, 1988), 219 .

12 See Chapter IV, above, pp. 88-91. 
Donald Munro's recent work on "human nature" in sung Neo-Confucianism and its continuity with aspects of modern Chinese intellectual history casts some light on the resonances from the Neo-Confucian tradition in Hu's notion of ti. The part of Hu's "unconscious legacy of the NeoConfucian past" Munro brings to our attention is Hu's "faith in the possibility of a consensus of values."13 Because of pragmatism's fundamental identity as a method, it "requires a consensus on moral first

principles...Philosophical pragmatists do not like to articulate first principles. They assume them."14 The American progressives from whom Hu learned pragmatism while a student of John Dewey's in the late 1910 s shared ti, or a "cultural essence" of belief in the values of progress through science and industrialization, the protestant work ethic, individualism, and human rights.15

Hu shi had faith that "modernizing the chinese mind" through education in "scientific thinking," would result in a "consensus on values" -- and that democracy would, naturally, prevail. Munro posits that the source of this faith is part of the legacy of Neo-Confucianism: the claim

13 Munro, 219.

14 Ibid. The emphasis is mine.

15 Ibid., 219-220. 
that a nation of "one mind" and in agreement on major principles of morality can be achieved through education and a belief in a universal moral sense.16 Hu's apparent naivete in ignoring the differences in historical setting of the two areas of the world -- the United states and China -- in applying the experience of one with "national consensus" to the circumstances of the other may be ascribed to this echo of Neo-Confuclanism in Hu's pattern of thinking. At the same time that an essentially Chinese notion is shaping Hu's thought, he is, in a sense partially substituting American ti for Chinese $\underline{t} \underline{i}$. His belief that pragmatism and "scientific thinking" would both create and take root in a "new national consensus" was conditioned both by Chinese tradition and a practical desire to see these concepts work in China. By assuming that the required "consensus on values" either already existed (as in the United States) or could be achieved through particular educational methods, the issue of ti is partially subsumed in the notion of usefulness, or yong, in Hu's thought.

The break between "conservatives" and nearly all other intellectuals in the May Fourth era concerning science was certainly over the issue of whether the tradition of

16 Ibid., 220. 
Chinese culture, particularly Confucianism should be cast out in favor of a new, modern "scientific" culture, borrowed or adapted from the West. The issue between liberals and radicals, between Hu Shi and Chen Duxiu, however, was not confucianism, but the difference between the liberals' gradualist "science-as-process" and the radicals" sense of "science-as-law," as "something to be in accordance with."

Jerome Grieder gives a clue to the fork in the road for 1 iberals and radicals in the May Fourth period that, although directed at their political concerns, is applicable as well to their notions about the meaning of science. Since the publication of Yan Fu's translations, Western science and technology were perceived by a significant number of Chinese intellectuals to lie at the heart of Western "wealth and power," however defined.

Although Grieder never mentions any names, Hu Shi and Chen Duxiu are representative liberal and radical (he may well have had them in mind):

The radicals, those who sooner or later gravitated toward the revolutionary program of Marxist-Leninist doctrine, found there a restatement... of the traditional idea that human behavior is conditioned by environment through the medium of social values, political forms and the cultural justifications for them... Though they redefined the meaning of "environment," stripping it of its Confucian moral connotations and substituting a materialist theory of social and cultural determinism, by creating culture as 
a derivative of political power they echoed a traditional perception... The liberals... attempted to break away from the totalistic tradition by affirming the possibility of individual creativity as a source of cultural values. To them, the "New Culture" movement meant not only emancipation from the particular culture of Confucianism, but...emancipation from the belief that man is merely the product of a cultural environment which he is powerless to control and which is itself the product of forces - either moral or material -- even more remote from ordinary observation. 17

In the context of Dr. Grjeder's remarks, though Chen Duxiu is usually painted as more political and more radical than Hu shi, and certainly was in term of his acceptance of Western political systems (Marxism generally being considered more radical than liberalism!). At the same time he is just as indebted to Confucian values as Hu. In particular, his adherence to the notion of culture as "totalistic" -- he regarded both china and the culture of the "West" (read:France) as seamless and "total" -- recalls the Confucian notion of tianxia [t'ien-hsia], that is, of all under Heaven being within the influence of Heaven's Way. As mentioned in Chapter VI, $18 \mathrm{Hu}$ maintained his skepticism and sense of the necessity of critique. Knowledge and reality were not seamless for Hu.

17 Jerome B. Grieder, "The Question of "Polltics" in the May Fourth Era," in Reflections on the May Fourth Movement, ed. Benjamin I. Schwartz (Cambridge, MA: Harvard Unlversity Press, 1972), 99.

18 See Chapter VI, above, p. 147. 
Early in Chen's writing career, when he had not yet arrived at the total conscious rejection of Chinese essences (ti) that marked his work after 1921, the sense of morality that Greider referred to above was still present.19 But he was already looking "outside" China in a different way than hu had. As early as 1915, Chen already exhibited elements of this totalistic rejection of the Chinese tradition in his use of the word shijiede ("worldy") for the English "cosmopolitan," a very outward facing expression compared to Hu Shi's datungzhuyi ("Great Unity-ism"), which is very inward looking, still seeing China as the center of civilization. 20

Chen's "looking outward" extended to his materialistic view of science. Science was, for him, a reflection of the "laws of Nature," and as such was steady-state and not open to criticism. The job of humans, in practicing science, then is to reflect the "laws of nature" in the policies and procedures of society. Science "contains no contradictions within itself," 21 and is as much as "truth." By as early as 1917, he had called for the chinese, and youth in particular, to make a choice between European and Chinese

19 See Chapter V, above, pp. 117-120.

20 See Chapter v, above, pp. 127-129.

21 see Chapter V, above, p. 125. 
culture -- no synthes is was consciously possible for chen Duxiu.

Chen's materialism combined with strong expectations of service to society and a belief that knowledge is for the benefit of society from his Confucian background, and contributed to his eventual turn to Marxism-Leninism, as a "science of society." His science was utterly monistic, unlike Hu's skeptical promise of pluralism and critique. And all mention of ti is gone. There is only matter. And its laws are the laws of the universe. Marxism's economic "laws" were the "science of human affairs" that his Confucianism had inadvertently taught him to look for. It no longer mattered that the philosophy of Marxism had developed within the intellectual history of not simply the West, but a specific locale -- nineteenth century Germany. Because it was "scientific," it was universally applicable - its truth value was transferable to China.

Chen's legacy lives on today in the current Chinese Communist government notion that modern science can be separated from the social/cultural matrix of Western Europe that created it. The current crackdown on pro-democracy student demonstrations that began in the spring of 1989 is, to some extent, a government response to the fact that when students are sent to the west to learn the "techniques" (yong) of modern science and technology, they often return 
to China with the "ideas" of the West as well. The current Chinese regime shares with one of the founders of the CCP, Chen Duxiu, the belief that the physical reality of science and technology (yong) can be completely separated from the underlying principles from which it developed. In China today, all is yong, ti seems to have dissipated. Marxism, as a "science of society" has been universalized to cover all instances of Chinese society, as science was in the "Debates on Science versus Metaphysics" in 1923.

Both the liberal view of science as a critical method, applicable to all of life, represented by $\mathrm{Hu}$ Shi, and the Marxist view of science as universal "law," have their Chinese antecedents in the thought of Yan Fu. He would no doubt have disapproved of both views. But his focus on "science as method," its power as an idea to transform the political and institutional structures of Chinese society, and the ways in which he expressed his views, consciously and unconsciously, to a great degree within the cosmology and language of Confucianism, were a major contribution to thought concerned with the meaning of science during the May Fourth period, in particular that of its major proponents, Hu Shi and Chen Duxiu. By beginning the debate about the role and meaning of science, some threads of his thought may still be found in official government ideology about science in China today. 
WORKS CITED

PRIMARY SOURCES -- IN CHINESE

Chen, Duxiu. "Benzhi suian zhi da bienshu" [A Reply to the Charges Against Our Journal]. Xin Qingnian [New Youth) 6.1 (January 1919): 1-2.

"Chinggao gingnian" [A Call to Youth]. Xin Qingnian [New Youth] 1.1 (September 15, 1915): $1-6$

Hu, Shi. Sishi zishu [Autobiography at Forty]. Taipei, R.O.C., 1969, [1954].

Kexue yu renshengquan [Science and the philosophy of life], 2 vols. With a preface by Hu shih. Shanghai: Yatung, 1927 [1923].

PRIMARY SOURCES -- IN ENGLISH

Dewey, John. "The Influence of Darwin on Philosophy." In The Influence of Darwin on Philosophy and other Essays in Contemporary Thought, 1-19. Bloomington, IN : Indiana University Press, 1965.

Hu, Shih. "Untitled essay." In Living Philosophies: A Series of Intimate Credos, 235-263. New York: Simon and Schuster, 1931.

Huxley, Thomas H. Evolution and Ethics and other Essays (Author's edition). New York and London: D. Appleton, 1894 .

"Evolution and Ethics [1893]." In Evolution and Ethics and Other Essays (Author's edition), 46-116. New York: D. Appleton, 1894.

\section{SECONDARY WORKS -- IN CHINESE}

Lin, Kan. "Wushu Weixin yu zhongguo Jindai sixiang Wenhua Shi" IThe Reform Movement of 1898 and the History of Modern China's Ideology and culturel. Lish1 Yanjiu (Historical studies) No. 5 (1983): 56-72. 
SECONDARY WORKS - - IN ENGLISH

Atwel1, william S. "From Education to Politics: the Fu she." In The Unfolding of Neo-Confucianism, ed. will iam Theodore de Bary, 333-367. Studies in Oriental Culture Number 10. New York: Columbia University Press, 1970.

Bailes, Kendall E. "Alexei Gastev and the soviet Controversy over Taylorism, 1918-1924." Soviet studles 29.3 (July 1977): 373-394.

Barnett, Suzanne Wilson. "Foochow's Academies: Public ordering and Expanding Education in the Late Nineteenth Century." The Journal of The Institute of Modern History (Academia Sinica, Taibei, R.O.C.) (1987): 513-537.

Chan, wing-tsit, translator and compiler. A Sourcebook in Chinese Philosophy. Princeton, NJ: Princeton University Press, 1963.

Chang, Hao. "Intellectual change and the reform movement, 1890-8.", pp. 274-338, In John K. Fairbank and Kwangching Liu, eds. Cambridge History of China. Volume 11: Late Ch'ing, 1800-1911, Part 2, 274-338. Cambridge: Cambridge University Press, 1980.

- Liang $C h^{\prime}$ i-ch'ao and Intellectual Transition in China, 1890-1907. Cambridge, MA: Harvard University Press, 1971.

Chou, Min-chih. Hu Shih and Intellectual Choice in Modern China. Michigan Studies on China. Ann Arbor, MI: University of Michigan Press, 1984.

Chow, Tse-tsung. The May Fourth Movement: Intellectual Revolution in Modern China. Harvard East Asian Studies, 6. Cambridge, MA: Harvard University Press, 1960 .

Cohen, Paul A. Discovering History in China: American Historical Writing on the Recent Chinese Rast. New York: Columbia University Press, 1984.

de Bary, William Theodore and Irene Bloom, eds. Principle and Practicality: Essays in Neo-Confucianism and Practical Learning. Neo-Confucian studies. New York: Columbia University Press, 1979. 
Dodds, E.R. "The Ancient Concept of Progress." In The Ancient Concept of Progress and other Essays on Greek Literature and Belief, 1-25. Oxford: Clarendon Press, Oxford University Press, 1973.

Elman, Benjamin. From Philosophy to Philology: Intellectual and Social Aspects of Change in Late Imperial China. Harvard East Asian Monographs, 110 . Cambridge, MA: Harvard University Press, 1984.

Feigon, Lee. Chen Duxiu: Founder of the Chinese Communist Party. Princeton, NJ: Princeton University Press, 1983 .

Furth, Charlotte. "Intellectual change: from the Reform movement to the May Fourth movement, 1895-1920." In John K. Fairbank, ed., The Cambridge History of China. Volume 12: Republican China 1912-1949, Part I, 322405. Cambridge: Cambridge University Press, 1983.

Greene, John C. "Science, Ideology, and World View." In Science, Ideology, and World View: Essays in the History of Evolutlonary Ideas, 1-21. Berkeley, CA: University of California Press, 1981.

Grieder, Jerome B. Chinese Intellectuals and the state in Modern China: A Narrative History. The Transformation of Modern China Series. New York: The Free Press, 1981 .

Hu Shih and the Chinese Renaissance: Liberalism in the Chinese Revolution, 1917-1937. Cambridge, MA: Harvard University Press, 1970.

"The Question of "Politics in the May Fourth Era." In Benjamin I. Schwartz, ed., Reflections on the May Fourth Movement: A Symposium, 95-101. Harvard East Asian Monographs, 44. Cambridge, MA: Harvard University Press, 1972 .

Hartwell, Robert M. "Historical Analogism, Public Policy, and social science in the Eleventh and Twelfth-Century China." American Historical Review 76 (1971): 690 727 .

Huang, Philip C. Llang $\mathrm{Ch}$ '1-ch'ao and Modern Chinese Liberalism. Publications on Asia of the Institute for Comparative and Foreign Area studies, Number 22. 
Seattle and London: University of Washington Press, 1972 .

Humme 1, Arthur w. Eminent Chinese of the Ch'ing Period (1644-1912), 2 Volumes. Washington, D.C.: Government Printing office (Library of Congress), 1944.

Ichisada, Miyazaki. China's Examination He 11: The Civil Service Examinations of Imperial China. Translated by Conrad Shirokauer. New Haven and London: Yale University Press, 1981 [1976].

Kagan, Richard C., translation and commentary. "Ch'en Tuhsiu's Unfinished Autobiography." China Quarterly 50 (April-June, 1972): 295-314.

Kloppenberg, James $T$. Uncertain Victory: Social Democracy and Progressivism in European and American Thought, 1870-1920. New York and Oxford: Oxford University Press, 1986.

Kwok, D. W. Y. Scientism in Chinese Thought, 1900-1950. New York: Biblo and Tannen, 1971. Reprinted from the 1965 edition, Yale University Press.

Legge, James, translator. Confucius: Confucian Analects, The Great Learning, and The Doctrine of the Mean. oxford: Clarendon Press, oxford University Press, 1893; New York: Dover, 1971.

Levenson, Joseph R. Liang $C h^{\prime} i-C h^{\prime a o}$ and the Mind of Modern China. Berkeley, CA: University of California Press, 1967.

Lin, Yü-sheng. The Crisis of Chinese Consciousness: Radical Antitraditionalism in the May Fourth Era. With a forward by Benjamin I. Schwartz. Madison, WI: University of Wisconsin Press, 1979.

"The Origins and Implications of Modern Chinese Scientism in Early Republican China: A Case study -The Debate on Science vs. Metaphysics in 1923." In Chung-hua min kuo ch'u ch'e li shih yen t'ao hui lun wen chi, 1912-1927 [Proceedings of the conference on the Early History of the Republic of China, 1912-1927, part 2, August 20-22, 1983. Taipei, Republic of China l, 1181-1200. Taipei, R.O.C: Institute of Modern History, Academia Sinica, 1984. 
Lotman, Yurij and B. A. Uspensky. "On the semiotic Mechanism of Culture." In Hazard Adams and Leroy Searle, eds., Critical Theory Since 1965, 410-422. Tallahassee, FL: University Presses of Florida, 1986.

Mumford, Lewis. Technics and Civilization. New York: Harcourt, Brace and World, 1962 [1934].

Munro, Donald J. Images of Human Nature - A Sung portrait. Princeton, NJ: Princeton University Press, 1988 .

Najita, Tetsuo. Visions of Virtue in Tokuqawa Japan: The Kaltokudo, Merchant Academy of Osaka. Chicago and London: University of Chicago Press, 1987.

Peterson, willard J. "Fang I-chih: Western Learning and the "Investigation of Things." " In William Theodore de Bary, ed., The Unfolding of Neo-Confucianism, 369411. New York: Columbia University Press, 1975.

Pusey, James Reeve. China and Charles Darwin. Harvard East Asian Monographs, 100. Cambridge, MA: Harvard University Press, 1983.

Said, Edward. Oriental1sm. New York: Random House, 1978; New York: Vintage, 1979.

Schwarcz, Vera. The Chinese Enlightenment: Intellectuals and the Leqacy of the May Fourth Movement of 1919. Berkeley, CA: University of California Press, 1986.

Schwartz, Benjamin I. "Ch'en Tu-hsiu and the Acceptance of the Modern West." Journal of the History of Ideas 12.1 (Jan. 1951): 61-74.

"Ch'en Tu-hsiu: Pre-Communist Phase." Papers on China 2: 167-197. Mimeographed for private distribution by the Committee on International and Regional studies, Harvard University, May 1948.

- In Search of Wealth and Power: Yen Fu and the West. Cambridge, MA: Harvard University Press, 1964.

"The Limits of 'Tradition Versus Modernity' as Categories of Explanation: The Case of the Chinese Intellectuals." Daedalus 101.2 (Spring 1972): 71-88.

"Themes in intellectual history: May Fourth and 
after." In Denis Twitchett and John K. Fairbank, eds., The Cambridge History of China. Volume 12: Republican China 1912-1949, Part I, 406-450. Cambridge: Cambridge University Press, 1983.

Segal, Howard P. Technological Utopianism in American Culture. Chicago and London: University of Chicago Press, 1985.

Sivin, Nathan. "Wang Hsi-shan." In Charles Coulston Gillispie, ed., Dictionary of Scientific Biography, Volume 14, 159-168. New York: Charles Scribner's Sons, 1976 .

Teng, Ssu-yu and John K. Fairbank, eds. China's Response to the West: A Documentary Survey, 1839-1923. Cambridge, MA: Harvard University Press, 1961. 